\title{
MODELO DE REFERÊNCIA PARA OPERACIONALIZAÇÃO E RECONFIGURAÇÃO DE REDES DE CONSTRUÇÃO CIVIL
}

Tese apresentada à Escola de Engenharia de São Carlos da Universidade de São Paulo, para obtenção do título de Doutor em Engenharia de Produção.

Área de Concentração: Processos e Gestão de Operações

Orientador: Prof. Associado Fábio Müller Guerrini 
AUTORIZO A REPRODUÇÃO E DIVULGAÇÃO TOTAL OU PARCIAL DESTE TRABALHO, POR QUALQUER MEIO CONVENCIONAL OU ELETRÔNICO, PARA FINS DE ESTUDO E PESQUISA, DESDE QUE CITADA A FONTE.

Ficha catalográfica preparada pela Seção de Tratamento da Informação do Serviço de Biblioteca - EESC/USP

\footnotetext{
A663m Araújo, Larissa Elaine Dantas de
Modelo de referência para operacionalização e reconfiguração de redes de construção civil. / Larissa Elaine Dantas de Araujo ; orientador Fábio Müller Guerrini. -- São Carlos, 2012.

Tese (Doutorado - Programa de Pós-Graduação e Área de Concentração em Engenharia de Produção)-- Escola de Engenharia de São Carlos da Universidade de são Paulo, 2012 .

1. Redes de colaboração. 2. Construção civil. 3. operacionalização. 4. Reconfiguração. I. Título.
} 


\section{FOLHA DE JULGAMENTO}

Candidata: Engenheira LARISSA ELAINE DANTAS DE ARAUJO.

Título da tese: "Modelo de referência para operacionalização e reconfiguração de redes de construção civil".

Data da defesa: $17 / 08 / 2012$

\section{Comissão Julgadora:}

Prof. Associado Fábio Müller Guerrini (Orientador)

(Escola de Engenharia de São Carlos/EESC)

Prof. Associado Antonio Freitas Rentes

(Escola de Engenharia de São Carlos/EESC)

Prof. Dr. Mateus Cecilio Gerolamo

(Escola de Engenharia de São Carlos/EESC)

Prof. Dr. Alceu Gomes Alves Filho

(Universidade Federal de São Carlos/UFSCar)

Prof. Dr. Celso Carlos Novaes

(Universidade Federal de São Carlos/UFSCar) $\underline{\text { Resultado: }}$
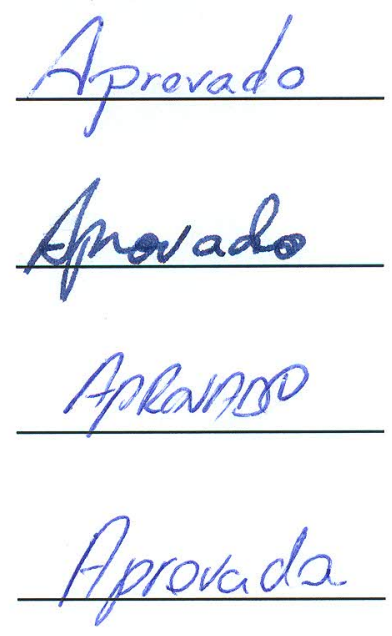

Aprodro

Coordenador do Programa de Pós-Graduação em Engenharia de Produção Prof. Titular Henrique Rozenfeld

Presidente da Comissão de Pós-Graduação:

Prof. Titular Denis Vinicius Coury 

À minha mãe, Virgínia Maria Dantas de Araújo, meu exemplo de vida, mestre incansável do que é nobre, bom, essencial. 


\section{AGRADECIMENTOS}

À Deus, por sua bondade infinita tão presente em minha vida. Por cada dia, cada descoberta, cada aprendizado. Pelo dom da paciência.

Ao Professor Fábio Müller Guerrini, pela orientação cuidadosa e entusiasta desde o primeiro momento deste Doutorado. Por compartilhar sua sabedoria em gestos simples, frases memoráveis e didática singular. A ele minha enorme gratidão e admiração.

A Claudius por compartilhar comigo sua vida e me fazer perceber o valor de cada dia. Que este privilégio seja eterno.

Aos meus pais, Virgínia e Henrique, por tudo o que sou, pelo valor da família, pelo amor incondicional. Por acreditarem e confiarem em todos os meus sonhos.

À minha irmã Bianca e meu cunhado Paulo Eduardo, pelo incentivo constante em todas as etapas desta formação. À minha afilhada Maria Eduarda, uma menina linda e muito especial, minha alegria constante! À pequena Isabela Maria, um novo presente.

À minha grande família Dantas e Araújo, sempre unida e representada nesse agradecimento pelas minhas lindas avós Maria de Lourdes e Margarida.

À Eunice, Cláudio e Tatiana Barbosa pela acolhida e carinho sempre tão presentes.

Aos meus amigos conquistados na cidade de São Carlos: aos afilhados Eduardo e Mônica, sempre perto, onde quer que estejam; ao carinho fraterno da família de Helen e Sérgio Wolf; a Naja por compartilhar sempre coisas boas e pela disponibilidade e ajuda constante; a Silvana e Alex, Walter e Suzana, Gustavinho e Marininha, pela preciosa amizade. A todos que tive o prazer de conhecer e conviver em anos muito especiais.

À minha amiga Catarina Careta, meu anjo da guarda, um mundo de sabedoria com o mais belo dos corações. À Lillian Gambi, nossa parceira, pelo companheirismo, disponibilidade e humildade.

Aos demais queridos amigos da "turma do Laboratório de Gestão": Danilo Hisano, Francisco, Jeferson Straatmann, Juliana Kurumoto, Lauro Osiro, Lie Yamanaka, Olivia Oiko, Rafael Lima e Yovana Barrera. E agregados: Ana Paula Barquet, Dani Pigosso e Sabrina Sousa. Aos novos alunos que renovam essa turma especial. 
Aos amigos de longa data sempre muito presentes: Lívia Nepomuceno, Luana Aquino, Ana Clara Teixeira e Juliano Barbosa, Manuela e Bruno Medeiros, Larissa Marinho, Mariana Almeida, Marina Soares e família de Rose Bruck Pereira. A todos os amigos dos diversos lugares e fases da vida que completam minha felicidade.

Ao Professor Antônio Freitas Rentes pela preciosa contribuição na minha trajetória acadêmica e profissional.

Aos Professores Edmundo Escrivão Filho e Alceu Gomes Alves Filho pelas valiosas sugestões no exame de Qualificação. Aos professores Celso Novaes e Mateus Gerolamo pela participação e contribuições na Defesa da Tese.

Ao Professor Raimar Scherer, pela acolhida para Estágio de Pesquisa e disponibilização da infraestrutura do Instituto de Informática da Construção da TU Dresden. À Sra. Ilona Jantzen pelo cuidado e atenção. Aos amigos Frank Hilbert, Alexander Benevolesnkiy, Andrej Hollmann, Kathrin Binye e Ksenia Rybenko, pesquisadores do Instituto.

Ao Engenheiro Erik Aquino, pela ajuda com a pesquisa.

Aos funcionários do Departamento de Engenharia de Produção: Claudete Poianas, Juliana Paganelli, Luiz Fernando Ferreira, Sueli Regina Ferreira, Talita Caetano e Vanessa.

À Fundação de Amparo à Pesquisa do Estado de São Paulo - FAPESP, pela Bolsa de Doutorado concedida. 


\section{RESUMO}

ARAUJO, L. E. D. Modelo de referência para operacionalização e reconfiguração de redes de construção civil. 2012. 118 p. Tese (Doutorado) - Escola de Engenharia de São Carlos, Universidade de São Paulo, São Carlos, 2012.

A Construção Civil é um setor econômico que depende de relacionamentos interorganizacionais para viabilizar o seu produto. É comum a formação de consórcios para obras de grande porte de infraestrutura, estabelecendo relacionamentos flexíveis de cooperação. Entretanto, existe uma carência de estudos sob o recorte analítico de redes considerado o seu ciclo de vida e especificamente as fases de operacionalização e reconfiguração da construção. A tese tem como objetivo o desenvolvimento de um modelo de referência para as fases de operacionalização e reconfiguração de redes de construção civil, e especificamente obras de infraestrutura urbana de metrô. O Modelo foi desenvolvido seguindo um processo de elaboração, contemplando: revisão bibliográfica, elaboração de estrutura conceitual de referência, representação de uma realidade atual, definições de mudança e descrição do Modelo de Referência. Foram utilizados o Modelo de Conceitos, Modelo de Processos e Modelo de Atores e Recursos da Metodologia EKD (Enterprise Knowledge Development) apoiando a representação dos resultados. A estrutura conceitual de referência e a representação de uma realidade atual utilizaram o método de Estudo de Caso. Como resultado obteve-se um Modelo de Referência que permite a coordenação das atividades da rede sob a ótica da colaboração.

Palavras-chave: Redes de colaboração, construção civil, operacionalização, reconfiguração. 


\section{ABSTRACT}

ARAUJO, L. E. D. Reference Model for Operation and Reconfiguration of Construction Networks. 2012. 118 p. Tese (Doutorado) - Escola de Engenharia de São Carlos, Universidade de São Paulo, São Carlos, 2012.

The Construction is an industry that depends on interorganizational relationships to enable its product. It is common the consolidation of consortia for major works of infrastructure, establishing flexible relationships for cooperation. However, there is a lack of studies on the analytical approach of networks considered their life cycle and the specific steps for the operation and reconfiguration of the construction phases. The thesis aims at developing a Reference Model for the phases of operation and reconfiguration of construction network, and specifically subway infrastructure works. The model was developed following a development process comprising: a literature review, the development of conceptual framework of reference, a representation of current reality, changing definitions and description of the Reference Model. The Concepts Model, the Process Model and the Actors and Resources Model from the EKD (Enterprise Knowledge Development) Methodology were used, supporting the representation of the results. The conceptual framework of reference and the representation of a current reality used the case study method. As a result a Reference Model was

obtained. It allows the coordination of network activities from the perspective of collaboration.

Keywords: Collaborative networks, construction, operation, reconfiguration. 


\section{LISTA DE FIGURAS}

Figura 1.1 - Estrutura Conceitual para desenvolvimento de Modelo de Referência

Figura 2.1 - Visão da Mudança do EKD-CMM

Figura 2.2 - Processo de Elaboração do Modelo de Referência utilizando Gestão de Mudança

Figura 3.1 - Áreas de Conhecimento da Gestão de Operações em Construção Civil

Figura 3.2 - Modelo de Conceitos para Operacionalização e Reconfiguração em Construção Civil

Figura 4.1 - Agrupamento das entidades do Modelo de Conceitos para Operacionalização e Reconfiguração em Redes de Construção Civil visando a Colaboração

Figura 4.2 - Modelo de Conceitos para Colaboração em Redes de Construção Civil

Figura 5.1 - Modelo de Processos para fases de Operacionalização e Reconfiguração do Consórcio

Figura 5.2 - Modelo de Atores e Recursos do Consórcio

Figura 6.1 - Modelo de Processos para Operacionalização e Reconfiguração de Redes de Construção Civil

Figura 6.2 - Modelo de Atores e Recursos para Operacionalização e Reconfiguração de Rede de Construção Civil

Figura 6.3 - Integração entre os modelos que compõem o Modelo de Referência 


\section{LISTA DE QUADROS}

Quadro 1.1 - Protocolo do Estudo de Caso Múltiplo em Centros de Pesquisa de Referência

Quadro 1.2 - Protocolo do Estudo de Caso em Consórcio de Construção Civil 21

Quadro 2.1 - Definições de Modelo de Referência. $\quad 30$

Quadro 3.1 - Indicadores de Desempenho para a Construção Civil 43 


\title{
LISTA DE SIGLAS
}

\author{
ARIS Architecture of Integrated Information Systems \\ BIM Building Information Modeling \\ BPMN Business Process Modeling Notation \\ CAD Computer Aided Design \\ CIM Computer Integrated Manufacturing \\ EKD Enterprise Knowledge Development \\ ERP Enterprise Resource Planning \\ ETO Engineering to Order \\ GIS Geographic Information System \\ IDEF3 Integrated Definition Methods 3 \\ PCP Planejamento e Controle da Produção \\ RFID Radio-Frequency Identification \\ SCM Supply Chain Management \\ TIC Tecnologia de Informação e Comunicação \\ UML Unified Modeling Language \\ VMI Vendor Managed Inventory
}




\section{SUMÁRIO}

$\begin{array}{lll}1 & \text { INTRODUÇÃO } & 15\end{array}$

$\begin{array}{lll}1.1 & \text { Tema da Pesquisa } & 18\end{array}$

$\begin{array}{llr}1.2 & \text { Problema de Pesquisa } & 18\end{array}$

$\begin{array}{lll}1.3 & \text { Objetivo } & 18\end{array}$

1.4 Relevância da Pesquisa $\quad 18$

1.4.1 Caracterização do Setor da Construção Civil 19

1.5 Caracterização da Pesquisa 19

1.5.1 Questões de Pesquisa 20

1.5.2 Técnicas de Coleta e Análise de Dados 22

1.6 Estrutura Conceitual da Pesquisa 22

1.7 Considerações Finais $\quad 24$

2 MODELAGEM DE NEGÓCIOS E MODELOS DE REFERÊNCIA 25

2.1 Modelagem de Negócios 25

2.2 Técnicas e métodos de modelagem de negócios 26

2.2.1 Metodologia EKD $\quad 27$

2.3 Modelos de Referência 29

2.4 Elaboração de Modelos de Referência 31

2.5 Considerações Finais 34

3 OPERACIONALIZAÇÃO E RECONFIGURAÇÃO EM REDES DE 35

3.1 Redes de Empresas $\quad 35$

3.2 Competências Essenciais $\quad 37$

3.3 Processos, Atores e Recursos da Rede 38

3.4 Ciclo de Vida de Redes 38

3.5 Operacionalização e Reconfiguração 39

3.5.1 Medição de Desempenho na construção civi 43

3.5.2 Planejamento e Controle na construção civil 44

3.5.3 Gestão do Conhecimento na construção civil 46

3.5.4 Gestão de Recursos na construção civil 49

3.5.5 Gestão da Cadeia de Suprimentos na construção civil 50

3.5.6 Tecnologia de Informação e Comunicação na construção civil 51

3.5.7 Modelo de Conceitos para a Operacionalização e Reconfiguração 53

3.6 Considerações Finais 56 
4 COLABORAÇÃO EM REDES DE CONSTRUÇÃO CIVIL 57

4.1 Redes Colaborativas em Construção Civil 57

4.2 Descrição do Estudo de Caso Múltiplo realizado 59

4.2.1 A abordagem Suíça 60

4.2.2 A abordagem britânica $\quad 62$

4.2.3 A abordagem alemã 64

4.3 Modelo de Conceitos para Colaboração em Redes de Construção Civil 66

4.4 Considerações Finais 68

$5 \quad$ COLETA DE DADOS $\quad 69$

5.1 Caracterização do Objeto de Estudo 70

5.2 Modelo de Processos 73

5.3 Modelo de Atores e Recursos 76

5.4 Verificação do Modelo de Conceitos para Operacionalização e 79

$\begin{array}{ll}\text { Reconfiguração em Construção Civil } & 79 \\ 5.5 \quad \text { Considerações Finais } & 80\end{array}$

$6 \quad$ ANÁLISE DE DADOS E RESULTADOS 81

6.1 Análise de Dados, Modelos Elaborados e definições de mudanças 81

6.1.1 Modelos de Conceitos 81

6.1.2 Modelo de Processos 84

6.1.3 Modelo de Atores e Recursos 85

6.2 Resultados: Modelo de Referência para Operacionalização e 86

Reconfiguração de Redes de Construção Civil 86

6.2.1 Modelo de Processos 86

6.2.2 Modelo de Atores e Recursos 89

6.3 Representação Integrada do Modelo de Referência 92

6.4 Considerações Finais 94

$\begin{array}{lll}7 & \text { CONCLUSÃO } & 95\end{array}$

$\begin{array}{ll}\text { REFERÊNCIAS } & 101\end{array}$

$\begin{array}{ll}\text { APÊNDICE } 1 & 113\end{array}$

$\begin{array}{ll}\text { APÊNDICE } 2 & 117\end{array}$ 


\section{INTRODUCÃO}

A Construção Civil está entre os setores nacionais que buscam fortalecimento e competitividade. A partir do ano de 2004, a construção civil no Brasil tem operado em expansão, com aumento dos investimentos em obras de infraestrutura e em unidades habitacionais, inclusive superando as taxas negativas de crescimento, em 2009, em função da crise econômica financeira internacional. No ano de 2010 o PIB setorial cresceu $11,6 \%$ (DIEESE, 2011). O ano de 2011 caracterizou-se por um processo natural de acomodação das atividades, buscando o ponto de equilíbrio sustentável do crescimento setorial, significando que o ciclo virtuoso iniciado em 2004 continua - a Construção Civil permaneceu registrando resultados positivos (apesar de inferiores a 2010) (CBIC, 2011).

Este aquecimento da construção civil também é esperado e verificado para a construção de grande porte com investimentos previstos para execução de obras de infraestrutura de transportes e logística, exploração do pré-sal, Copa do Mundo de 2014 e Jogos Olímpicos de 2016. Entre 2011 e 2014 serão realizadas as obras da segunda fase do PAC (Programa de Aceleração do Crescimento do Governo Federal), trazendo grandes investimentos em infraestrutura logística, energética, social e urbana, com o planejamento de obras estruturantes em prazos mais longos (CBIC, 2011; DIEESE, 2011). Diante de tantas perspectivas otimistas, o próprio estudo do DIEESE (2011, p. 8) aponta o grande desafio enfrentado pelo segmento: "o enfrentamento da precária capacidade de gestão dos investimentos, a gestão empresarial deficiente nos canteiros de obras, a falta de qualificação profissional dos trabalhadores e a regulamentação ambiental".

O cenário internacional, principalmente de países em desenvolvimento tem sido semelhante: um grande número de obras de infraestrutura e provisão de construções para suprir déficits habitacionais sendo executados, dentro de pautas de investimento nacionais. 
Projetos de construção são, na maior parte das vezes, complexos e dinâmicos, especialmente na sua fase de operação, em que uma cadeia de suprimentos bastante fragmentada é necessária (LEE; PEÑA-MORA; PARK, 2006; RUTTEN; DORÉE; HALMAN, 2009). Em projetos de larga escala, ou construção pesada, essa complexidade é ainda maior, demandando uma rede extensa de pessoas e recursos entre várias funções e organizações. Entretanto, a gestão destes projetos ainda é feita de forma tradicional e resulta em um ambiente com muitos conflitos e desperdícios - a razão para que o setor seja considerado ineficiente (YU et al., 2009).

Retomando estudos anteriores, no intervalo de dez anos (1996-2006), observou-se que as grandes empresas da construção civil perderam espaço para as de menor porte, passando de $71,1 \%$ a $64,0 \%$ do valor das construções executadas no período pelas empresas de grande porte. Este dado do IBGE (2006) pode estar relacionado ao processo "interno" de terceirização do setor, com as empresas se especializando em determinadas fases das obras e desencadeando uma contração de serviços envolvendo empresas de construção. Conforme ressaltam Karim, Marosszeky e Davis (2006), aproximadamente 90\% das obras de construção são realizadas por uma grande variedade de empresas subcontratadas, enquanto o principal contratante tende e focar-se na gestão e coordenação da obra.

Assim, o setor possui um grande número de obras realizadas com a consolidação de redes de empresas. Uma rede de empresas é caracterizada pela presença de múltiplas (três ou mais) organizações ligadas de forma multilateral, conectadas para facilitar o alcance de um objetivo comum (PROVAN; FISH; SYDOW, 2007).

Uma das formas mais comuns de constituição de redes de empresas de Construção Civil é o consórcio - a associação de empresas (companhias ou quaisquer outras sociedades), sob o mesmo controle ou não, com a finalidade de executar determinado empreendimento, não tendo personalidade jurídica (BRASIL, Lei $\mathrm{n}^{\circ}$ 6.404, de 15 de dezembro de 1976). Pela mesma lei, os consórcios são constituídos mediante contrato aprovado pelo órgão da sociedade competente para autorizar a alienação de bens do ativo não-circulante. Este tipo de contrato ocorre geralmente após licitação, conforme a Lei 8.666 (BRASIL, Lei no 8.666, de 21 de junho de 1993), que estabelece normas gerais sobre licitações e contratos administrativos pertinentes a obras, serviços no âmbito dos Poderes da União, dos Estados, do Distrito Federal e dos Municípios. A utilização do suporte legal da instituição (consórcio) fundamenta-se também na garantia dos contratos (PLISSON et al., 2007).

As redes originam-se, na maioria das vezes, da necessidade de as empresas se unirem para executarem, em conjunto, todas as fases dos projetos necessários à conclusão do 
empreendimento na construção civil, principalmente as obras de infraestrutura de grande porte. Tais obras podem ser conceituadas como Sistemas de Grande Projeto de Engenharia sob encomenda (Engineering to Order - ETO) (PIRES, 2004). Estes sistemas são constituídos para entrega de um produto único, nos quais não há rigorosamente um fluxo do produto, mas de processos, com uma sequencia predeterminada de atividades que deve ser seguida, com pouca ou nenhuma repetitividade.

As redes de Construção Civil possuem ciclo de vida delimitado, portanto, o consórcio pode ser considerado uma rede flexível, pois é constituído para atendimento de um objetivo e é encerrado com seu alcance. As fases do ciclo de vida de uma rede para uma obra de construção civil são: criação ou formação, operacionalização ou aplicação, evolução ou reconfiguração e dissolução ou metamorfose (CAMARINHA-MATOS; AFSARMANESH, 2008, CHENG; LI, 2002).

$\mathrm{Na}$ indústria da construção civil, entretanto, são comuns problemas como falta de cooperação, confiança limitada e comunicação ineficiente entre os atores de um projeto, levando a um ambiente de conflitos. Neste tipo de situação, a formação de parcerias na forma de redes é notadamente uma oportunidade de se obter ganhos (BLACK; AKINTOYE; FITZGERALD, 2000; CHAN et al, 2004).

A constituição de redes neste setor, motivada na maioria das vezes apenas por carência de capacidades e competências para execução de um projeto completo e obtenção de vantagens financeiras, prejudica sua eficiência considerado o seu ciclo de vida. $A$ atenção maior é voltada para a criação e dissolução da rede depois de cumpridos seus objetivos.

A gestão de redes de Construção Civil e os consórcios, podem receber significantes contribuições pela representação do modo de fazer negócio: os modelos de negócios ou modelos de empresas. Estes modelos, especialmente para a representação de processos, estão presentes geralmente na agenda das empresas de Manufatura (NELSON et al, 1999), e apesar de existirem diversos métodos de modelagem já desenvolvidos pela Academia e pela Indústria, a adoção efetiva e massiva de modelos de processos ainda não tem sido significativamente verificada nos negócios de construção (TZORTZOPOULOS et al., 2005).

Portanto, a inexistência de referências práticas e conceituais para a coordenação entre os diversos processos e atores envolvidos nas redes de construção civil, nas fases de operacionalização e reconfiguração, e na ordenação de suas competências, apresenta-se como o desafio deste estudo para obtenção de vantagem competitiva desejada pelas redes constituídas. 


\subsection{Tema da Pesquisa}

Esta pesquisa foi desenvolvida sob o recorte analítico de redes, analisando as fases de operacionalização e reconfiguração de redes do setor da Construção Civil - especificamente uma obra de grande porte de infraestrutura com constituição de consórcios, para construção de linha de metrô.

\subsection{Problema de Pesquisa}

Com base na contextualização do tema desenvolvido, tem-se como hipótese a inexistência de referências práticas e conceituais para a coordenação de atividades nas fases de operacionalização e reconfiguração de redes de empresa de Construção Civil para obras de infraestrutura de grande porte, na maior parte executadas sob a figura jurídica de consórcio.

\subsection{Objetivo}

O objetivo desta pesquisa é desenvolver um modelo de referência para as fases de operacionalização e reconfiguração de redes de construção civil constituídas para a execução de obras de grande porte de infraestrutura urbana.

\subsection{Relevância da Pesquisa}

Este trabalho está centrado na elaboração de um modelo de referência para os processos das fases de operacionalização e reconfiguração de execução de serviços em redes de Construção Civil, consideradas obras de Grande Porte.

Um modelo de referência é definido por Vernadat (1996) como "uma representação de um conjunto de elementos organizados entre si para uma finalidade". Esses modelos são utilizados para representar e permitir o entendimento da estrutura em termos de atividades e processos de uma organização, analisar seus processos de negócios e, muitas vezes, apoiar processos de mudança.

A elaboração de um modelo de referência visa identificar as atividades/processos das fases da obra e as relações entre os diversos participantes, permitindo incorporar diretrizes apontadas nos trabalhos de Black, Akintoye e Fitzgerald (2000), Cheng e Li (2002), Chan et al. (2004), Eriksson, Nilsson e Atkin (2008), Lönngren, Rosenkranz e Kolbe (2010), Salman, Skibniewsky e Basha (2007), Vennström e Eriksson (2010) e Yang et al. (2010) para obtenção de sucesso, consideradas as formações de parcerias e redes em construção. 
O intuito do modelo de referência para as fases de uma obra de grande porte de metrô com constituição de consórcio é permitir uma sistematização metodológica dos processos de operacionalização e reconfiguração da cooperação de forma eficaz, considerando o conceito de ciclo de vida de redes, pressupondo uma relação de "ganha-ganha" entre as empresas da rede.

\subsubsection{Caracterização do Setor da Construção Civil}

A Construção Civil é um setor de extensa cadeia produtiva, que no ano de 2011 representou $8,1 \%$ do PIB nacional. Possui imensa capacidade de absorção de mão de obra, além da extraordinária capacidade de gerar renda por toda a economia. O segmento possui mais de 160 mil estabelecimentos formais em todo o Brasil, possui mais de 2,8 milhões de trabalhadores com carteira de trabalho assinada e é responsável por expressiva parcela dos investimentos nacionais (CBIC, 2011).

Pela Classificação Nacional de Atividades Econômicas - CNAE 2.0 (IBGE, 2012) as atividade da construção civil envolvem: a construção de edifícios, obras de infraestrutura e serviços especializados para construção. No ano de 2010, as empresas da atividade de obras de infraestrutura, segmento analisado neste trabalho, se destacaram pela maior contribuição no valor total das receitas brutas auferidas. O valor de $\mathrm{R} \$ 114,3$ bilhões representou 43,5\% do total da receita bruta do setor em 2010 (CBIC, 2011).

Barrie e Paulson (1992) ressaltam que as construções de grande porte são na maioria dos casos: voltadas para infraestrutura, bastante intensivas em equipamentos, financiados por órgãos públicos, com projetos fornecidos por agências públicas e a responsabilidade da construção determinada por meio de licitações/concorrência. Neste tipo de construção é requerida grande capacitação em Engenharia. Assim, o tipo de obra a ser analisado é caracterizado como uma obra de Engenharia sob encomenda (Engineering to Order - ETO). Para Pires (2004) nos sistemas ETO os principais processos de negócios são feitos sob encomenda (de acordo com as necessidades do cliente): vender, projetar produto, planejar produção, produzir e entregar. Este é o tipo de sistema utilizado no setor de bens de capital e em grandes projetos, como no caso de obras de grande porte construção civil.

\subsection{Caracterização da Pesquisa}

Esta pesquisa tem uma abordagem predominantemente qualitativa voltada à análise do processo de gestão de obras em construção civil. Envolve a interpretação de uma situação específica, cujas análises e classificações são feitas de forma subjetiva, visando oferecer 
modelo de referência que possa ser aplicado a outras realidades. Os dados apresentados são de natureza descritiva, em detrimento de análises numéricas, porém foram coletados de forma sistematizada e planejada, por meio de roteiros semiestruturados. Referências relevantes, consultas a especialistas e profissionais, constituíram-se de fonte direta de coleta de dados.

Foi realizada uma investigação descritiva do objeto, permitindo descrição das características de determinada população ou fenômeno, ou estabelecimento de relações entre variáveis envolvendo uso de técnicas padronizadas de coleta de dados (GIL, 1991).

\subsubsection{Questões de Pesquisa}

Todas as seções do trabalho que apresentam resultados que auxiliam o alcance do objetivo da pesquisa, utilizam a metodologia de modelagem EKD (Enterprise Knowledge Development) apresentada por Bubenko Jr. et al (2001), tentando elucidar as questões das fases da pesquisa. O EKD é uma coleção integrada de métodos, técnicas e ferramentas para apoiar ao processo de análise, planejamento, projeto e mudanças de um negócio. Constitui portanto, a forma para se pensar, racionalizar e entender o negócio. É uma metodologia composta de: Modelo de Objetivos, Modelo de Regras, Modelo de Processos, Modelo de Atores e Recursos, Modelo de Conceitos e Modelo de Requisitos e Componentes Técnicos. A aplicabilidade e uso da Metodologia EKD é melhor abordada no Capítulo 2 desta Tese.

Para a pesquisa foi utilizada também a metodologia de Estudo de Caso, em caráter descritivo. Esta estratégia de pesquisa é aplicável às análises pretendidas pelo trabalho por tentar responder às questões do tipo "como" e/ou o "por que". Yin (2003) justifica que "questões do tipo 'como' e 'por que' são mais explanatórias e é provável que levem ao uso de estudos de casos". O Estudo de caso é, portanto, um método aplicável para o exame de acontecimentos contemporâneos - investigação empírica que analisa um fenômeno dentro de seu contexto da vida real (YIN, 2003).

Após realização de extensa revisão bibliográfica, sistematizada e apresentada no Capítulo 3, foram feitas entrevistas com pesquisadores de referência da gestão em construção civil, para melhor entendimento dos assuntos abordados em operacionalização e reconfiguração em redes colaborativas de construção. As questões investigadas nesta fase da pesquisa estão declaradas no Quadro 1.1 - contendo o Protocolo do Estudo de Caso Múltiplo em Centros de Pesquisa de Referência, segundo proposição de Yin (2003). Os resultados desta investigação estão descritos no Capítulo 4, sobre colaboração em redes de construção civil. 


\begin{tabular}{|c|c|}
\hline \multicolumn{2}{|r|}{ Protocolo do Estudo de Caso Múltiplo em Centros de Pesquisa de Referência } \\
\hline Questão do Estudo & $\begin{array}{l}\text { Quais as abordagens consideradas pelos centros de pesquisa para a } \\
\text { operacionalização e reconfiguração em construção - considerando a perspectiva de } \\
\text { colaboração? }\end{array}$ \\
\hline $\begin{array}{l}\text { Unidades de Análise } \\
\text { e Local }\end{array}$ & $\begin{array}{l}\text { - Instituto de Construção e Gestão de Infraestrutura do Instituto Federal Suiço de } \\
\text { Tecnologia de Zurique (ETH Zürich); } \\
\text { - Centro de Tecnologia de Informação da Universidade de Salford, Reino Unido } \\
\text { (University of Salford); } \\
\text { - Instituto de Informática da Construção da Universidade Técnica de Dresden, } \\
\text { Alemanha (TU Dresden). }\end{array}$ \\
\hline Limites de Tempo & Julho e Agosto de 2011. \\
\hline Validade interna & $\begin{array}{l}\text { Baseado nas questões coletadas de extensa revisão de literatura recente em mais de } \\
160 \text { artigos internacionais indexados em bases de dados. }\end{array}$ \\
\hline \multirow{4}{*}{$\begin{array}{l}\text { Questões do estudo } \\
\text { de caso }\end{array}$} & Principal abordagem considerada em colaboração para redes de construção; \\
\hline & Considerações sobre o ciclo de vida da rede; \\
\hline & $\begin{array}{l}\text { Principais considerações a respeito de operacionalização e reconfiguração em } \\
\text { construção; }\end{array}$ \\
\hline & $\begin{array}{l}\text { Questões específicas relacionadas às áreas de conhecimento para operacionalização } \\
\text { e reconfiguração de redes de construção civil; }\end{array}$ \\
\hline
\end{tabular}

Quadro 1.1 - Protocolo do Estudo de Caso Múltiplo em Centros de Pesquisa de Referência

Foi analisada também uma obra de construção civil de grande porte, onde houve formação de consórcio. Após levantamento dos consórcios em operação, foi selecionada uma obra representativa na caracterização de uma rede sólida e estruturada, que permitiu a coleta de dados de questões relacionadas às fases de operacionalização e reconfiguração. O Estudo de Caso constituiu-se de um requisito fundamental para o processo de elaboração do Modelo de Referência, oferecendo uma realidade inicial para a qual mudanças foram propostas visando um modelo futuro com melhorias.

O Quadro 1.2 contém a declaração do protocolo do Estudo de Caso, definindo a questão central da pesquisa, as fontes de informação e questões secundárias a serem respondidas.

\begin{tabular}{|l|l|}
\hline \multicolumn{2}{|l|}{ Protocolo do Estudo de Caso em Consórcio de Construção Civil } \\
\hline Questão do Estudo & $\begin{array}{l}\text { Como estão estruturadas as fases de operacionalização e reconfiguração das fases da } \\
\text { obra verificada? }\end{array}$ \\
\hline Unidade de Análise & Obra de grande porte de infraestrutura. \\
\hline Local & Estado de São Paulo \\
\hline Limites de Tempo & Março de 2011 a Fevereiro de 2012. \\
\hline \multirow{3}{*}{ Validade interna } & $\begin{array}{l}\text { Adequação aos requisitos para formação de redes de Camarinha-Matos e } \\
\text { Afsarmanesh (2008) e às fases do ciclo de vida de redes de Camarinha-Matos e } \\
\text { Afsarmanesh (1999) e Cheng e Li (2002) }\end{array}$ \\
\hline \multirow{4}{*}{$\begin{array}{l}\text { Questões do estudo } \\
\text { de caso }\end{array}$} & Quantas empresas estão participando da obra? \\
\cline { 2 - 3 } & Como é o relacionamento dos diversos atores para a obra? \\
\cline { 2 - 3 } & Qual o padrão de reconfiguração existente para as atividades? \\
\cline { 2 - 3 } & $\begin{array}{l}\text { Como são tratadas as ordens reconfiguradas? Como são escolhidos novos parceiros? } \\
\text { Como são re-configurados os prazos? }\end{array}$ \\
\hline
\end{tabular}

Quadro 1.2 - Protocolo do Estudo de Caso em Consórcio de Construção Civil 
A escolha e utilização de apenas uma obra de grande porte nesta fase da pesquisa justificase por dois motivos: 1) por pretender-se conhecer de forma aprofundada uma obra da tipologia selecionada, cuja complexidade e o grande número de variáveis a serem analisados demandam um levantamento extenso de informação nas dimensões de tempo e escopo e 2) pela própria dificuldade de encontrar obras com as mesmas características, com constituição de consórcio, ocorrendo no mesmo momento, de modo que um Estudo de Caso Múltiplo fosse possível, e assim generalizações ou comparações pudessem ser levantadas.

\subsubsection{Técnicas de Coleta e Análise de Dados}

Como instrumentos de coleta de dados foram utilizados a observação linear, formal e direta das informações ante as situações questionadas e a entrevista estruturada por meio de roteiros. Um primeiro roteiro (contido no APÊNDICE 1) contemplou os parâmetros de observação indicados na revisão bibliográfica e os fatores empíricos coerentes e foi aplicado com pesquisadores da área de conhecimento desta pesquisa, conforme premissas do Protocolo de Estudo de Caso do Quadro 1.1 - Protocolo do Estudo de Caso Múltiplo em Centros de Pesquisa de Referência. Um segundo roteiro, também com base em levantamento teórico, porém visando uma coleta de dados mais aprofundada (APÊNDICE 2), foi aplicado com profissionais responsáveis da área de gestão da produção e/ou planejamento do Consórcio selecionado. Esta coleta de dados objetivou melhor entendimento e formalização de um contexto observado, tratado como realidade atual, para proposição de mudança, e desenvolvimento do Modelo de Referência. O Quadro 1.2 Protocolo do Estudo de Caso em Consórcio de Construção Civil - contém as premissas desta fase do trabalho.

As observações relevantes e informações coletadas foram tratadas por análise de conteúdo que objetiva alcançar uma pretensa significação, um sentido estável, conferido pelo autor, no qual a produção de sentido se refere a uma realidade dada. Pauta-se prioritariamente por uma visão conteudística (ROCHA, DEUSDARÁ, 2005). No caso deste trabalho, foi empregada para análise de material qualitativo obtido através de entrevistas de pesquisa.

\subsection{Estrutura Conceitual da Pesquisa}

Com base no contexto descrito na apresentação deste trabalho e nos parâmetros metodológicos ora apresentados, tem-se na Figura 1.1, representada por meio de um 
modelo de conceitos gerado com a metodologia EKD, a estrutura conceitual que guiou a elaboração deste trabalho e que serviu como base para atingir seu objetivo.

Empresas de Construção Civil constituem um Consórcio para a execução de uma obra de grande porte de infraestrutura. Por restrições de capacidade e necessidade de competências e recursos diversos, essas empresas contratam outras empresas de construção e serviços, compondo uma rede de empresas. Essa composição é então representada, após Estudo de Caso selecionado, no Modelo de Atores e Recursos.

Entende-se que a rede opera como uma Empresa Virtual, cujo ciclo de vida é delimitado, já que a obra de grande porte também possui essa delimitação temporal, passando pelas fases de criação, operacionalização e reconfiguração e dissolução. Uma série de processos são previstos na execução desta obra, sendo estes representados no Modelo de Processos, viabilizado pelo Estudo de Caso. Como o interesse especial deste trabalho é nos processos que ocorrem nas fases de operacionalização e reconfiguração, a Revisão Bibliográfica apresenta o Modelo de Conceitos para estas fases, apoiando processos de Gestão de Operações em Construção Civil.

Verifica-se a necessidade de abordar a colaboração como direcionador das decisões para melhor eficiência das redes de construção civil em suas fases de operacionalização e reconfiguração, sendo apresentado um refinamento do Modelo de Conceitos, resultado da Revisão Bibliográfica. Todos os modelos são gerados com a metodologia EKD.

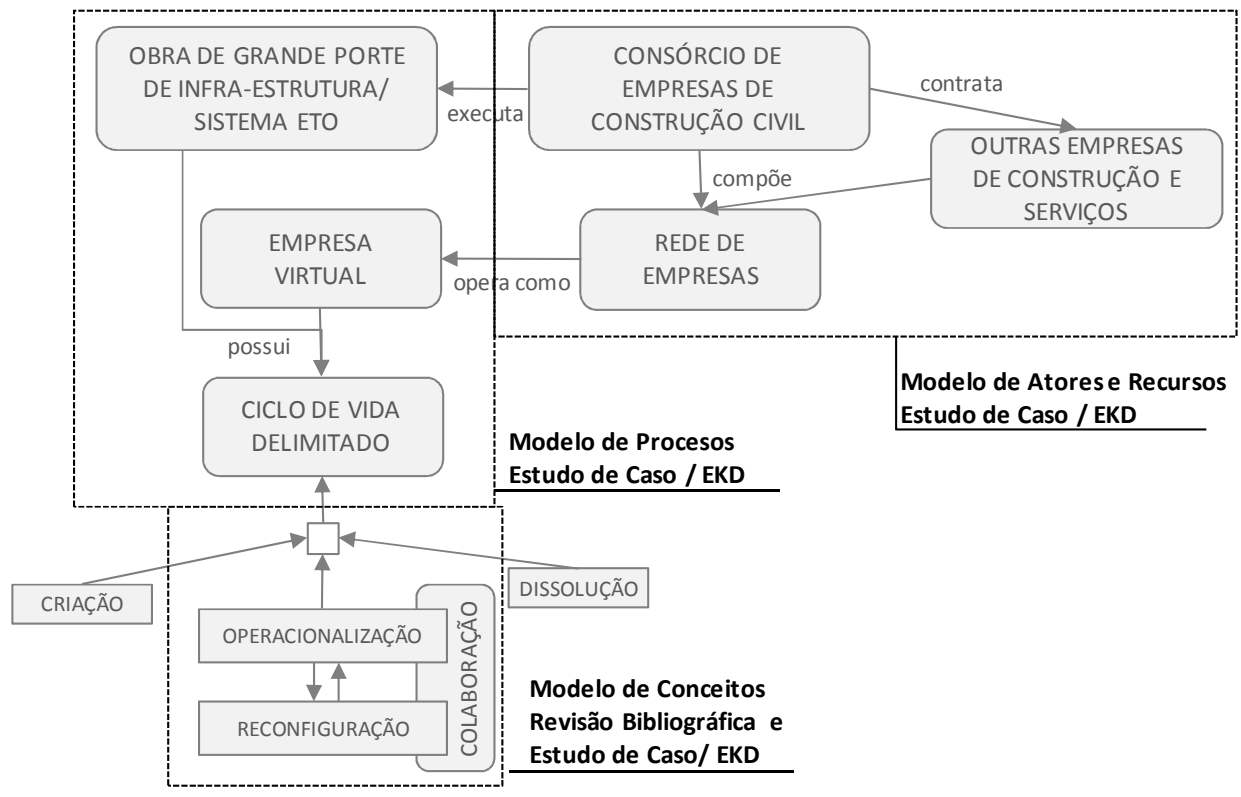

Figura 1.1 - Estrutura Conceitual para desenvolvimento de Modelo de Referência 
A Estrutura representada é uma referência ao encadeamento lógico dos temas e assuntos abordados como apoio ao desenvolvimento do Modelo de Referência. Os Modelos mencionados, que servirão de base ao objetivo principal, identificam, portanto, a delimitação de escopo considerada nas grandes áreas representadas.

\subsection{Considerações Finais}

Este capítulo possui a estruturação epistemológica da pesquisa, partindo de seu contexto e delimitando questões, objetivo e metodologia, encerrando com o escopo considerado. A Tese é composta de mais seis capítulos.

O segundo capítulo inicia a abordagem teórica da tese, versando sobre modelos de negócios e modelos de referência, estabelecendo o processo de construção do modelo de referência desenvolvido. No capítulo seguinte, é realizada revisão bibliográfica dos principais assuntos abordados no trabalho, concluindo com uma estrutura sintetizada sobre operacionalização e reconfiguração em construção civil. A esta estrutura elaborada deu-se especial atenção aos aspectos relacionados à colaboração, refinando-se o modelo de conceitos por meio de consulta a especialistas da área, resultando no Capítulo 4. O Capítulo 5 , resultado de coleta de dados realizada em Consórcio constituído para obra de grande porte de infraestrutura, apresenta os modelos de processos e atores e recursos, como representação de uma realidade atual, utilizada para o desenvolvimento do modelo de referência. As oportunidades de mudança observadas na realidade atual representada e no referencial teórico elaborado são discutidas no Capítulo 6. Neste capítulo é feita a descrição detalhada do Modelo de Referência para operacionalização e reconfiguração de redes de construção civil, coerente com as oportunidades de mudança discutidas. Por fim, são colocadas as considerações pertinentes, concluindo sobre elaboração, objetivo e resultados do trabalho, explicitando oportunidades de pesquisa futuras, compondo o Capítulo 7. 


\section{MODELAGEM DE NEGÓCIOS E MODELOS DE REFERÊNCIA}

Este capítulo busca contribuir para a compreensão das principais questões relacionadas à Modelagem de Negócios e que neste trabalho tratam especificamente da gestão de Redes de Construção Civil. Inicia por conceituar a modelagem de empresas e discutir seus benefícios, além de apresentar sucintamente técnicas e ferramentas utilizadas para modelagem. Aprofunda-se na metodologia EKD, detalhando os aspectos dos submodelos que serão desenvolvidos nos capítulos posteriores. Em seguida, discute o uso e aplicabilidade de Modelos de Referência e um procedimento de referência para elaborá-los, como suporte ao objetivo final deste trabalho.

\subsection{Modelagem de Negócios}

Os avanços ocorridos na Tecnologia de Informação e Comunicação e o advento de novos paradigmas de Manufatura como Manufatura Integrada por Computador (Computer Integrated Manufacuting - CIM), Produção Enxuta (Lean Production) e a Empresa Estendida (Extended Enterprise), visando à integração da empresa ou entre empresas, requerem novas formas de pensar os negócios, para os quais a modelagem de empresas tornou-se um pré-requisito (VERNADAT, 1996).

Nas visões de Bubenko Jr. et al. (2001) e Vernadat (1996), a modelagem de empresas visa fornecer: a) uma melhor compreensão e uma representação uniforme da empresa, compartilhando o conhecimento sobre o negócio; b) apoio ao desenvolvimento de novas partes da empresa, estabelecimento de visão, estratégias ou novas formas de operação e suporte de sistemas de informação, e; c) um modelo utilizado para controlar e monitorar as operações da empresa, assegurando a aceitação de decisões tomadas pelos envolvidos no negócio, por sua possibilidade de participação. Em linhas gerais, envolve o desenvolvimento e a garantia de qualidade do negócio. 
Ainda para Vernadat (1996, p. 19) "uma empresa é composta de uma coleção de processos de negócios que ocorrem em paralelo, executados por um conjunto de entidades funcionais (ou recursos), que contribuem para os objetivos do negócio". Ele acrescenta que o termo empresa significa a parte da empresa que necessita ser representada, cujo escopo e tamanho são definidos pelos usuários do negócio, ou o que a empresa considera importante para a sua operação. Assim, ao longo deste capítulo adota-se a terminologia modelagem de negócios em detrimento de modelagem de empresas, considerando que aquele termo presume maior flexibilidade de escopo e escala.

Para Bubenko Jr. (1992 ${ }^{1}$ apud Bubenko Jr. et al., 2001, p.5) "modelar significa essencialmente descrever um conjunto de fenômenos abstratos ou concretos de uma forma estruturada e, eventualmente, formal."

Entende-se que modelar significa representar uma realidade observada ou desejada, respeitando-se o uso de linguagem padrão. No caso da modelagem de negócios, representam-se um ou mais dos seguintes aspectos, ou combinações entre eles: atividades, funções, responsabilidades, recursos, objetivos, requisitos etc.

Uma empresa ou negócio pode ser modelado sob diversas perspectivas, dependendo do método adotado e do problema analisado utilizando o método (BUBENKO JR. et al., 2001).

\subsection{Técnicas e métodos de modelagem de negócios}

Conforme abordado, o modelo requer o uso de linguagem padrão que pode ser mais formal (linguagem matemática) ou menos formal (linguagens naturais). As linguagens existentes possuem técnicas e métodos para o seu desenvolvimento, em função de seus procedimentos e notações. Algumas linguagens bastante conhecidas são:

- Linguagem Unificada de Modelagem (Unifyed Modelling Language - UML) desenvolvida pelo Object Management Group (OMG, 2011), é definida como "uma linguagem gráfica para a visualização, especificação, construção e documentação de artefatos de um sistema intensivo em uso de software". Possui três principais pontos de vista: modelo de caso, modelo estático e modelo dinâmico (CoSpaces, 2009);

- Arquitetura para Sistemas de Informação Integrados (Architecture for Integrated Information Systems - ARIS) - trata de questões mais tradicionais e orientadas a

\footnotetext{
${ }^{1}$ BUBENKO JR., J. A. On the evolution of information systems modelling - a Scandinavian perspective, SYSLAB Report No. 92-023-DSV, SYSLAB, Department of Systems and Computer Science, Royal Institute of Technology, Kista, Sweden, 1992.
} 
negócios das empresas (estrutura funcional) como processamento de ordens, planejamento e controle da produção, controle de inventário, entre outros. Possui as visões funcional, de dados, organizacional, de saída e de controle (SCHEER, 1994; VERNADAT, 1996);

- Métodos de Definição Integrados 3 (Integrated Definition Methods 3 - IDEF3) - constrói descrições estruturadas, fornecendo uma base de conhecimento para o desenvolvimento de modelos analíticos e gráficos. Possui duas entidades de modelos: a) o modo de fluxo de processos que define "como as coisas funcionam" e; b) o modo de rede de mudança do estado do objeto que sumariza as mudanças permitidas pelas quais um objeto pode passar em um processo particular (IDEF3, 2011).

- Notação de Modelagem de Processos de Negócios (Business Process Modelling Notation - BPMN) - visa prover uma notação facilmente compreensível pelos usuários do negócio, criando uma ponte entre o desenho dos processos de negócio e a implementação dos processos. Especificidades: as atividades componentes do processo são chamadas de tarefas; as atividades podem ser sequenciais, em paralelo ou conectadas por portais; os processos podem ter diversos participantes, e cada um pode ser representado em uma raia, e; os participantes colaboram pela troca de mensagens (BPMN, 2011).

Entretanto, estas técnicas mais utilizadas para modelagem de processos de negócios (UML, ARIS, IDEF, BPMN), não são perfeitamente adequadas à descrição de processos de colaboração, pois não possuem as notações mais apropriadas e simples para representar os padrões de coordenação de múltiplos atores participando em trabalhos colaborativos ao mesmo tempo em que mantêm a consistência na representação do processo em geral (CoSpaces, 2009). Considera-se que possuem certo grau de formalidade, e alguns aplicamse a contextos mais estáticos e tradicionais de manufatura e/ou prestação de serviços, requerendo também aplicativos ou programas específicos para seu uso.

\subsubsection{Metodologia EKD}

Utiliza-se a Metodologia EKD na provisão de Modelos de Negócios de interesse e no posterior desenvolvimento do Modelo de Referência, pois esta metodologia é considerada mais flexível e menos formal, permitindo maior riqueza de informações ainda que preserve o uso de notações padronizadas.

Bubenko Jr. et al. (2001) ressaltam que os modelos EKD são independentes de qualquer tecnologia - o mesmo modelo pode ser implementado em diferentes plataformas 
tecnológicas e será válido independentemente das mudanças na tecnologia. Ele pode ser facilmente elaborado à mão e/ou representado em programas de amplo uso e fácil interface.

"O EKD é uma abordagem que provê uma forma sistematizada e controlada de analisar, compreender, desenvolver e documentar uma empresa e seus componentes, pelo uso da Modelagem de Negócios." (BUBENKO JR. et al, 2001, p.22). Ele tem como resultados uma série de modelos conceituais que examinam uma empresa e seus requerimentos a partir de um número de perspectivas inter-relacionadas.

Dentre os modelos oferecidos pelo EKD e que são de importantes para a pesquisa estão o Modelo de Conceitos, o Modelo de Processos e o Modelo de Atores e Recursos, todos descritos no guia de utilização do EKD de Bubenko Jr. et al. (2001).

O Modelo de Conceitos foi escolhido para a verificação dos assuntos envolvidos na operacionalização e reconfiguração de redes de construção civil e da colaboração nessas fases, dado o caráter de revisão de literatura destas seções da pesquisa. O principal objetivo do Modelo de Conceitos é servir de dicionário para se entender sobre "coisas" e "fenômenos", podendo ser utilizado no desenho de Bases de Dados. A base de Dados é constituída pelos assuntos identificados na revisão de literatura, estabelecendo as suas relações, dependências e generalizações de modo a auxiliar no entendimento sobre a Gestão de Operações em Construção (fases de operacionalização e reconfiguração) e sobre os aspectos relevantes para a colaboração nestas fases do ciclo de vida da rede. Estes modelos são apresentados no Capítulo 3 - Operacionalização e Reconfiguração de Redes de Construção Civil - e no Capítulo 4 - Colaboração em Redes de Construção Civil.

O modelo é formado por conceitos, relações semânticas (indicadas por setas e verbos, denotam precedência e/ou dependência, e o papel das relações, e também representam agrupamentos e generalizações parciais ou totais, entre componentes do modelo) e atributos informacionais (caracterização do conceito). Os conceitos e atributos podem ser tangíveis ou intangíveis, e auxiliam principalmente o entendimento de informações e fluxos do Modelo de Processos. Orientando sua elaboração estão algumas questões: como os conceitos se relacionam, porque o conceito é necessário, quando ele é necessário, quais as instâncias dos conceitos (atributos relacionados).

O Modelo de Processos descreve as atividades e funções organizacionais, de forma similar aos fluxogramas de processos, considerando as transformações de materiais e informações e representando suas entradas e saídas. Também fazem parte do modelo processos e informações externas que se relacionam com os processos internos. 
Os componentes de um Modelo de Processos são: processos (coleção de atividades), processos externos (atividades fora do escopo da atividade organizacional), conjunto de informações ou materiais (aquilo que se transfere entre processos internos ou externos). Processos podem ser compostos de subprocessos.

Como elementos norteadores da elaboração deste modelo estão: quais os principais processos da empresa, como os processos estão relacionados, a necessidade dos processos, materiais e fluxo de informação, o que está contido no modelo de conceitos, regras que acionam o processo, atores responsáveis pela realização e apoio ao processo.

Já o Modelo de Atores e Recursos é utilizado para descrever como estão relacionados os diferentes atores e recursos e como é sua relação com os componentes do Modelo de Processos. Este Modelo permite definir quem deve fazer ou executar os processos e tarefas e como são definidas as relações e responsabilidades dos diversos atores da rede. Suas questões-chave são: quem está ou deveria estar realizando determinados processos e tarefas e como são as estruturas de informação e responsabilidade dos atores definidos.

Seus componentes são: Unidade Individual (pessoa, que pertence a Unidade Organizacional, quando sua habilidade ou papel esclarece de alguma forma ou adiciona significado ao modelo e suas relações), Unidade Organizacional (todas as estruturas organizacionais de uma empresa como grupos, departamentos, divisões), recursos não humanos (tipos de máquinas, sistemas de diferentes tipos, equipamentos) e papel (atribuição para realizar processos ou atingir objetivos).

O Modelo de Processos e de Atores e Recursos estão representados no Capítulo 5 Estudo de Caso - com base na realidade observada em um Consórcio de Construção Civil, e novamente no Capítulo 6 - Análise de Dados e Resultados - como composição do Modelo de Referência desenvolvido.

Os Modelos de Negócios são pontos de referência comum entre várias áreas, de forma que os interessados no negócio não estão restritos a determinadas aplicações ou grupos particulares. Por essa possibilidade de constituir compreensão comum, Modelos de Negócios, muitas vezes, constituem ou podem servir de Modelos de Referência.

\subsection{Modelos de Referência}

Modelos de Referência são conceituados de diversas formas na Literatura. Algumas definições adaptadas do trabalho de Fettke e Loos (2007) são resumidas no Quadro 2.1. Segundo estes autores as definições de modelo de referência variam entre características 
de: melhores práticas (provê melhores práticas para conduzir negócios), aplicabilidade universal (representa uma classe de domínios e não uma empresa particular) e replicabilidade (estrutura conceitual que pode ser reutilizada em uma multiplicidade de projetos de sistemas de informação).

\begin{tabular}{|l|l|}
\hline \multicolumn{1}{|c|}{ Autor } & \multicolumn{1}{c|}{ Definição } \\
\hline Vernadat (1996) & $\begin{array}{l}\text { Modelo padronizado que seja reconhecido e aprovado por todas as partes } \\
\text { interessadas e que possa ser utilizado como base para o desenvolvimento ou } \\
\text { avaliação de outros modelos específicos. }\end{array}$ \\
\hline Zilbovicius (1999) & $\begin{array}{l}\text { Operam como prescrições para os agentes que tomam decisões a respeito de } \\
\text { práticas a serem empregadas no campo da organização da produção. }\end{array}$ \\
\hline Chalmeta et al. (2001) & $\begin{array}{l}\text { Descrevem as relações entre a empresa e mundo externo, incluindo seus } \\
\text { requisitos e restrições e representando as dependências dinâmicas entre as } \\
\text { atividades. }\end{array}$ \\
\hline Rosemann (2003) & $\begin{array}{l}\text { São modelos conceituais genéricos que formalizam práticas recomendadas para } \\
\text { certo domínio. }\end{array}$ \\
\hline vom Brocke (2007) & $\begin{array}{l}\text { Modelo de informação que as pessoas desenvolvem ou utilizam para suportar a } \\
\text { construção de modelos de aplicação, e são utilizados no projeto de outros modelos } \\
\text { específicos de uma organização por meio da apresentação de solução genérica. }\end{array}$ \\
\hline Fettke e Loos (2007) & $\begin{array}{l}\text { Representam formatos reutilizáveis de regras organizacionais, processos ou } \\
\text { tecnologias. São modelos que estruturam e guiam a criação dos modelos } \\
\text { específicos da organização. }\end{array}$ \\
\hline
\end{tabular}

Quadro 2.1 - Definições de Modelo de Referência.

Fonte - Adaptado de Fettke e Loos, 2007.

A definição considerada neste trabalho corrobora com a visão de Vernadat (1996), vislumbrando principalmente as características de melhores práticas e replicabilidade, e de Chalmeta et al. (2001) pela consideração das dependências dinâmicas entre as atividades.

Estes modelos provêm benefícios teóricos e práticos. Pela perspectiva prática, Fettke e Loos (2007) ressaltam que eles podem ser usados em diferentes cenários:

- Na derivação de um modelo de empresa particular - pode ser reutilizado e adaptado às necessidades de uma empresa específica;

- Na validação de modelos específicos da empresa - pode ser utilizado como benchmarking para avaliar os modelos existentes na empresa, identificando eventuais falhas;

- No desenvolvimento de aplicações práticas - pela provisão de estruturas genéricas que são classes de domínios, e;

- Na seleção de pacotes ERP (Enterprise Resources Planning) - pela descrição de funcionalidades pode-se comparar e selecionar o pacote de ERP apropriado à Empresa. 
Bremer e Lenza (2000, p. 272) ressaltam que "o objetivo do modelo de referência é prover a empresa com uma solução inicial para seus processos de negócios, para que, através dessa, seja especificado e detalhado o modelo particular da empresa." Deste modo, a elaboração de modelos de referência possui as seguintes vantagens (VERNADAT, 2006):

- redução de tempo e custo no desenvolvimento do modelo particular;

- comparação das atividades da empresa com as atividades propostas no modelo (como por exemplo as melhores práticas);

- melhor suporte na implantação de sistemas de gestão empresarial integrados.

Cada processo de modelagem destina-se a um diferente contexto, o que envolve fatores técnicos, econômicos, sociais, entre outros (FETTKE; LOOS, 2007). Entretanto, normalmente o processo de construção dos modelos não é documentado em projetos de modelagem de referência. Por isso, Ahlemann e Gastl (2007), desenvolveram um modelo de processo para construção e documentação de modelos de referências de base empírica e que podem ser validados. Nurcan e Rolland (2003) propõem, por sua vez, um multi-método para a definição da mudança organizacional, utilizando a metodologia EKD. Estes procedimentos são explorados a seguir, identificando os aspectos considerados nesta tese.

\subsection{Elaboração de Modelos de Referência}

O uso de um modelo de processo para a construção de modelos de referência facilita e permite, entre outros benefícios, a compreensão e a reprodutibilidade de resultados de pesquisa (AHLEMANN; GASTL, 2007).

O modelo de processo de Ahlemann e Gastl (2007) é dividido em cinco fases:

1. Identificação do Problema e Planejamento. Necessita primeiramente da identificação do problema para definição clara e precisa do domínio do modelo. Em seguida é necessário observar algumas normas e padrões aplicáveis. Deve-se então selecionar a técnica de representação do modelo, os envolvidos no processo, a tecnologia requerida e um planejamento clássico de projeto.

2. Construção do Modelo. Inicia-se por analisar o estágio atual de domínio de conhecimento sobre o problema, construindo-se posteriormente uma estrutura de referência. Essa estrutura é submetida às críticas de interesse para permitir a elaboração de modelo inicial.

3. Validação. O modelo inicial é submetido à avaliação permitindo o seu refinamento. 
4. Teste Prático. Uma primeira aplicação do modelo pode permitir a resolução de problemas práticos de uma organização, oferecendo novos refinamentos e melhorias incrementais ao Modelo de Referência.

5. Documentação. Os resultados observados da pesquisa são um pré-requisito para compreensão e validade entre diferentes áreas de conhecimento. Recomenda-se fornecer a descrição do processo de construção, anotações dos elementos do modelo, documentação dos estudos de caso e uma tabela com os elementos do modelo.

Nurcan e Rolland (2003) propõem o método denominado EKD-CMM (Enterprise Knowledge Development-Change Management Method - Desenvolvimento do Conhecimento da Empresa - Método de Gestão de Mudança) como uma forma sistemática para organizar e guiar a gestão da mudança. Este método visa documentar uma empresa, seus objetivos, processos de negócios e sistemas de suporte, auxiliando as empresas a desenvolver conscientemente estruturas para implementar mudanças (NURCAN; ROLLAND, 2003).

O alcance dos objetivos do método depende de quatro passos descritos e representados na Figura 2.1 (NURCAN; ROLLAND, 2003):

1. Análise reversa. Abstrair um modelo a partir da realidade atual, o modelo "como é" (As-ls model). Em muitos casos não existem modelos conceituais da organização atual.

2. Definição da Mudança. Integrar a definição de mudança no modelo "como é" (As-Is), definindo o modelo para a organização futura, o modelo "para ser" (To-Be model).

3. Implementação da Mudança. Implementar a nova forma de organização baseada no modelo "para ser" (To-Be).

4. Integração da Missão. Levar em consideração o contexto existente durante a implementação da mudança.

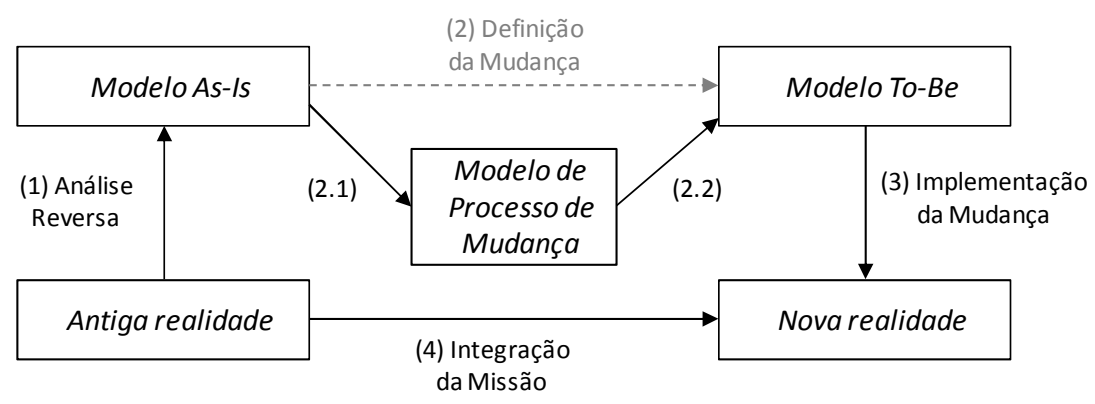

Figura 2.1 - Visão da Mudança do EKD-CMM

Fonte - Nurcan, Rolland, 2003, p. 65. 
Respeitando a nomeação dada aos modelos pelo método descrito, utilizam-se neste trabalho os termos "modelo As-Is" e "modelo To-Be", referindo-se aos estágios "como é" e "para ser", respectivamente, conforme representação da Figura 2.1.

Percebe-se por esta representação que existe a possibilidade de desenvolver o modelo de processo de mudança, que descreve como realizar a mudança, incluindo a descrição de cenários alternativos que a empresa deve seguir para reorganizar-se atendendo aos requisitos específicos para o estágio futuro e obedecendo às restrições impostas a empresa pelo seu ambiente, chamadas de "forças contextuais". O modelo de processo de mudança descreve todas as rotas possíveis que a empresa pode seguir para atingir seu estágio futuro visado no qual todas as restrições impostas pelas forças contextuais serão satisfeitas (NURCAN; ROLLAND, 2003).

Por questões particulares do planejamento e realização deste trabalho, foi adotado um processo de elaboração do Modelo de Referência que adota aspectos do modelo de processo de Ahlemann e Gastl (2007) e do Método de gestão de mudança utilizando o EKD de Nurcan e Rolland (2003).

Corroborando com as restrições específicas e com a Estrutura Conceitual do Trabalho para o Desenvolvimento do Modelo de Referência, apresentada no Capítulo 1, tem-se a seguinte sequência para elaboração do Modelo de Referência desta pesquisa:

1. Identificação do Problema e Planejamento. Diagnóstico do problema observado no Objeto de Pesquisa (o Consórcio), definição do objetivo da Modelagem e planejamento da Coleta de Dados como suporte aos passos seguintes;

2. Elaboração do Modelo. Mapear estágio atual de domínio de conhecimento sobre o problema, elaborando sua estrutura de referência, posteriormente avaliada e refinada;

3. Análise Reversa. Elaboração do Modelo a partir de realidade atual, obtendo-se o(s) modelo(s) As-Is;

4. Definição da Mudança. Análise descritiva das possibilidades de mudança do(s) modelo(s) As-Is para obtenção do(s) modelo(s) To-Be;

5. Documentação do Modelo. Descrição das entidades representadas no modelo To-Be coerentes com as possibilidades apontadas na definição de mudança e com o objetivo definido, obtendo-se o Modelo de Referência, representando uma possível realidade futura. 
Tal estrutura de elaboração é representada na Figura 2.2 - Processo de Elaboração do Modelo de Referência utilizando Gestão de Mudança, proposta pelo autor.

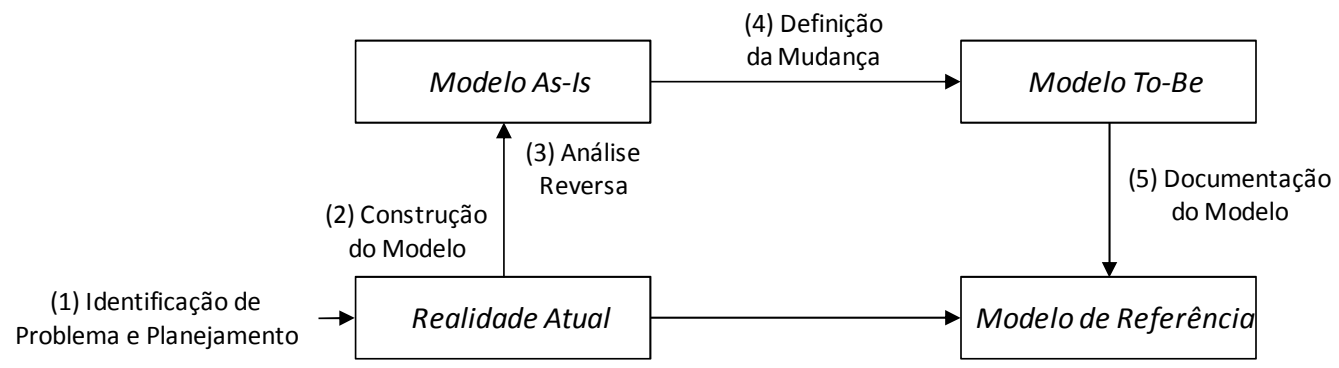

Figura 2.2 - Processo de Elaboração do Modelo de Referência utilizando Gestão de Mudança

Observa-se assim que as fases suprimidas a partir das referências anteriores dizem respeito às atividades de validação e teste prático ou implementação da mudança.

Ainda que possua como fase do trabalho a apresentação de Estudo de Caso realizado em um Consórcio de Construção Civil, considera-se que esta Tese trata de uma proposição de Modelo de Referência generalista, com caráter teórico, e cuja aplicação e consequente refinamento podem ser resultado de novas pesquisas.

\subsection{Considerações Finais}

O entendimento sobre Modelagem constitui um aspecto introdutório ao desenvolvimento dos capítulos seguintes. Modelos de Negócio serão apresentados como síntese de revisão bibliográfica e representação de dados coletados por meio de Estudo de Caso. Um Modelo de Referência, adotando processo de elaboração explorado e baseado na literatura, na consulta a pesquisadores da área e em um Estudo de Caso em Consórcio de Construção Civil, constitui o principal resultado do trabalho.

A combinação adaptada de duas sequências diferentes encontradas na literatura, para a obtenção de um processo de Elaboração do Modelo de Referência utilizando Gestão de Mudança, é fundamental para nortear a elaboração do Modelo de Referência para operacionalização e reconfiguração de redes de construção civil. De forma contra intuitiva, a própria estrutura de elaboração da tese obedece às fases sugeridas pelo referido processo.

Assim, este capítulo explicita a importância da atividade modelar e seus resultados e benefícios, justificando a adoção dessa prática no trabalho. 


\section{OPERACIONALIZACÃO E RECONFIGURACÃO EM REDES DE CONSTRUCÃO CIVIL}

\subsection{Redes de Empresas}

A formação de redes de empresas tem sido uma tendência para o aumento da competitividade e promoção da sustentabilidade dos diversos negócios nos mercados dinâmicos e em expansão. Segundo Amato Neto (2000 p. 34) "a formação e desenvolvimento de redes de empresas vêm ganhando relevância não só para a economia de países industrializados, como para os chamados países emergentes, ou de economias em desenvolvimento".

Mas, é notável nos diversos trabalhos desenvolvidos e publicados sobre este assunto que as redes não possuem uma definição uniforme, existindo falta de consenso nos diversos paradigmas envolvidos e lacunas para o desenvolvimento do assunto no âmbito acadêmico e nas aplicações práticas possíveis (BELL; DEN OUDEN; ZIGGERS, 2006; PROVAN; FISH; SYDOW, 2007). O assunto é tratado sob a ótica de um recorte analítico, na carência de uma teoria consolidada.

Assim, a pesquisa utiliza a definição de Camarinha-Matos e Afsarmanesh (2008), para os quais a constituição de colaboração na forma de rede se dá quando existe algum tipo de organização entre as atividades de seus constituintes, a identificação do papel dos participantes, e algumas regras de governança. Cada organização tem seu perfil e competências, pode ser responsável por um ou mais processos e colaborar com o fornecimento de produtos e/ou serviços (PLISSON et al, 2007).

Apesar da vasta literatura existente sobre redes de empresas e alianças estratégicas, e estrutura de governança das redes, conforme Bell, Den Ouden e Ziggers (2006) e Provan, 
Fish e Sydow (2007), a literatura sobre estes dois pontos relacionados ao setor de Construção Civil é bastante limitada (HO et al, 2009).

Basicamente, a formação de redes em relações de parceria em construção civil converte a tradicional dependência de crédito em uma rede sólida de partes (CHENG; LI, 2002), visando a redução de custos e maior ocorrência do atendimento de prazos (CHAN et al., 2004).

As redes resultam na diminuição das adversidades do ambiente, no aumento da satisfação dos clientes e na compreensão das dificuldades enfrentadas pelas outras partes. Para obtenção deste resultado, garantindo agregação de valor e entrega mais eficientes (RAHMAN; KUMARASWAMY; LING, 2007), são necessários: confiança, boa comunicação, comprometimento, entendimento das regras, consistência e atitudes flexíveis (BLACK; AKINTOYE; FITZGERALD, 2000).

As redes em construção civil também podem ser consideradas Empresas Virtuais (VEs), conforme Camarinha-Matos e Afsarmanesh (2005), pois são iniciadas para um projeto específico e terminam junto com sua conclusão (HO et al, 2009). Rezgui (2007, p. 102) ressalta que "de fato, a indústria da construção já adota o modus operandi de uma VE há décadas" abrangendo todo o ciclo de vida do projeto. Segundo Olave e Amato Neto (2001), nas suas dimensões funcional e institucional, a empresa virtual é caracterizada pela combinação das melhores competências essenciais das empresas cooperadas.

As relações de cooperação utilizam, muitas vezes, o apoio legal da instituição - como constituição de consórcios e joint ventures - para terem garantia de cada um de seus contratos (PLISSON et al., 2007). Assim, o risco dos empreendedores, principalmente em grandes projetos, é dividido entre os parceiros da rede (OLAVE; AMATO NETO, 2001).

A existência de iniciativas voltadas para a coordenação das redes virtuais em manufatura, como o Virtuelle Fabrik (Fábrica Virtual) na Suíça (KATZI; CROWSTON, 2008; VIRTUELLE FABRIK, 2009), incentivou iniciativa similar para a Construção Civil denominada VirtuellBau - Construção Virtual (VIRTUELLBAU, 2009). O VirtuellBau é a maior rede de construção na Suíça. Uma coligação de liderança das empresas de construção de médio e pequeno portes.

O exemplo do VirtuellBau para a Construção Civil (VIRTUELLBAU, 2009) aborda a integração de know-how técnico, custos subsidiados, apresentação e dedicação e redução da burocracia. A missão da colaboração está centrada não apenas nas reuniões de empresas, mas na compreensão do desafio de constituir colaboração e comunicação entre 
todos os membros envolvidos. Seu direcionamento estratégico atende aos requisitos listados como fatores de sucesso para as redes em construção civil de Black, Akintoye e Fitzgerald (2000), Cheng e Li (2002) e Chan et al. (2004) ao considerar, além dos aspectos já abordados: comunicação, compartilhamento de responsabilidades, atendimento de prazos, rastreamento de competências e um sistema integrado como produto.

\subsection{Competências Essenciais}

Muitas redes de empresas são constituídas no intuito de reunir competências diversas. Assim, é consolidada uma competência essencial que diferencia e capacita a rede ante os objetivos de sua formação. A habilidade de colaborar com parcerias tornou-se uma competência essencial em negócios contemporâneos (WESTPHAL; THOBEN; SEIFERT, 2008). Para Javidan (1998), as competências essenciais são as habilidades e áreas de conhecimento que são compartilhadas pelas unidades de negócio e resultam da integração e harmonização das competências das unidades estratégicas de negócio.

Javidan (1998) considera que as empresas podem determinar suas competências essenciais pela avaliação de seus recursos (as entradas para a cadeia de valor da organização, podendo ser de natureza física, humana e organizacional - tangíveis ou intangíveis), capacidades (refletem a habilidade de a organização explorar seus recursos baseadas em funcionalidades, consistindo em uma série de processos de negócio e rotinas) e competências (integração e coordenação multi-funcional das capacidades).

Como exemplos de recursos quantificáveis em construção civil tem-se: equipamentos disponíveis necessários, o número de obras da mesma natureza que a empresa já participou, o faturamento de cada obra, o número de anos de experiência dos engenheiros em obras da mesma natureza, os ativos líquidos e linhas de crédito.

Podem ser determinados como capacidades: atendimento aos objetivos de desempenho estabelecidos, grau de especialização e número de engenheiros disponíveis no corpo técnico da empresa em função de cada especialidade requerida como consultor interno (graduação, especialização, mestrado e doutorado), entre outros.

Como exemplo de competências, pode-se citar o direcionamento para a execução de obras específicas (número de obras pelo número de contratos para segmentos específicos) e o número de oportunidades de negócio que a empresa pode atender simultaneamente pelo faturamento de cada oportunidade. 
Assim, a definição, modelagem e representação de competências de uma organização dependem dos objetivos traçados para uma determinada tarefa (ERMILOVA; AFSRAMANESH, 2010). Deste modo, é pertinente conhecer os processos, atores e recursos da rede.

\subsection{Processos, Atores e Recursos da Rede}

Um processo é um conjunto de atividades que transformam entradas (inputs) em saídas (outputs) em termos de informações ou materiais (JAVIDAN, 1998; BUBENKO et al., 2001).

Para modelar processos é necessário avaliar cada processo, o fluxo de informação contido no negócio e suas respectivas interações. Esses processos geralmente possuem interações e responsabilidades executadas por diversos atores e recursos (BUBENKO et al., 2001).

Os atores de uma rede produtiva representam os indivíduos essenciais, possuidores de habilidades e papéis específicos, que desempenham importantes responsabilidades de forma a agregar valor. Já os recursos podem ser definidos como as unidades organizacionais (departamentos, equipe técnica, projetos, etc.) e recursos não humanos (maquinários e sistemas) que forem relevantes para a constituição da rede (BUBENKO et al., 2001).

Em obras de consórcio de construção tem-se como atores o próprio consórcio, o contratante, as empresas participantes do consórcio, empresas subcontratadas, etc. Como recursos podem ser citados a experiência geral, recursos financeiros, equipamentos, etc.

\subsection{Ciclo de Vida de Redes}

É imprescindível considerar, que as relações entre empresas podem ser caracterizadas por diferentes fases de acordo com o ciclo de vida das relações estabelecidas. Considera-se que um consórcio constituído para projeto específico possui um ciclo de vida delimitado. Ressalta-se que diversas descrições e delimitações de ciclos de vida, modelos e interpretações são encontradas na literatura.

As fases do ciclo de vida segundo Camarinha-Matos e Afsarmanesh (1999) e CamarinhaMatos e Afsarmanesh (2008), para as organizações de redes virtuais, são:

- Criação - iniciação e recrutamento dos parceiros, negociação do contrato, e definição dos deveres e níveis compartilhados, culminando na fundação da rede. Neste ponto são 
elencáveis os parceiros essenciais (responsáveis pelos componentes e serviços críticos) e parceiros subsidiários (suprem componentes e serviços de menor importância);

- Operacionalização ou aplicação - quando a rede efetivamente entra em operação para o atingimento das metas traçadas de acordo com o projeto. São necessárias nesta fase funcionalidades como gerenciamento de pedidos, planejamento e programação distribuídos e dinâmicos, gerenciamento e coordenação das tarefas. O PCP é uma atividade que apóia os vários níveis dos membros da rede;

- Evolução ou reconfiguração - estruturação de mudança necessárias nas relações da rede - baseada em eventos excepcionais da fase de operacionalização relacionados à incapacidade momentânea de algum parceiro ou a necessidade de aumento de força de trabalho, e;

- Dissolução - a rede pode ser dissolvida com o atingimento do objetivo inicial ou ser reativada em uma nova forma, com novos propósitos. Encerram-se as atividades do projeto inicial.

Cheng e Li (2002) sugerem estrutura semelhante para o ciclo de um projeto de Construção Civil, para os quais as fases de criação, operacionalização e reconfiguração, e dissolução correspondem respectivamente a: formação, aplicação e conclusão.

\subsection{Operacionalização e Reconfiguração}

O processo de negócio clássico "Produzir" no caso da construção civil é "Construir". A fase de operacionalização é aquela caracterizada pela geração de valores, portanto, pela consolidação do processo de negócio iniciado.

A reconfiguração acontece porque os acordos iniciais não são estáveis no decorrer do tempo (eventos não previsíveis) e, por isso, devem estar permanentemente em revisão. Os parceiros individuais irão sofrer reorganização, a fim de manter o acerto nas relações, ressaltando a importância da compreensão e estreitamento entre as partes (RAHMAN; KUMARASWAMY; LING, 2007). No caso dos consórcios de construção civil, a reconfiguração ocorre dada a especialização e competência de cada empresa para cumprir as etapas da obra.

Considera-se que a fase de operacionalização é a mais importante, e que a evolução ou reconfiguração pode ocorrer em paralelo com este estágio (CAMARINHA-MATOS; AFSARMANESH, 2008). 
Assim, com um recorte voltado para essas fases de negócio da construção, entende-se que a Gestão de Operações é uma abordagem que contempla todas as áreas de conhecimento e conceitos relacionados à operacionalização e reconfiguração de redes.

A gestão de operações foca a área de execução de um sistema produtivo. Conforme delimita Vollmann et al. (2006, p. 83), representa "a missão que a produção deve realizar para que os objetivos estratégicos da empresa sejam satisfeitos".

Deste modo, a Gestão de Operações contempla uma série de áreas de decisão. Autores como Pilkington e Meredith (2009), fizeram análises bibliométricas das publicações sobre esta área de estudo para o período de 1980 a 2006, identificando grupos de conhecimento ligados principalmente a: estratégia de manufatura, qualidade e suas métricas, métodos estatísticos, desenho de processos, serviços, flexibilidade, métodos qualitativos, cadeias de suprimentos, inovação de produtos/serviços, visão baseada em recursos, medição e Balanced Scorecard, e controle de inventário.

Em estudo semelhante, Taylor e Taylor (2009) encontraram como principais tópicos de discussão da Gestão de Operações entre os anos de 2004 e 2009, em ordem de freqüência de ocorrência, a gestão da cadeia de suprimentos, estratégia de operações, gestão de desempenho, operações de serviços, métodos enxutos (lean), sistemas de planejamento de recursos, gestão da qualidade e desenvolvimento/design de produtos.

Choudhari, Adil e Ananthakumar (2010) propõem em sua estrutura de pesquisa seis áreas de decisão de sistemas produtivos, que incluem em seu escopo muitos dos assuntos anteriormente relacionados: Planejamento e Controle da Produção, Estrutura Organizacional e Controle, Recursos Humanos, Instalações, Fornecimento e Tecnologia de Processos. A delimitação sistemática destas seis áreas, baseada em estudos de outros autores, sugere ainda que cada uma delas envolva tipos diferentes de decisão e combinadas ao tipo de produto, mercado e sistema produtivo, possam guiar as escolhas para o sistema.

A maior parte das classificações apresentadas é generalização e ajusta-se bem a sistemas tradicionais de manufatura e serviços. Outros estudos, por exemplo, acrescentam à pauta da Gestão de Operações as relações inter-firmas (BINDER; EDWARDS, 2010), a integração com competências enxutas - lean (PARRY; MILLS; TURNER, 2010) e funções menos tradicionais como o marketing (PAIVA, 2010). Arditi e Polat (2010) mencionam as áreas de pesquisa encontradas em programas acadêmicos de Construção Civil e Gestão: gestão de contratos, gestão de projetos, programação, gestão de equipamentos, tecnologia de construção e pesquisa em Construção Civil e Gestão. 
Entretanto, nenhum estudo encontrado estabelece as áreas relacionadas especificamente a Gestão Operacional de sistemas ETO, ou explicitamente obras de Construção Civil. Portanto, optou-se por, a partir da Revisão Bibliográfica realizada, delimitar as grandes áreas de conhecimento para a gestão de operações em construção civil, utilizando como base uma adaptação das áreas propostas por Arditi e Polat (2010) e Choudhari, Adil e Ananthakumar (2010):

- planejamento e controle da produção;

- gestão de recursos (pessoas, equipamentos e ferramentas);

- gestão do conhecimento (inovação e competências);

- gestão da Cadeia de Suprimentos (relações na cadeia, fornecimentos de materiais e controle de inventários);

- medição de Desempenho e;

- tecnologia de Informação e comunicação.

Dainty, Briscoe e Millet (2001) ressaltam a dificuldade de prover soluções ou técnicas no projeto de cadeias de redes em construção civil, pois elas são na maioria criadas para apenas um projeto e dissolvidas após a sua conclusão. A gestão efetiva dessas "Empresas Virtuais" demanda novas abordagens aos métodos e modelos que são utilizados para a coordenação das atividades de projeto (KELLER et al., 2006).

Ainda sob uma perspectiva operacional na gestão de redes, Landesman e Scazzieri (1996) defendem que a decomposição do sistema produtivo como pressuposto pela análise explícita de redes ou subsistemas irá resultar na formação de "redes dinâmicas", ou subsistemas de atividades produtivas relacionadas umas às outras pela emergência e difusão de novos impulsos, seja por mudanças externas ou internas ao sistema. Sugerem ainda a identificação de três níveis distintos de coordenação entre os elementos de produção, que são associados respectivamente a: tarefas, agentes e materiais em processo.

Em sua estrutura e função o sistema produtivo da construção, segundo Vrijhoef e Koskela (2000), é caracterizado pela convergência de materiais para onde o produto é feito, por ser uma cadeia temporária voltada para um projeto no qual acontecem repetidas reconfigurações dos participantes, e por um sistema make-to-order - MTO (feito sob encomenda), no qual cada projeto cria um novo produto ou protótipo. No caso de obras de grande porte a tipologia é considerada de Engenharia sob encomenda (Engineering to Order 
- ETO) (PIRES, 2004). A indústria da Construção Civil é geralmente mais dinâmica na sua cadeia de suprimentos se comparada às outras indústrias (SEGERSTEDT; OLOFSSON, 2010).

Mudanças ocorridas em um sistema representam a transição de um modo relativamente estável de operação de um processo produtivo para outro, sendo um processo no qual diferentes elementos do sistema ajustam-se ao novo modo de operação (LANDESMAN; SCAZZIERI, 1996). Por exemplo, se um melhor planejamento de atividades não é solução para problemas de coordenação, os recursos, e os agentes que os controlam, devem ser mais flexíveis (BANKVAL et al., 2010).

A partir das abordagens explicitadas com influência na gestão operacional de redes de construção civil, propõe-se a estrutura da Figura 3.1, relacionando as áreas do conhecimento da Gestão de Operações em Construção Civil, com as fases do ciclo de vida de uma obra e os níveis de coordenação entre os elementos de produção.

A Figura 3.1 representa também a intensidade com que cada uma dessas áreas é abordada em relação às fases do ciclo de vida, ocorrendo em menor intensidade nas áreas claras dentro das barras. A posição dos quatro assuntos centrais no eixo vertical indica sua influência dentro dos níveis de coordenação, com a possibilidade de existência de intersecções. As zonas cinzentas nos extremos do eixo vertical simbolizam a inserção dos assuntos Medição de Desempenho e Tecnologia da Informação e Comunicação na forma de apoio à estrutura, independentemente do nível de coordenação.

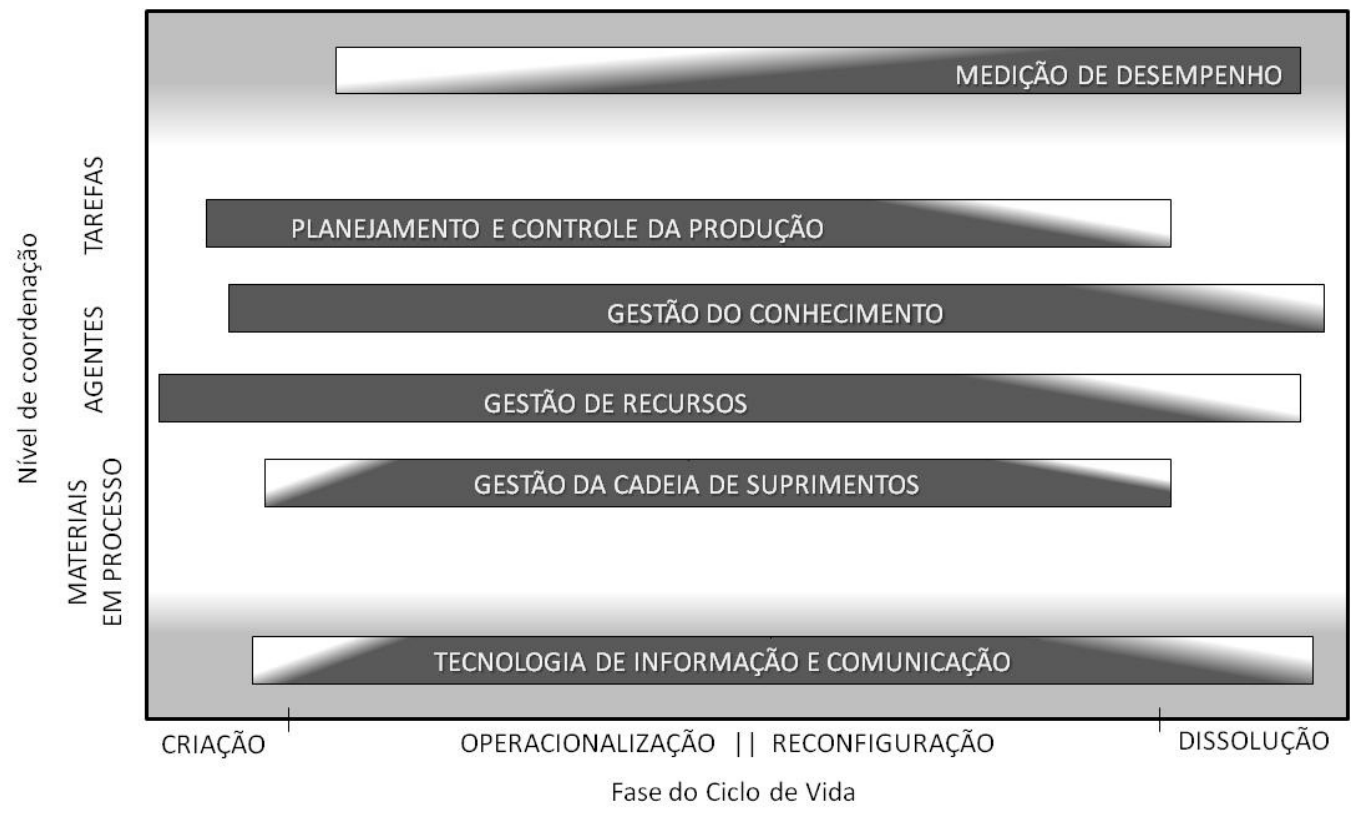

Figura 3.1 - Áreas de Conhecimento da Gestão de Operações em Construção Civil 


\subsubsection{Medição de Desempenho na construção civil}

Existe atualmente um grande número de pesquisas focadas na Medição de Desempenho e sua implementação, porém, poucas abrangem especificamente negócios que operam no setor da Construção Civil (NUDURUPATI; ARSHAD; TURNER, 2007).

Uma boa parte dos estudos encontrados voltados para o setor trata da identificação dos Indicadores de Desempenho, ou proposição de Sistemas de Medição e suas métricas associadas, dentro de alguns recortes específicos: desempenho de firmas que utilizam TIC (EL-MASHALEH; O'BRIEN; MINCHIN, 2006), análise da ocorrência de defeitos na cadeia de subcontratações (KARIM; MAROSSZEKY; DAVIS, 2006), indicadores gerenciais para avaliar a dinâmica de projetos de construção e método para examinar o desempenho de gestores ante essa dinâmica (LAUFER; SHAPIRA; TELEM, 2008; TELEM; LAUFER; SHAPIRA, 2006), indicadores tradicionais da Construção (NUDURUPATI; ARSHAD; TURNER, 2007), avaliação das dimensões de desempenho com base no Balanced Scorecard (YU et al., 2007), indicadores associados à gestão do risco em construção (ZOU; ZHANG; WANG, 2007), modelo de avaliação da satisfação para a gestão de projetos (YANG; PENG, 2008), índices para medir e comparar o desempenho em processos de reengenharia (CHENG; TSAI; LAI, 2009), medidas para sistemas que utilizam tecnologia 4D (DAWOOD; SIKKA, 2009), indicadores para a fase de concepção do projeto (HAPONAVA; AL-JIBOURI, 2009), indicadores para determinação do nível de confiança entre parceiros de projetos (GUERRIERO; KUBICKI; HALIN; 2010; LAU; ROWLINSON, 2010), produtividade de mão-de-obra (IBBS; LIU, 2010), nível de satisfação dos contratantes com a performance dos indivíduos e sistemas escolhidos para o projeto (MINCHIN et al., 2010), indicadores para obras públicas de grande porte (TOOR; OGUNLANA, 2010).

Foram encontrados cerca de 80 indicadores, muitos comuns entre os trabalhos e resumidos no Quadro 3.1. Ressalta-se que um indicador pode se desdobrar em uma ou mais métricas.

\begin{tabular}{l|l|l|}
\hline INDICADORES & & \\
\hline $\begin{array}{l}\text { lucratividade } \\
\text { qualidade }\end{array}$ & $\begin{array}{l}\text { desempenho da segurança } \\
\text { eficiência do planejamento }\end{array}$ & $\begin{array}{l}\text { market share dos envolvidos no projeto } \\
\text { investimento em Pesquisa e Desenvolvimento }\end{array}$ \\
\hline eficiência & aderência à programação & capabilidade tecnológica e informatização \\
\hline eficácia & sustentabilidade ambiental & satisfação de clientes internos e externos \\
\hline crescimento & desempenho dos agentes & alinhamento dos requisitos das partes interessadas \\
\hline estabilidade & eficiência da comunicação & desenvolvimento de recursos humanos \\
\hline tempo & desempenho de equipes & competência organizacional \\
\hline custo & & \\
\hline
\end{tabular}

Quadro 3.1 - Indicadores de Desempenho para a Construção Civil 
O benchmarking também é uma ferramenta utilizada para avaliações conforme trabalhos de Cheng, Tsai e Sutan (2009) e Ahuja, Yang e Shankar (2010).

Outros autores desenvolveram "fatores de sucesso" ou elementos de entrave que influenciam o desempenho dos negócios de construção, novamente com recortes específicos: fatores para acabar ou diminuir as disputas de reinvidicação de atrasos em relações de parcerias com contratos (YATES; EPSTEIN, 2006), considerações para a elaboração de projetos resultando no sucesso de sua execução (YU et al., 2006), fatores que causam atrasos em projetos de construção (ALAGHBARI et al., 2007), estrutura fuzzy para resolver problemas de pré-qualificação de concorrentes para projetos de construção feitos no modo de licitação (LI; NIE; CHEN, 2007), adoção e comprometimento da organização para a inovação (LING et al., 2007), metodologia da Gestão de Valor para o aumento do valor em projetos (MALE et al., 2007), fatores e critérios para o desempenho de consultores externos na gestão de projetos (NITITHAMYONG; TAN, 2007), fatores importantes para o sucesso das Joint-ventures internacionais (OZORHON et al., 2007; OZORHON et al., 2010), fatores que impactam na viabilidade de projetos de Infra-estrutura de grande porte (SALMAN; SKIBNIEWSKY; BASHA, 2007), barreiras percebidas pelos clientes para formação de parcerias e promoção de mudanças (ERIKSSON; NILSSON; ATKIN, 2008; VENNSTRÖM; ERIKSSON, 2010), o impacto de diferentes processos de planejamento para o sucesso de um projeto (ZWIKAEL, 2009), fatores chave de sucesso para as alianças estratégicas na indústria da construção (LÖNNGREN; ROSENKRANZ; KOLBE, 2010), referências práticas para o uso de sistemas de subcontratação (TAM; SHEN; KONG, 2010), eliminação de barreiras de comunicação pela formação de parcerias (XIE et al., 2010), uma estrutura para o gerenciamento eficaz das partes interessadas de um projeto (YANG et al., 2010).

A confiança apresenta-se como um aspecto viabilizador de relações de parcerias, compondo uma discussão também muito freqüente para a melhoria de desempenho de projetos de construção. Para Karlsen, Græe e Massaoud (2008), a confiança é importante na construção do bom funcionamento dos negócios, ela é resultado de boas relações entre as partes interessadas dos projetos.

\subsubsection{Planejamento e Controle na construção civil}

A gestão de projetos (planejamento e controle) é uma competência central para a indústria da construção (ZWIKAEL, 2009). 
Yang (2007) elaborou um mapa contendo as técnicas de planejamento utilizadas em construção, de modo a sintetizar o conhecimento já difundido sobre o assunto. Os conceitos abordados, e trabalhos encontrados nestes enfoques foram:

- Técnicas de simulação - Sistema de Programação baseada em Simulação Simplificada (S3 - Simplified Simulation-based Scheduling) (LU; LAM; DAI, 2008); Representação matemática para inferir futuros alternativos para o desenvolvimento de sistemas de simulação (ANDERSON; MUKHERJEE; ONDER, 2009); Modelo de simulação de Construção Enxuta incluindo fluxo unitário de peças e produção puxada, reestruturação de trabalho e multifuncionalidade (SACKS; ESQUENAZI; GOLDIN, 2007);

- Técnicas de seqüenciamento linear - Modelo robusto de otimização multi-objetivo para o planejamento e programação de projetos de construção repetitivos (HYARI; EL-RAYES, 2006); Identificação formal e processo de re-sequenciamento para suportar a geração rápida de alternativas de seqüências em programas de construção, utilizando os princípios da inteligência artificial (KOO; FISCHER; KUNZ, 2007);

- Método do caminho crítico (CPM) - Sistema de Otimização Colônia de Formigas para calcular tanto os aspectos determinísticos quanto probabilísticos das redes PERT/CPM (ABDALLAH et al., 2009; DUAN; LIAO, 2010).

- Avaliação da programação e técnicas de controle - Estrutura conceitual e um modelo de sistema para a gestão da variação das ordens programadas (ARAIN; PHENG, 2007); Soluções para amenizar problemas de variações nos projetos de construção pública (ALNUAIMI et al., 2010); Atualização de programação com uso de câmeras de alta resolução com as imagens das atividades do canteiro de obras (BOHN; TEIZER, 2010);

- Avaliação gráfica e técnicas de revisão - Produção de imagens 4D CAD como apoio para programação (STAUB-FRENCH; RUSSELL; TRAN, 2008); Sistema para representar o progresso da construção não somente com uso do CPM, mas de uma representação gráfica sincronizada com a programação de trabalho agrupada a GIS, um software de planejamento de projetos e CAD (POKU; ARDITI, 2006); Algoritmo que deriva uma ordem de construção a partir de um modelo sólido da edificação, utilizando 4D CAD (VRIES; HARINK, 2007);

- Planejamento e alocação de recursos - Programar sem considerar recursos não é realista e pode causar atrasos de cronograma (IBBS; NGUYEN; 2007; KIM, 2009); 
- Planejamento e análise de redes - arquitetura para conexão de processos (O'BRIEN et al., 2008); Estratégias de planejamento colaborativas com uso de uma plataforma baseada na Web (VERHEIJ; AUGENBROE, 2006);

- Análise de atrasos - método de previsão fornecendo previsões probabilísticas de duração do projeto (KIM; REINSCHMIDT, 2010);

- Problemas relacionados ao balanço tempo-custo;

- Programação da Corrente Crítica - Teoria das Restrições.

Uma integração sistemática da perspectiva estratégica e dos detalhes operacionais pode ajudar a aumentar o desempenho de processos na medida em que permite aos gestores da construção identificar áreas de processos com potencial de melhoria que abordagens tradicionais podem deixar de lado (PEÑA-MORA et al., 2008).

Dentro de uma perspectiva mais moderna, Sacks et al. (2010) estruturam e analisam as relações e interações entre os conceitos BIM e Construção Enxuta, podendo-se identificar as sinergias potenciais existentes ao planejar suas estratégias de adoção dessas duas filosofias. Paralelamente, Sacks, Radosavljevic e Barak (2010) oferecem uma estrutura de implementação do KanBIM combinando e representando uma alternativa a conceitos e tecnologias de programação. Seus resultados alcançam melhoria do fluxo de trabalho e redução de desperdícios com a visualização do produto e do processo.

\subsubsection{Gestão do Conhecimento na construção civil}

A gestão do conhecimento é uma competência chave para a indústria da construção, pois mesmo com o caráter único de cada projeto, pode-se chegar a uma organização de aprendizagem com grandes oportunidades de armazenagem, acesso e compartilhamento do conhecimento (CARRILLO; CHINOWSKY, 2006; CHINOWSKY; CARRILLO, 2007), e por isso, essa gestão deve ser integrada com a estratégia de negócios das empresas (DAVE; KOSKELA, 2009).

As principais práticas ou passos para a implantação da Gestão do Conhecimento para a Construção Civil e seus sistemas e tecnologias de auxílio são resumidas com base nos trabalhos de Carrillo e Chinowsky (2006), Yin, Tserng e Tsai (2008), Dave e Koskela (2009), Chan, Walker e Mills (2009), Ribeiro (2009) e Teerajetgul, Chareonngam e Wethyavivorn (2009): 
- Alinhar a Gestão do Conhecimento com os objetivos estratégicos da empresa - qual a estratégia que melhor se aplica à organização (mais centrada em pessoas, procedimentos ou tecnologia de informação);

- A alta gerência deve sinalizar a importância da Gestão do Conhecimento, e auxiliar sua integração à estratégia do negócio, liderança visionária;

- Identificar quais os ativos de conhecimento mais importantes na organização e estabelecer sistemas de repositório eficientes;

- Entender o que constitui o conhecimento para a empresa, que conhecimento precisa ser obtido, e quais são os incentivadores e barreiras para a criação do conhecimento e seu compartilhamento;

- Integrar as fontes internas e externas de conhecimento dentro das ferramentas disponíveis de modo a aprender com outros;

- Utilizar TICs para promover redes de cooperação ou colaboração (também por meio de ferramentas simples de Internet ou Intranet, e de sistemas ERPs), envolvendo toda a organização no processo de Gestão do Conhecimento;

- Realizar reuniões durante a fase geração de valor do negócio para capturar as experiências aprendidas estabelecendo um nível de confiança entre empregados, para o compartilhamento de conhecimento;

- Identificar métricas de médio e longo prazo, criando sistemas de recompensa (retornos e incentivos) relacionados ao conhecimento e criação de especialidade (competências e habilidades individuais).

Outras abordagens tratam da importância da Gestão do Conhecimento para Projetos de Construção no processo de tomada de decisão, relacionadas a eventos de mudança e resolução de problemas: constitui uma ferramenta para evitar disputas e conflitos (CHEN, 2008); criação e compartilhamento de diferentes formas de conhecimento entre membros de um projeto durante reuniões presenciais, principalmente (SENARATNE; SEXTON, 2009); fomenta o desenho de um sistema de inteligência artificial como abordagem para a retenção e utilização de conhecimento advindo da experiência dos profissionais envolvidos e da qualidade do conhecimento acumulado em experiências prévias (CHENG; ROY, 2010) e elaboração da arquitetura e do sistema para a Tomada de Decisão baseada em Conhecimento (KANAPECKIENE et al., 2010).

Ainda, as interfaces interativas virtuais auxiliam no processo de gestão da construção pela exposição do status do projeto, auxílio no processo de tomada de decisão e melhoria na comunicação entre os participantes do projeto (RUSSEL; CHIU; KORDE, 2009). 
A formação dos profissionais da área de engenharia para a gestão e sua compreensão sobre os conceitos de Gestão do Valor, são discussões relacionadas ao conhecimento presentes nos trabalhos de Arditi e Polat (2010) Bowen et al. (2010), respectivamente.

Rezgui, Hopfe e Vorakulpipat (2010) apresentam a gestão do conhecimento para a indústria de Arquitetura, Engenharia e Construção (AEC) como passível de atingir 3 diferentes gerações: a primeira é o Compartilhamento de Conhecimento (uso de TICs - ênfase no acesso à informação), a segunda envolve a Conceitualização e Desenvolvimento do Conhecimento (aspectos humanos e organizacionais - perspectiva processual em saber e agir) e a última geração de Criação de Valor do Conhecimento (redes de pessoas, capital social, capital intelectual, ativos tecnológicos, e gestão de mudanças - o conhecimento é uma capabilidade). Em trabalho aplicado, Vorakulpipat, Rezgui e Hopfe (2010) identificam esta última geração em times virtuais de construção - uso de bases de conhecimento de projetos compartilhadas - apontando os recursos sócio-culturais que influenciam a criação de valor.

Assim, cabe lembrar que, atualmente, na indústria da Construção, as inovações não contemplam somente a combinação criativa de materiais, mas, devido à fragmentação da cadeia de valor, também envolve a combinação das organizações promovendo desenvolvimento de novos produtos, novas organizações (alianças e redes estratégicas), novos processos e design (auxiliado pela inovação aberta - open innovation) e novas práticas de gestão da construção (LING et al., 2007; RUTTEN; DORÉE; HALMAN, 2009). Dentro desta abordagem, Kumaraswamy et al. (2006) propõem uma plataforma virtual para promover colaboração de projetos voltados à gestão de informação e conhecimento, de modo que possam ser obtidas sinergias das iniciativas de P\&D voltadas para tal. Este tipo de plataforma é especialmente importante para a gestão do conhecimento em projetos de grande porte (DEMAID; QUINTAS, 2006) e empresas grandes e geograficamente dispersas (CARRILLO; CHINOWSKY, 2006).

Neste contexto, são pertinentes as considerações de Na, Ofori e Park (2006) e Rutten, Dorée e Halman (2009) sobre a estruturação de um Sistema Nacional de Inovação para a construção civil para a cooperação inter-organizacional. Os principais agentes seriam: clientes, contratantes ou empreiteiros (locais e estrangeiros), agências reguladoras e governo, institutos profissionais e institutos de pesquisa nacionais, consultores especialistas e fornecedores. 


\subsubsection{Gestão de Recursos na construção civil}

A Gestão de Recursos aborda os elementos presentes na estrutura de agentes de transformação (pessoas, capital, materiais e ferramentas). Luu et al. (2009) utilizam Redes Bayesianas para quantificar a probabilidade dos atrasos em projetos de construção de países em desenvolvimento, identificando que dificuldades financeiras de proprietários e contratantes, experiência inadequada do contratante e falta de materiais são as principais causas de atrasos da construção, justificando a importância dessa área de conhecimento para a gestão de operações em Construção Civil.

A correta alocação de mão-de-obra operacional pode aumentar a eficiência dos projetos. Neste sentido, Thomas e Horman (2006) colocam os princípios para gestão da mão-deobra: medição de desempenho, programação diária de trabalho, atribuições de trabalho, estruturação de equipes, minimização/eliminação de interrupções, trabalhadores multifuncionais, uso de pré-montagens e módulos e estruturação de equipes paralelas. Tal abordagem de equipe, ou times, é detalhadamente tratada pelo método THRP (Team-based Human Resource Planning - Planejamento de Recursos Humanos baseado em times) alocando os recursos humanos baseado nos processos inter-funcionais, de modo que os projetos e a capacidade de trabalho sejam aumentados (CHENG; TSAI; XIAO, 2006). Abordagem semelhante é feita no modelo de Orabi et al. (2010). Para Rezgui (2007), os aspectos humanos e organizacionais têm grande influência sobre a pesquisa, desenvolvimento e avaliação dos potenciais das soluções de times de trabalho virtuais, aplicáveis ao contexto da Construção Civil.

Mas, os profissionais que ocupam posições de liderança dos projetos também possuem discussões voltadas às atribuições de suas funções. Para Styhre (2006), a função do gestor de projetos de construção, que para autores mais modernos está relacionada à autoridade e liberdade, incentivando a criatividade e inovação, continua ainda muito ligada às atividades burocráticas, ou à autoritarismo, poder e orientação para tarefas, advindas também da descentralização de atividades (TOOR; OFORI, 2008). Recomenda-se que as atividades tradicionais (emissão de relatórios, documentações, padronizações) sejam executadas de forma repaginada, no sentido de diferentes comportamentos de liderança, competências e estilos - uma liderança autêntica (TOOR; OFORI, 2008).

A gestão de programação emergiu como um serviço terceirizado que abrange todos os aspectos do ciclo de vida de uma construção (RASDORF; GRASSO; BRIDGERS, 2010). Este tipo de serviço é contratado por diferentes direcionadores do escopo do empreendimento quando consideradas as iniciativas públicas e privadas. 
Considerando os arranjos produtivos mais modernos, sujeitos à governança coorporativa, Rebeiz e Salameh (2006) colocam a formação de diretorias/gerência de projetos por profissionais que não acumulem funções da gestão central do negócio como mais vantajosa em termos de desempenho financeiro.

No tocante aos recursos relacionados ao aporte financeiro das obras, tem-se a tendência apontada por Ke et al. (2009) da constituição das PPPs (Parcerias Público-Privadas), principalmente na provisão do desenvolvimento de infra-estrutura pública. As principais abordagens relacionadas são (KE et al., 2009; TANG, SHEN; CHENG, 2010): investimento, execução, viabilidade econômica, fatores de sucesso do projeto, pacote financeiro, gestão de riscos, período de concessão, parcerias, questões de governança e pesquisa integradora.

Já as questões relacionadas aos recursos físicos abordam: aplicação da tecnologia de RFID para o monitoramento de ferramentas em ambientes de construção, melhorando o uso do tempo e auxiliando inventário e coleta de dados para Operação e Gestão (GOODRUM; MCLAREN; DURFEE, 2006); otimização do planejamento de recursos em projetos de construção de larga escala, analisando-se as variáveis tempo e custo (KANDIL; EL-RAYES, 2006); seleção de equipamentos utilizando variáveis quantitativas e qualitativas, para avaliar custos e benefícios das alternativas (GOLDENBERG, SHAPIRA, 2007).

\subsubsection{Gestão da Cadeia de Suprimentos na construção civil}

Cadeias de suprimentos em projetos de construção representam um desafio de coordenação devido, principalmente, à sua natureza descontínua (SERGERSTEDT; OLOFSSON, 2010).

Adaptações de conceitos, ferramentas e modelos existentes como auxílio à gestão da cadeia de suprimentos em construção civil também são discutidos: solução para lacunas no método Last Planner para gerenciar a logística de materiais (ALA-RISKU; KÄRKÄINEN, 2006); questões práticas relacionadas a rotas fixas e diferentes tipos de frotas veiculares viabilizando o transporte e entregas pontuais para clientes e empresas modernas (TARANTILIS; KIRANOUDIS, 2007); um modelo baseado em sincronização, utilizando os princípios da teoria das restrições e produção enxuta para diminuir a falta de sincronia e processos desnecessários na gestão de materiais (TSAI; YANG; LIN, 2007); foco no marketing de relacionamentos (criação de valor para os clientes e desdobramento deste valor a todos os interessados no negócio) nas cadeias (DAVIS, 2008); uso de uma solução de VMI (Vendor Management Invetory - Estoque Gerenciado pelo Fornecedor) promovendo 
eficiência na logística de itens pequenos (TANSKANEN et al., 2009); procedimento simples para a emissão de ordem, produção e entrega de materiais com fundamentos genéricos (BANKVAL et al., 2010).

Dois assuntos merecem destaque para a Gestão da Cadeia de Suprimentos: a Produção Enxuta e a formação de parcerias.

Yu et al. (2009) indicam uma abordagem prática de Produção Enxuta utilizando mapeamento de fluxo de valor, focando na criação de um fluxo estável de produção ao invés de eliminar perdas individuais. Em um estudo mais abrangente, Eriksson (2010), elaborou uma estrutura de implementação de aspectos relacionados à construção enxuta (lean construction) contemplando: redução de desperdícios, foco no processo, foco no cliente, melhoria contínua, relações de cooperação e perspectivas do sistema. Os resultados de uma survey avaliando esta implementação, indicam que a formação de parcerias podem constituir uma base adequada para o desenvolvimento da construção enxuta.

Khalfan, McDermott e Swan (2007) exploram os aspectos relacionados às mudanças necessárias para a constituição de confiança no ambiente da cadeia de suprimentos da construção civil - na tentativa de prover uma cultura de solução de problemas. Para os profissionais que atuam no setor, a gestão da Cadeia de Suprimentos é considerada como um sinônimo de relações de parcerias, sendo algo difícil de implantar dado a fatores contextuais/culturais (FERNIE; THORPE, 2007).

Assim, Voordjik, Meijboom e Haan (2006) discutem sobre a modularidade - propriedade de separar e recombinar os componentes de um sistema - nas dimensões de produto, processo e cadeia de suprimentos - como forma de promover flexibilidade para satisfazer uma maior variedade de requisitos dos clientes. Considerando esta dinâmica da cadeia, Holmen, Pedersen e Jansen (2007) ressaltam que uma iniciativa de suprimento em rede pode ser considerada um meio de compor uma estrutura parcialmente conectada, podendo assumir um comportamento de auto-reforço (reprodução automática de padrões) ou de seqüência reativa (estímulos geram uma seqüência de reações fortemente ligadas).

\subsubsection{Tecnologia de Informação e Comunicação na construção civil}

A utilização de aplicativos de TICs (Tecnologias de Informação e Comunicação) tem sido crescente em projetos de construção civil para a coleta, produção e disponibilização das informações. 
Os benefícios percebidos pela adoção de TICs são explorados nos trabalhos de Craig e Sommerville (2006), Rowlinson e Croker (2006), Yu, Lee e Kim (2006), Ahuja, Yang e Shankar (2009a; 2009b). Tatari, Castro-Lacouture e Skibniewski (2007) explicitam as dimensões e os benefícios da adoção de TICs (sistemas ERP particularmente), contemplando muitos dos citados pelos autores referenciados:

- Operacionais (redução do tempo de ciclo, aumento da produtividade, aumento da qualidade, redução de custos);

- Gerenciais (aumento da eficiência, melhoria no processo de decisão e planejamento e melhor gestão de recursos);

- Estratégicos (suporte ao crescimento do negócio, geração ou manutenção de competitividade, desenvolvimento de inovação de negócios, permissão da expansão para novos negócios, melhor relacionamento com fornecedores, distribuidores e partes relacionadas no negócio);

- Infraestrutura de Tecnologia de Informação (aumento da flexibilidade do negócio, aumento da própria infraestrutura de TIC, redução dos custos de TIC);

- Organizacionais (visão compartilhada da empresa, facilita o aprendizado de negócios e ampliação das habilidades dos empregados, suporte das mudanças organizacionais em termos de estrutura e processos e empowerment de empregados).

A adoção de TIC na indústria da construção não é meramente técnica, mas acompanhada de muitas mudanças nos processos de gestão (FROESE, 2010). Lam, Wong e Tse (2010) apresentam obstáculos humanos e organizacionais para a obtenção das reais vantagens de adoção de sistemas TICs. Assim, as estratégias de implementação dessa tecnologia devem estar bem alinhadas com as relacionadas à gestão de mudanças (HENDERSON; RUIKAR, 2010).

Alguns trabalhos também explicitam o uso da Internet (web) para viabilizar a tecnologia de informação: aplicação baseada na web usando RFID para a gestão da cadeia de suprimentos (WANG; LIN; LIN, 2007); estrutura para um sistema semântico baseado na web para efetiva gestão da informação colaborativa (ANUMBA et al., 2008; CHASSIAKOS; SAKELLAROPOULOS, 2008); sistema ERP baseado na web para a gestão desde procedimentos simples de automação de escritório, até o planejamento de cadeias de suprimentos (TARANTILIS; KIRANOUDIS; THEODORAKOPOULOS, 2008); bancada telemática digital incorporando computador móvel, comunicação wireless e uma mesa de interface horizontal para a colaboração sincronizada entre o canteiro de obras e escritório fora do canteiro (DONG et al., 2009); criação de um portal inovador, com participação da academia, governo e indústria em uma obra de PPP (RUUSKA; TEIGLAND, 2009). 
Arain (2008), Lin (2008), Lin et al. (2008) utilizam a tecnologia da informação como forma de auxílio à retenção e acesso de bases de conhecimentos e experiências úteis para processos decisórios.

Neves e Guerrini (2010) propõem um modelo de requisitos e componentes técnicos como auxilio à formação e gerência de redes entre empresas da construção civil, visando desenvolvimento de sistema de informação para o setor. Hartmann, Fischer e Haymaker (2009) também fazem recomendações para o desenho de sistemas de informação, bem como Salem e Mohanty (2008) para a adoção de TICs na construção civil, argumentando que a maioria das soluções existentes não endereça os requisitos dos reais dos sistemas construtivos, com muitas inovações, porém com carências em muitas áreas.

\subsubsection{Modelo de Conceitos para a Operacionalização e Reconfiguração}

O Modelo de Conceitos da Figura 3.2 elaborado a partir da Revisão da Literatura é uma tentativa de representar as relações entre os diversos assuntos em pauta na Gestão de Operações da Construção Civil.

O Modelo considera como principais conceitos as áreas de conhecimento sugeridas como base para os processos de operacionalização e reconfiguração.

O Conceito 1, Medição de Desempenho, envolve a determinação de Indicadores de Desempenho (Conceito 7) - grande número de variáveis de métricas, muitas vezes agrupados em dimensões, auxiliando na concepção dos Sistemas de Medição de Desempenho (Conceito 8). Esses conceitos também podem ser apoiados por práticas de Benchmarking. A Medição de Desempenho visa conhecer e controlar as variáveis e suas grandezas, para garantir o desempenho das dimensões relacionadas aos demais conceitos explorados no Modelo.

O Planejamento e Controle da Produção - Conceito 2 -, desdobra-se em abordagens tradicionais e mais contemporâneas, direcionado pelos aspectos estratégicos e operacionais do negócio. Predominantemente, sistemas de PCP voltados para a Construção Civil podem ser considerados de Gestão de Projetos. Atualmente, as ferramentas e sistemas disponíveis fazem uso de Tecnologias de Informação e Comunicação, na provisão de representações visuais, auxiliando no acompanhamento da programação. Os sistemas ERPs também são utilizados como ferramentas de apoio ao planejamento e controle.

A Gestão do Conhecimento (Conceito 3) tem forte influência nos processos de Tomada de Decisão (Conceito 9), que por sua vez, depende de variáveis relacionadas a pessoas e 
tecnologia. Aquele conceito é incentivador da Inovação ou Criação de Valor (Conceito 10) que pode se dar na forma de novas organizações, produtos, processos ou práticas de gestão. A cooperação inter-organizacional também viabiliza a inovação e incentiva a criação de parcerias e redes de empresas como novas formas de organização. As Empresas Virtuais emergem como uma forma de operação em rede de empresas.

O Conceito 4, Gestão de Recursos, envolve as dimensões pessoas, ferramentas, equipamentos e capital. A correta alocação dessas dimensões é um desafio que precisa ser considerado no Planejamento e Controle da Produção. A dimensão pessoas e suas variáveis possui forte relação com a Gestão do Conhecimento. Considerando caso particular de obra de grande porte, o capital pode ser viabilizado por Parcerias Público-Privadas.

A Gestão da Cadeia de Suprimentos (Conceito 5) é bastante apoiada por abordagens mais contemporâneas de gestão, notadamente o planejamento e análise de Redes, consideradas as parcerias e estruturas de fornecimento, com grande enfoque em relacionamentos e na construção de confiança entre as partes. Há uma série de ferramentas de Tecnologia de Informação e Comunicação que dão suporte a este novo modo de gestão.

O Conceito 6, Tecnologia de Informação e Comunicação, é utilizado por todas as demais áreas, evidenciando ser atualmente um requisito básico de todos os sistemas, disponibilizando informações e dados baseados na Web, nos servidores internos das empresas, e nos Softwares e Sistemas que podem oferecer soluções individuais ou integradas de uma ou mais áreas do conhecimento.

Ressalta-se que, dada a intencionalidade de modelar os conceitos mais relevantes de cada área, foram omitidas as informações relacionadas às condições particulares dos países/regiões dos estudos revisados. Ainda, a exploração desses conceitos é utilizada como apoio à modelagem, destacando suas relações mesmo quando algumas definições não foram estabelecidas. 


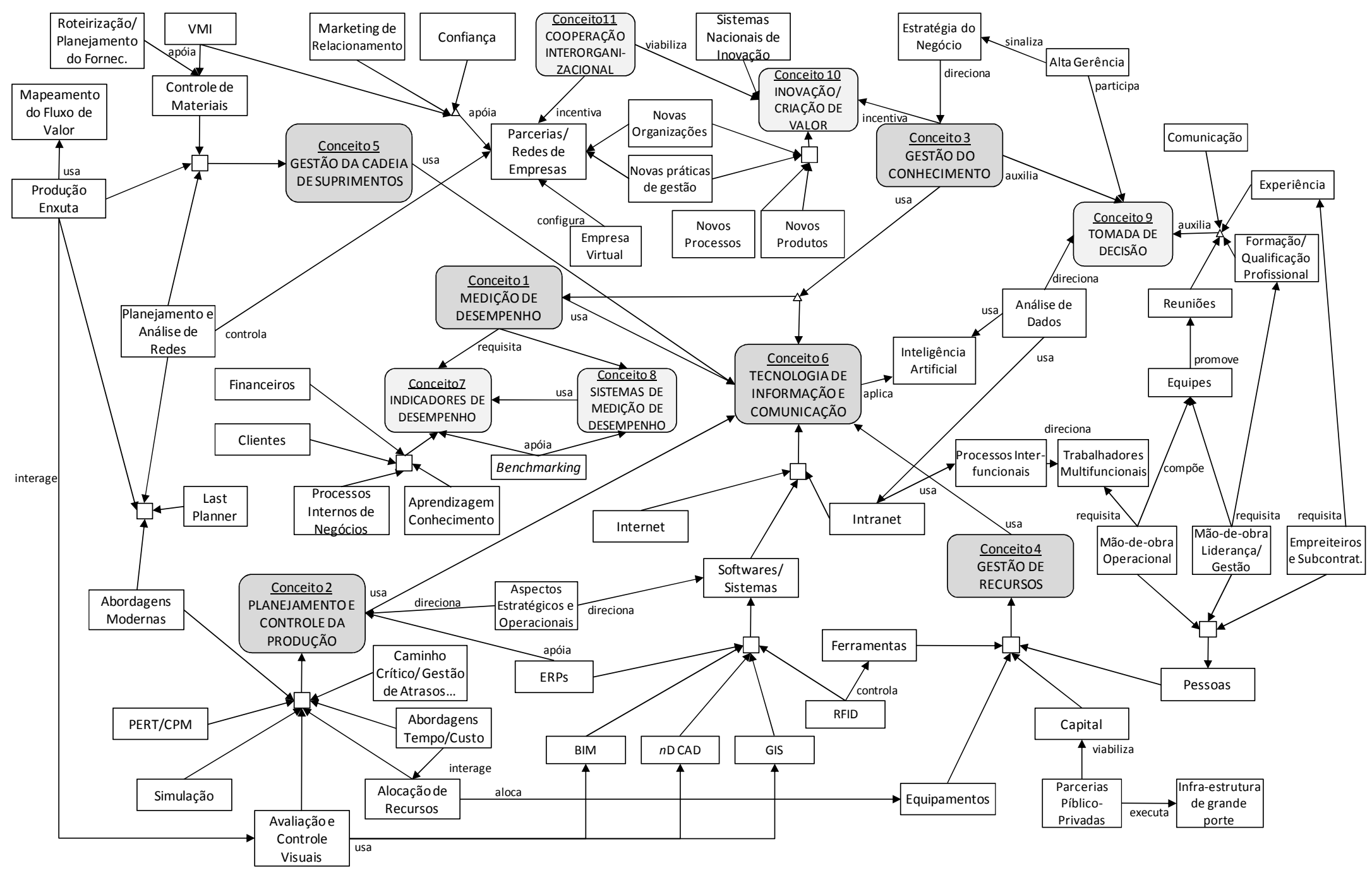

Figura 3.2 - Modelo de Conceitos para Operacionalização e Reconfiguração em Construção Civil 


\subsection{Considerações Finais}

Esta Revisão Bibliográfica é apresentada como apoio ao desenvolvimento do Modelo de Referência - objetivo do trabalho, sendo limitada em função das variáveis que serão utilizadas neste modelo. O Modelo de Conceitos apresentado é um resultado dentro das proposições do trabalho e constitui-se de base conceitual fundamental para o Modelo de Referência.

O recorte analítico de redes apoia a estrutura conceitual delimitando o ambiente de análise do objeto de estudo, suas principais características e sua forma de configuração como Empresa Virtual, considerada uma obra de grande porte de Construção Civil. Também são apontadas as vantagens do trabalho em cooperação (parcerias) neste setor, como novo desafio de coordenação.

A discussão sobre as competências essenciais esperadas em projetos de construção configurados como uma rede, sob as variáveis propostas por Javidan (1998) permite um entendimento dos aspectos requeridos no projeto que, relacionados aos processos, atores e recursos, oferecem uma visão integrada do perfil da rede.

Considerando ainda a delimitação temporal da obra, tem-se que o ciclo de vida da rede pode oferecer oportunidades de análise diferentes em função de suas fases. Logo, as fases de operacionalização e reconfiguração que ocorrem em paralelo, são marcadas por um grande número de variáveis relacionadas ao processo de Gestão de Operações. As áreas de conhecimento relacionadas a esta gestão permitem identificar muitas dessas variáveis que, representadas como conceitos ou entidades no Modelo de Conceitos, auxiliam no entendimento sobre a dinâmica e complexidade das fases. 


\section{COLABORACÃO EM REDES DE CONSTRUCÃO CIVIL}

Neste capítulo estabelecem-se as premissas básicas para a colaboração em Redes de Construção Civil. Inicia-se por discutir quais aspectos caracterizam as Redes Colaborativas em Construção, retomando as áreas de conhecimento da Gestão de Operações em Construção discutidas na Revisão Bibliográfica. Em seguida, descreve-se a condução de uma pesquisa utilizando dados de Centros de Pesquisa visitados, considerados de referência na área. A Coleta de Dados nestes Centros de Pesquisa visou o refinamento do Modelo de Conceitos apresentado no Capítulo anterior para uma abordagem voltada à colaboração. De posse de três diferentes visões formalmente coletadas por entrevistas e de materiais relevantes disponibilizados, apresenta-se um Modelo de Conceitos para Colaboração em redes de Construção Civil.

\subsection{Redes Colaborativas em Construção Civil}

Redes Colaborativas têm emergido no cenário mundial em uma grande variedade de formas (CAMARINHA MATOS; AFSARMANESH, 2005, 2008). Essas novas formas de operação de negócio têm se apresentado como ingredientes de sucesso, tendo o setor da construção civil grande potencial de beneficiar-se por sua adoção (REZGUI, 2007).

Uma Rede Colaborativa é um grupo de entidades autônomas, geograficamente distribuídas e heterogêneas (envolvendo organizações e pessoas). Essas entidades possuem diferentes ambientes de operação, cultura, capital social, e metas e elas colaboram para o alcance de metas comuns ou compatíveis, utilizando o suporte de redes de computadores (CAMARINHA MATOS; AFSARMANESH, 2005). Empresas Virtuais são tipos de Redes Colaborativas. 
É sabido que a Empresa Virtual traz vantagens para seus membros. Para a Medição de Desempenho destes arranjos, o desenvolvimento de indicadores de desempenho baseado nos benefícios da rede provê uma ferramenta para analisar a evolução de processos de colaboração bem como o desempenho individual de membros da rede, conforme ressalta Camarinha-Matos e Abreu (2007).

A Gestão de Empresas Virtuais em termos de Planejamento e Controle demanda métodos e modelos utilizados para a coordenação de atividades de projeto (Gestão de Projetos). Uma iniciativa apropriada é descrita no trabalho de Keller et. al (2006), com a proposta de uma arquitetura para planejamento, execução e controle de processos entre empresas de forma dinâmica. Verheij e Augenbroe (2006), por sua vez, propõem a geração sistemática de planos de projeto pelo uso de lógica e inteligência de estratégias de planejamento colaborativas.

Uma Gestão de Conhecimento colaborativa deve abranger diferentes iniciativas: prover uma forma efetiva de compartilhamento de conhecimento entre operações com funções similares e geograficamente dispersas (DAVE; KOSKELA, 2009), constituir uma forma de gerar inovação em construção (RUTTEN; DOREÉ; HALMAN, 2009) e também permitir a melhoria da comunicação e coesão entre membros, com uso de base de conhecimento dedicada (REZGUI, 2007).

Nas Redes Colaborativas, os Recursos Humanos são o principal fator na Gestão de Recursos. Deste modo, esta área apresenta muitas interfaces com a Gestão do Conhecimento e com a busca de alocação apropriada para as competências essenciais. A meta é alcançar uma cultura de criação de valor de conhecimento em que os recursos tecnológicos, as redes entre pessoas (times, equipes), o capital social, o capital intelectual e a gestão de mudanças sejam mixados na proporção mais adequada ao negócio (VORAKULPIPAT; REZGUI; HOPFE, 2010).

Para a Gestão da Cadeia de Suprimentos o aspecto mais discutido é a confiança entre os participantes da cadeia de suprimentos, entre os líderes e suas equipes (REZGUI, 2007) e também as dimensões intra e interorganizacionais (ZOU; ZHANG; WANG, 2007). Considerando que a cadeia opera em um ambiente dinâmico em que agentes, tarefas e materiais em processo estão fortemente relacionados uns com os outros (LANDESMAN; SCAZIERI, 1996), o domínio do planejamento e controle de Empresas Virtuais também possui muitos dos princípios de Gestão da Cadeia de Suprimentos.

A Tecnologia de Informação e Comunicação, juntamente com a Gestão do Conhecimento, são considerados os aspectos mais discutidos quando referem-se aos 
ambientes de colaboração em operações. Muitas propostas, modelos, arquiteturas foram desenvolvidos para atender aos requisitos únicos de Empresas Virtuais (CAMARINHAMATOS; AFSARMANESH, 2003, 2005, 2008; GORANSON, 1999; KELLER et al., 2006).

\subsection{Descrição do Estudo de Caso Múltiplo realizado}

No período de Junho a Agosto de 2011, uma entrevista semiestruturada foi realizada em dois centros de pesquisa europeus renomados, com o objetivo de coletar as questões mais relevantes para a Gestão de Operações em Redes Colaborativas de Construção. Informações relevantes de mesma natureza também foram coletadas de um centro de pesquisa, no qual a pesquisadora realizou Estágio de Pesquisa de doutorado entre os meses de junho e setembro do mesmo ano. Deste modo, utilizando três abordagens diferentes, foi possível refinar e melhorar o Modelo de Conceitos elaborado. Para tal, focouse nos conceitos principais e suas interdependências, obtendo-se um modelo mais sintetizado sem perdas na dimensão de escopo.

A entrevista semiestruturada propôs questões relacionadas ao Modelo de Conceitos apresentado e consequentemente relacionadas à revisão sistemática de literatura que o antecedeu. Um roteiro com uma breve descrição dos objetivos da pesquisa e dos tópicos de interesse foi enviado antecipadamente para os entrevistados (APÊNDICE 1). As entrevistas foram realizadas nos próprios Centros de Pesquisa.

Durante as entrevistas, os respondentes também foram incentivados a referenciar trabalhos ou artigos de relevância para o esclarecimento das questões. Foram disponibilizados materiais impressos de significativa relevância, como diretrizes normativas, manuscritos de artigos, relatórios de projetos, etc. Com base nas respostas, nas referências indicadas e nos materiais fornecidos, foi elaborado um texto abordando toda a informação adquirida. A cópia digital do texto foi enviada para confirmação e autorização de uso no projeto de Doutorado.

Duas abordagens referem-se a países da Europa Ocidental (Alemanha e Suiça) e uma abordagem de país da Europa Setentrional (Reino Unido). Apesar de se acreditar que diferenças culturais e legais pudessem influenciar alguns pontos da entrevista, foram verificadas muitas similaridades entre as pesquisas, posteriormente refletidas nos resultados das abordagens apresentados.

Assim, os centros de pesquisa, projetos de interesse e materiais consultados são apresentados juntamente com a informação coletada. Estas informações são sintetizadas e discutidas a seguir. 


\subsubsection{A abordagem Suíça}

O primeiro Centro de Pesquisa visitado localiza-se em Zurique. Os pesquisadores entrevistados, dois alunos de Doutorado, com amplo envolvimento nos projetos do Centro de Pesquisa, do Instituto de Construção e Gestão de Infraestrutura do Instituto Federal Suíço de Tecnologia de Zurique (ETH Zürich) trabalham com ciclo de vida orientado a construção e processos de negócios, tais como prestação de serviços, gestão e processos de apoio na indústria da construção. Para implementação estratégica, buscam promover desempenho e inovação na indústria da construção por meio de revisão conceitual baseada em conhecimento científico no processo de desenho orientado pelo ciclo de vida, integrando planejamento, execução e utilização na pesquisa e educação (BAUPROZESS- UND BAUUHNTERNEHMENSMANAGEMENT, 2011).

Um trabalho muito relevante indicado é a abordagem colaborativa para a modelagem processos de negócio para a industrialização da construção de Girmscheid e Rinas (2012), e a estrutura conceitual nele apresentada. O trabalho tem como resultado, entre outros, uma representação de como um sistema complexo de cooperação entre diferentes atores pode se comportar e quais canais para (inter)ação devem ser estabelecidos.

As principais percepções coletadas a partir da pesquisa realizada neste centro são desenvolvidas nos parágrafos seguintes. Adota-se a sequência de descrição correspondente a sequência de investigação sugerida pelo Roteiro para entrevista semiestruturada.

Abordagens de colaboração são mais adequadas a relações de longo prazo - a Empresa Focal, constituída para comandar os processos em rede na cadeia de criação valor, tem um papel importante no controle de participantes e processos da rede, também encorajando um maior envolvimento entre as partes - um caráter institucional que não é verificado em Empresas Virtuais (GIRMSCHEID; RINAS, 2012, RINAS; GIRMSCHEID, 2009).

Considerando relações estáveis em termos de rede de empresas, a fase de planejamento de um projeto de construção é a mais importante, sendo a fase de operação o reflexo de decisões tomadas no planejamento. Assim, a Gestão de Operações considera princípios enxutos, engenharia simultânea (uso do BIM) e a filosofia de Melhoria Contínua aprimorando e aperfeiçoando métodos, processos e sistemas construtivos ao longo do ciclo de vida dos projetos. 
Deste modo, a medição de desempenho é considerada uma fonte de informação para a Melhoria Contínua, e tem como principal direcionador as necessidades do cliente - que são verificadas durante todo o curso do projeto, pela adequação das decisões tomadas (GIRMSCHEID; RINAS, 2012, HARTMANN; GIRMSCHEID, 2004).

Gestão de Recursos e Planejamento e Controle da Produção são executados principalmente em nível individual, e controlados em uma perspectiva de gerenciamento de projetos para o nível da colaboração - a Empresa Focal assume a governança da rede, buscando as melhores competências e encorajando iniciativas empreendedoras dos participantes, como forma de promoção da Inovação e da Melhoria Contínua.

Ainda, para atingir esse objetivo, a confiança e princípios da Produção Enxuta são os direcionadores das questões relacionadas com a Gestão da Cadeia de Suprimentos relações contratuais são usualmente caras, complexas e levam ao desperdício de tempo. 0 desperdício de tempo também tende a ser diminuído pelo alcance de uma cadeia enxuta, para a qual a industrialização da construção incentiva padronização e melhor gestão de materiais e processos (GIRMSCHEID; RINAS, 2012).

A Gestão do Conhecimento também está relacionada à Melhoria Contínua, à Evolução e Inovação, tendo alguma dependência de uso das TICs - a meta é atingir uma Melhoria Contínua incremental em detrimento de implementações radicais, com apoio de Institutos de pesquisa, que são na maior parte das vezes, direcionadores deste processo (RINAS; GIRMSCHEID, 2011).

Plataformas Colaborativas dão o apoio de TIC para os projetos, como forma de alcançar a colaboração pelo uso de uma cadeia digitalizada na qual todas as partes têm acesso à informação, considerando seus papéis e permissões específicos. Softwares específicos são utilizados principalmente na fase de planejamento dos projetos (CAD/Autodesk, Nemetschek, BIM, entre outros). O planejamento presume a utilização dos princípios de customização em massa para a indústria da construção, de modo que a pré-fabricação seja obtida ao final.

Percebe-se que a abordagem Suíça busca avançar em temos de padronização de processos e industrialização da construção, possuindo como motivador o mercado que busca maior geração de valor do ponto de vista do cliente. Esta perspectiva justifica o foco das pesquisas desenvolvidas em relações de redes estáveis, com uso do modelo da Empresa Focal. Entretanto, importantes premissas sobre a colaboração para grandes projetos puderam ser verificadas. 


\subsubsection{A abordagem britânica}

Na Escola do Ambiente Construído da Universidade de Salford, o segundo Centro de Pesquisa visitado foi o Centro de Tecnologia de Informação em Construção, seguido de uma visita ao THINKLab. Em uma breve descrição, o primeiro tem oferecido contribuições significativas para a comunicação, visualização, integração e pesquisa de sistemas inteligentes, bem como protocolos de processos, modelos de produtos, sistemas baseados em conhecimento e vários ambientes de computação integrados (CENTRE FOR INFORMATION TECHNOLOGY IN CONSTRUCTION, 2011). O THINKLab é um espaço de pesquisa futurístico que provê estrutura física para o estímulo de debates, colaboração e inovação (THINKLAB, 2011).

As informações coletadas por meio de entrevista com o Diretor do Centro de Pesquisa e do material fornecido pelo Diretor Técnico do ThinkLab, refletem principalmente a experiência de sucesso de um projeto concluído, com participação do Centro de Pesquisa e com utilização da estrutura do ThinkLab, chamado de CoSpaces (COSPACES, 2011). O CoSpaces foi um projeto internacional financiado pela Comissão Europeia, com o objetivo de desenvolver modelos organizacionais e tecnologias distribuídas para o apoio a ambientes de trabalho colaborativos inovadores, para entidades individuais ou times de projeto no âmbito de diferentes Empresas Virtuais. Outros objetivos são o incentivo a parcerias efetivas, colaboração, criatividade, aumento da produtividade. O CoSpaces possuiu como participante uma grande empresa de Construção, a qual motivou uma abordagem específica para o setor no projeto, de onde origina-se a maior parte das informações relatadas.

A colaboração no contexto do projeto é mais característica e desejada nas fases de projeto/planejamento - ela deve ser considerada uma premissa não somente para a consolidação de parcerias, mas também na melhoria no processo de engenharia (suportando simulação, modelagem, prototipagem rápida, visualização). Entretanto, não é a sofisticação no uso de TICs o aspecto crítico para a colaboração e sim a profundidade e qualidade dessa colaboração, como ela é entendida para poder apoiar a rede (COSPACES, 2006).

A cooperação em construção pode ser apoiada pelo modelo de Empresa Virtual, possuindo ciclo de vida mais curto que outras abordagens de cooperação - pois esta é baseada em projeto e existe e opera de acordo com as necessidades e oportunidades do mercado (COSPACES, 2006). Em projetos de larga escala, as atividades demandam uma rede complexa de pessoas, funções relevantes e/ou organizações que normalmente se sobrepõem e são interativas (KAGIOGLOU et al., 1998). 
Conforme ressaltado, o ciclo de vida da Empresa Virtual é ainda mais curto que o ciclo de vida do projeto, com a gestão de operações sendo identificada apenas na fase de construção do projeto - a real fase de geração de valor para a qual se deve produzir uma edificação que satisfaça os requisitos dos clientes (KAGIOGLOU et al., 1998). Estes requisitos são as principais dimensões relacionadas à gestão estratégica e tática do negócio - os principais direcionadores do processo de tomada de decisão. Ainda, a Gestão de Operações é considerada por Khosrowshahi e Howes (2005) uma questão estratégica, pois nela os processos de tomada de decisão envolvem todas as atividades funcionais e operacionais dentro da organização.

Inovação e Pesquisa e Desenvolvimento são característicos de projetos de colaboração, estes possuem também um foco significativo na distribuição dos Recursos Humanos e na correta alocação de competências-chave - de modo que alcance-se um maior envolvimento e participação entre equipes (COSPACES, 2006). Sistemas de colaboração efetivos também são fundamentais para projetos de larga escala que utilizam Parcerias PúblicoPrivadas.

Para operar em um sistema de colaboração, confiança e padronização são direcionadores para questões relacionadas à Cadeia de Suprimentos - a seleção de parceiros de um projeto pode ser feita levando em consideração a habilidade de cada participante de trabalhar com novas tecnologias e a qualidade que ele pode trazer ao desenvolvimento do produto/processo.

No domínio das atividades de Planejamento e Controle trata-se do projeto, processo, produção e gestão de mudanças - possuindo forte relação com a logística e planejamento de entregas do produto requerendo efetiva comunicação de mudanças no projeto e sua execução (COSPACES, 2010; KAGIOGLOU et al., 1998).

Para atender ao requisito descrito, utilizam-se plataformas específicas de colaboração como dispositivo de Tecnologia de Informação e Comunicação - sendo esta área de conhecimento um importante direcionador da eficiência do processo e também uma ferramenta indispensável para a empresa de construção moderna (FRANCE et al., 2010).

A abordagem britânica possui um escopo mais amplo de atuação, pela verificação das informações relativas a um projeto internacional, voltado a diversos outros segmentos econômicos, não somente a construção.

Os resultados deste projeto justificam a importância da colaboração no apoio aos diversos campos de tomada de decisão, relacionados a grandes projetos de construção civil. 


\subsubsection{A abordagem alemã}

Esta abordagem pôde ser coletada a partir do material disponível no Instituto de Informática da Construção da Universidade Técnica de Dresden (TU Dresden). Este Centro de Pesquisa tem como principais tópicos de pesquisa: Modelagem da Informação da Construção (BIM), a modelagem de construção, gestão de canteiro de obras e projeto, logística de informação, sistemas distribuídos e métodos conceituais de modelagem. Coopera continuamente com a indústria, e deste modo, dissemina os resultados de pesquisa com ativo envolvimento com grupos de trabalho e corpos de normatização da própria indústria e de associações de pesquisa. Neste centro são coordenados projetos Europeus e projetos de pesquisa governamentais compartilhados (INSTITUT FÜR BAUINFORMATIK, 2011).

O Projeto "Mefisto", financiado pelo Ministério Federal Alemão de Educação e Pesquisa, tem o objetivo de desenvolver uma plataforma para a execução de projetos de construção na forma de um sistema de gestão de informação. O sistema permite simulações em tempo real, visuais e descritivas na base de dados operacionais atualizados em todos os níveis de abstração (MEFISTO, 2011). A primeira fase do projeto com duração de 3 anos (2009-2012) possui orçamento de 9,4 milhões de Euros e envolve grandes Empresas de construção e Universidades.

Deste Centro de Pesquisa, as informações coletadas resultaram do acesso facilitado ao material produzido e dos projetos em execução. O guia da entrevista semiestruturada não foi utilizado formalmente, apesar de muitas discussões técnicas e do material disponível terem oferecido facilmente respostas às questões propostas. O coordenador e um pesquisador do Projeto Mefisto, pesquisadores sênior do Instituto, foram consultados. $O$ autor realizou Estágio de Pesquisa neste Centro.

Considerando as discussões técnicas, os materiais disponibilizados e um trabalho de

relevância especial (SCHERER; SCHAPKE; KATRANUSCHKOV, 2010), são desenvolvidas nos próximos parágrafos as questões relevantes para a pesquisa.

Organizações Virtuais representam o resultado da dissolução das fronteiras internas e entre empresas, para as quais o uso de TICs possui um importante papel para apoiar a colaboração em construção (KELLER, 2007) - este tipo de organização é considerado como uma entidade formada por um conjunto dinâmico e multi-institucional de indivíduos e/ou instituições estabelecendo regras comuns para o compartilhamento de recursos e solução de problemas (GEHRE; KATRANUSCHKOV; SCHERER, 2007). 
Assim, na estrutura proposta por Scherer, Schapke e Katranuschkov (2010), para o projeto de plataformas de colaboração em construção, a atividade de planejamento e controle é relativa aos processos de materiais e informação - no primeiro caso trata do fluxo de materiais executado no canteiro de obras e no segundo caso no apoio das atividades de planejamento, programação e monitoramento (geralmente com uso de TIC). Similarmente, a Gestão da Cadeia de Suprimentos está relacionada à coordenação da construção e gestão da informação.

A Gestão de Recursos trata das instalações (facilities) da construção, seus equipamentos e organização do trabalho em grupos ou times, também refletindo aspectos da Gestão do Conhecimento (SCHERER; SCHAPKE; KATRANUSCHKOV, 2010). Novamente, a alocação correta das competências essenciais é fundamental para o fomento da Gestão do Conhecimento.

A Medição do Desempenho é refletida na análise e avaliação, no nível superior de uma ontologia para a plataforma de colaboração - trata de modelos que podem ser utilizados para estimar riscos, e avaliar e prever decisões que acontecem em outras áreas de conhecimento (níveis da estrutura conceitual de colaboração), também como premissa de Gestão do Conhecimento.

Conforme explorado por Scherer, Schapke e Katranuschkov (2010), plataformas de colaboração são desenhadas para apoiar a interoperabilidade dentro de três eixos: horizontal (entre diferentes atores), longitudinal (ao longo das fases do ciclo de vida) e vertical (diferentes níveis de tomada de decisão) - significa operar, respectivamente: entre diferentes modelos de dados de domínio específico, no desenvolvimento do modelo ao longo do tempo e entre diferentes níveis de abstração.

A abordagem alemã é mais centrada nos requisitos da estrutura do sistema de informação que apoia a colaboração entre empresas, para maior eficiência dos projetos. Um dos seus objetivos mais visíveis está no estabelecimento de princípios comuns para a indústria de construção, permitindo flexibilidade de especificações e combinação das informações do projeto de construção. Os princípios comuns podem ser representados por modelos que são facilmente compartilhados na plataforma de colaboração.

Assim, as informações dos Centros de Pesquisa discutidas apoiam a seção seguinte na proposição de um Modelo de Conceitos para colaboração em redes de construção civil. 


\subsection{Modelo de Conceitos para Colaboração em Redes de Construção Civil}

Considerando os trabalhos referenciados e o resumo dos resultados das entrevistas, as discussões de cada área de conhecimento e o tópico maior sobre a "colaboração" são feitas a seguir, justificando o Modelo de Conceitos obtido e representado na Figura 4.2.

Iniciando pela Medição de Desempenho, é estabelecido que esta deve abranger o maior número de atores da rede possível, de modo a permitir análise do negócio - a rede - e também ao nível individual, como também deve ser utilizada em todas as fases do ciclo de vida da rede, conforme sugere Camarinha-Matos e Abreu (2007). É um conceito que considera principalmente os requisitos dos clientes, conforme observado em todas as abordagens dos centros de pesquisa visitados, e a estratégia do negócio e metas do projeto.

A atividade de Planejamento e Controle da Produção será realizada principalmente em nível individual pelos participantes da rede, demandando ferramentas e soluções de TIC específicas, mesmo sendo realizada em grande parte do ciclo de vida da rede. A Gestão de Projetos referida por Keller et al. (2006) e Verheij e Augenbroe (2006) e consensual entre todos as abordagens dos centros pesquisados, está relacionada ao uso de Plataformas de Colaboração, como forma de assegurar a conexão entre os participantes da rede.

Considera-se que a Gestão do Conhecimento é incentivadora de Inovação, conforme Rutten, Doreé e Halman (2009), Centre for Information Technology in Construction (2011) e o projeto CoSpaces (2011) e também incentivadora de Melhoria Contínua, refletida nas indicações de Rezgui (2007) e Bauprozess- und Bauunternehmensmangement (2011).

Um tópico de especial atenção é o de Competências Essenciais, sendo geridas nas perspectivas de Recursos e Conhecimento, conforme coletado na perspectiva suíça, em Dave e Koskela (2009) e em Vorakulpipat, Rezgui, Hopfe (2010). Essas Competências devem apoiar a Inovação e a Melhoria Contínua e devem ser alocadas de modo a incentivar a confiança e parcerias em colaboração, com forte influência sob as empresas da rede.

Ainda, a Gestão de Recursos tem um importante papel na provisão de recursos financeiros e físicos, com os arranjos em Parcerias Público-Privadas sendo de especial relevância para projetos de larga escala (COSPACES, 2011; KE et al., 2009; SCHERER; SCHAPKE; KATRANUSCHKOV, 2010). A alocação dos recursos financeiros e físicos tem relação com as áreas de Medição de Desempenho e Planejamento e Controle.

A Gestão da Cadeia de Suprimentos lida com questões menos tangíveis em redes colaborativas comparado com abordagens tradicionais. Para essa abordagem temporária, as questões mais relevantes estão relacionadas não ao fluxo de Materiais, mas à melhoria 
das relações de parceria de modo a implementar princípios enxutos e novas tecnologias, para atender o requisitos de gestão das relações dinâmicas (CHENG; TSAI; XIAO, 2006; GIRMSCHEID; RINAS, 2012; LANDESMAN; SCAZIERI, 1996; YU et al., 2009).

As plataformas de colaboração, como resultado das abordagens coletadas em Keller et al. (2006) e nos Projetos CoSpaces (2011) e Mefisto (2011), são essenciais para o agrupamento de diferentes empresas em uma mesma base em colaboração. Essa ferramenta deve ser utilizada por toda a fase de operacionalização e reconfiguração, sendo de relevância especial para as atividades da Gestão da Cadeia de Suprimentos, do Planejamento e Controle e da Medição de Desempenho.

A colaboração em redes de construção civil deve ser atingida por meio de uma abordagem integrada incluindo, dentre outros, a interação entre os processos de fluxo de materiais (canteiro de obras), processos de informação e os processos de monitoramento e controle (plataforma TIC), conforme indicação de Scherer, Schapke e Katranuschkov (2010).

A Figura 4.1 representa o agrupamento das entidades do Modelo de Conceitos da Figura 3.2 considerando as premissas levantadas pelo Estudo de Caso Múltiplo, resultando na proposição do Modelo de Conceitos para Colaboração em Redes de Construção Civil da Figura 4.2, representada na sequencia.

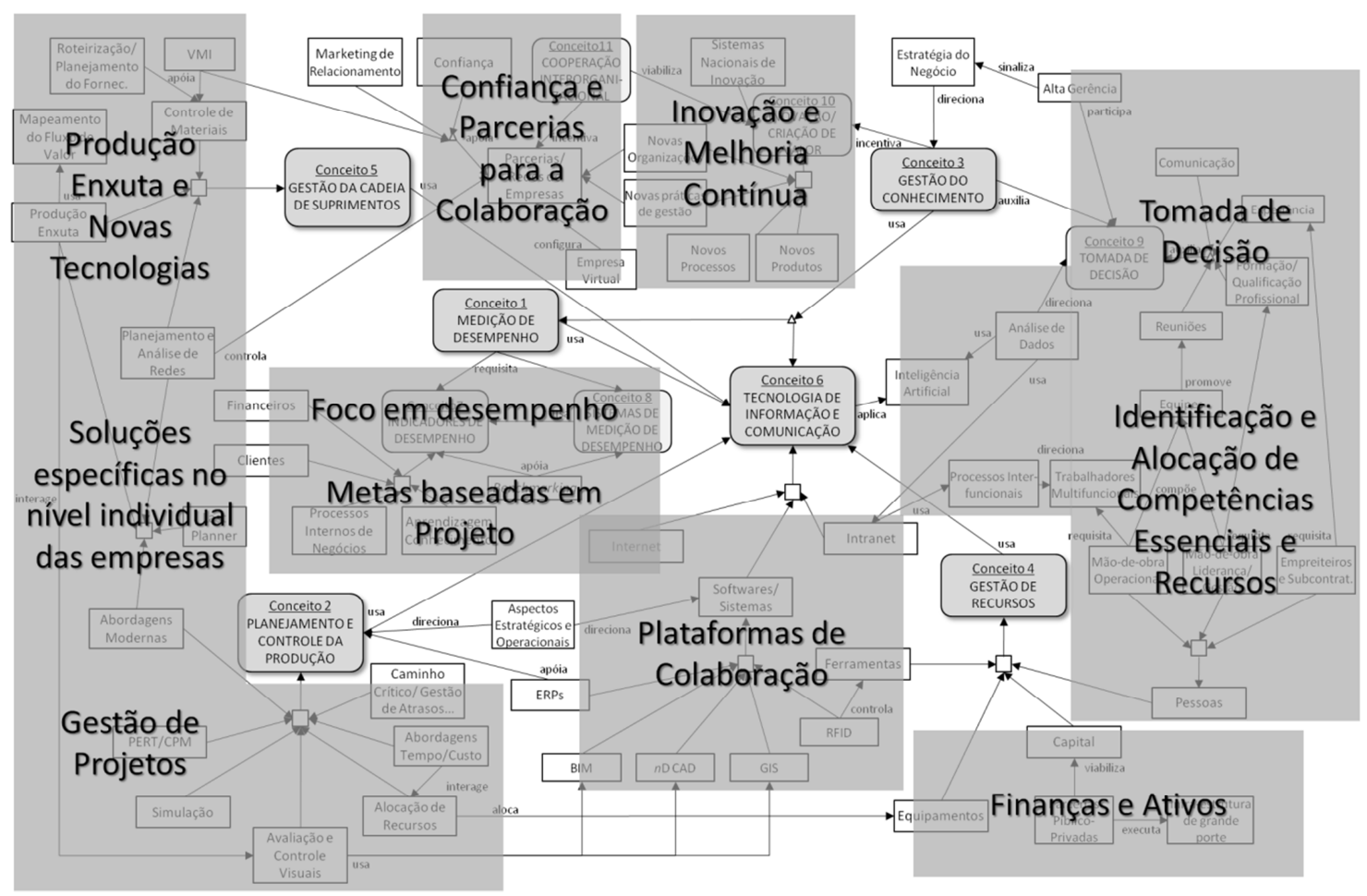

Figura 4.1 - Agrupamento das entidades do Modelo de Conceitos para a Operacionalização e Reconfiguração em Redes de Construção Civil visando a Colaboração 


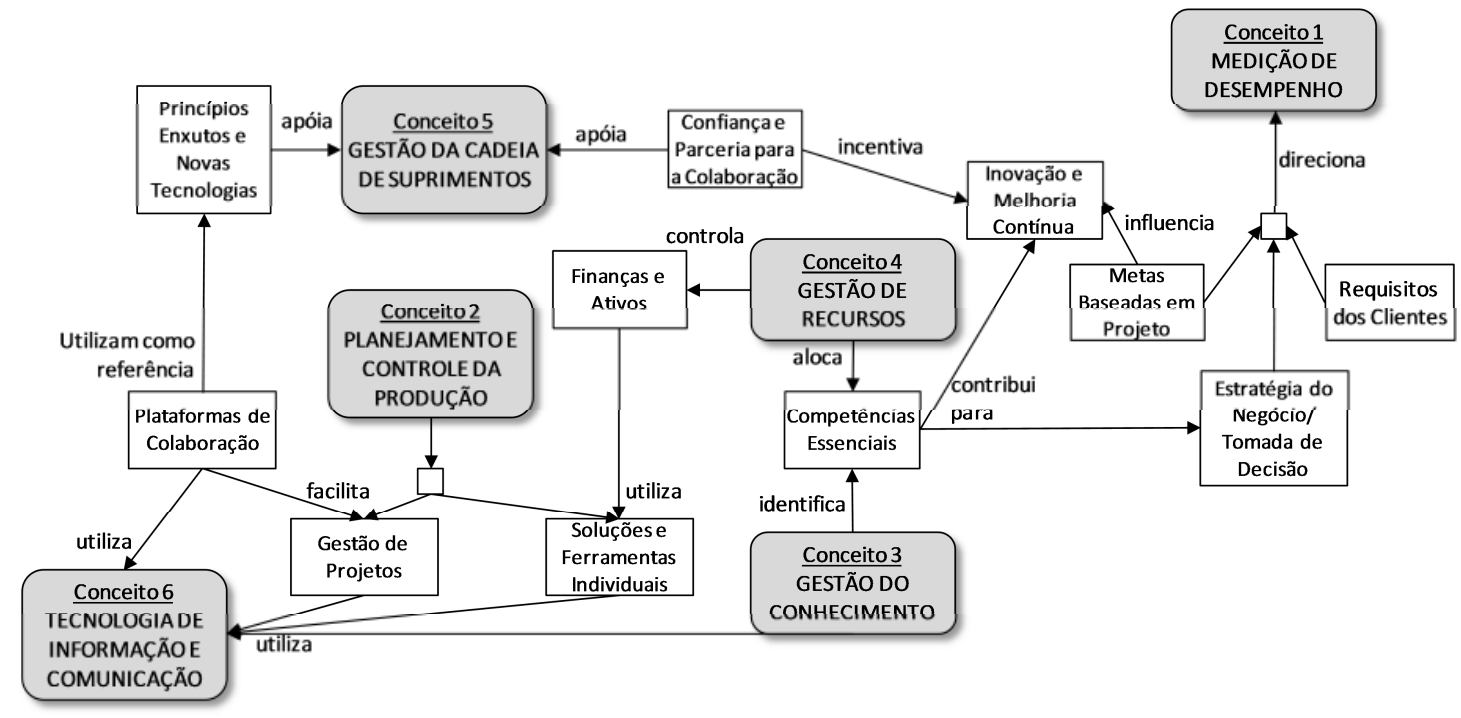

Figura 4.2 - Modelo de Conceitos para Colaboração em Redes de Construção Civil

\subsection{Considerações Finais}

Com o objetivo de estabelecer as premissas básicas para a colaboração em Redes de Construção Civil, esta seção considera os aspectos da Gestão de Operações para construção civil como um modelo instanciado que foi posteriormente refinado. $O$ refinamento baseou-se em revisão específica de literatura e especialmente no conhecimento de estudiosos da área. Apesar de o modelo poder ser considerado uma generalização do Modelo de Conceitos apresentado no Capítulo 3, defende-se que ele apresenta evolução com a obtenção de uma abordagem sistematizada, mais integrada e enxuta.

Enfatiza-se que, apesar de a maior parte do material coletado e dos centros de pesquisa visitados estejam relacionados à área de TIC, suas atividades são relevantes para apoiar a colaboração e não para que seja seu principal direcionador. Junto com a Medição de Desempenho, essas áreas fornecem ao sistema de colaboração informações necessárias para processos eficientes de tomada de decisão e gestão. A colaboração deve ser alcançada por atividades das áreas de conhecimento de forma interdisciplinar e integrada.

Quase todos os desenvolvimentos voltados à colaboração estão direcionados à fase de planejamento do ciclo de vida dos projetos: a fase de criação, considerando o ciclo de vida da Empresa Virtual. Esta característica atribui à pesquisa realizada (com foco nas fases de operacionalização e reconfiguração) ao mesmo tempo: a) a oportunidade de contribuir com novas abordagens para a área de gestão de operações em construção e; b) o desafio de oferecer resultados que sejam úteis quando considerada a fase prática de atividades de construção. 


\section{COLETA DE DADOS}

Apresentam-se os dados coletados por meio de Estudo de Caso, utilizando roteiros planejados para a Coleta de Dados. Possuindo como Objeto de Estudo um Consórcio constituído para execução de obra de Grande Porte de infraestrutura urbana, este é primeiramente caracterizado, com vistas ao melhor entendimento do escopo e complexidade da obra e da rede de empresas mobilizada para tal. Buscando compreender de forma mais detalhada a dinâmica de processos existentes para operacionalização e reconfiguração da obra, é apresentado seu Modelo de Processos, que tem forte relação com os participantes da obra, seu relacionamento e papéis, posteriormente apresentados no Modelo de Atores e Recursos. Em seguida são expostos alguns pontos considerados relevantes para o desenvolvimento do Modelo de Referência para Operacionalização e Reconfiguração da rede, resultantes também da coleta de dados. Por último são feitas análises permitindo concluir sobre a coleta de dados, fundamental para a proposição do Capítulo seguinte.

Os dados coletados foram obtidos por meio de entrevista, principalmente com Gerente de Contrato, e também com Coordenador de Planejamento e Engenheiro de Obra, além de consulta a documentos internos do Consórcio referentes à estrutura do projeto e cronogramas. As entrevistas foram conduzidas no canteiro de obras central do Consórcio. Também foram esclarecidas dúvidas e obtidas confirmações por meio de mensagens eletrônicas. Esta coleta de dados foi realizada entre os meses de abril e junho de 2012, após contato firmado em janeiro de 2012.

A fase de coleta de dados foi iniciada verdadeiramente em fevereiro de 2011 , quando foram contatados três outros Consórcios para realização do Estudo de Caso. O primeiro não retornou contato. O segundo permitiu a realização da pesquisa, chegando-se a caracterizar - Objeto de Estudo, porém não foi possível dar continuidade às fases seguintes de investigação. O terceiro também permitiu visita, em novembro de 2011 , e recebeu os roteiros com os dados a serem coletados, porém não viabilizou a continuidade do estudo. 


\subsection{Caracterização do Objeto de Estudo}

O Consórcio formado por duas Empresas de Construção brasileiras de Grande Porte é responsável por um Lote de obra de Infraestrutura urbana - Linha de Metrô -, com constituição de Parceria Público-Privada. A Empresa A é parte de um grupo maior que atua em diversos segmentos de negócios. No segmento de Engenharia e Construção é referência no setor de construção pesada pela sua participação nos principais projetos de infraestrutura desenvolvidos no Brasil, empregando cerca de 23,5 mil colaboradores e com receita líquida de mais de 5,1 bilhões de reais no ano de 2011. A Empresa $B$, do segmento de Engenharia e Construção, também é parte de um grupo com outras atuações de negócios, que atua no Brasil e na América Latina, desenvolvendo contratos das mais diversas naturezas, por meio do conhecimento acumulado em mais de 60 anos de história e do know-how em toda a cadeia de infraestrutura, além de diferenciada capacidade de estruturação de parcerias estratégicas.

A obra total possui quase 12 quilômetros de extensão e é considerada estratégica na malha urbana em que é instalada, também pela interligação com outras opções de transporte público. O orçamento total da obra é da ordem de 20 bilhões de reais.

O Consórcio foi selecionado por meio de processo licitatório, tendo como primeiro critério de seleção a proposta de Menor Valor Total conforme Planilha de Serviços e Preços, fornecida pelo contratante, tendo sido respeitadas as exigências e as especificações técnicas do Edital de convocação. Um orçamento base também foi utilizado como referência para aprovação do valor submetido pelo candidato.

As exigências e especificações técnicas que foram atendidas são descritas de acordo com a hierarquia de competências de Javidan (1998).

Os recursos quantificáveis para a obra são: disponibilidade de Tuneladora para escavação do Túnel em Shield; execução de mais de 20 obras de metrô, somando-se a experiência das duas empresas do consórcio; experiência em execução de túnel em Shield; experiência de execução de superestrutura de via permanente com sistema de atenuação de vibrações; faturamentos da ordem de 500 milhões a 5 bilhões de reais, dependendo do segmento de obra do subsetor (metrô, barragem, ponte, entre outros), sua extensão e complexidade.

As capacidades necessárias são: atendimento a todos os objetivos de desempenho estabelecidos em contrato, nas dimensões normativas (segurança, qualidade, meio ambiente, responsabilidade social) e de exigências particulares para cada uma das fases de obra; seleção de profissionais basicamente por tempo de experiência, variando entre 
mínimo de 15 (quinze) anos de formação e 5 (cinco) anos de experiência em trabalhos na posição de gerência de projeto ou de sistemas e 12 (doze) anos de formação e 4 (quatro) anos de experiência em trabalho na posição de chefe de planejamento ou de produção, observando-se baixa ocorrência de especialização no corpo técnico após graduação - cabe ressaltar que houve replicação de corpo técnico de obra de metrô recentemente concluída.

E as competências aplicáveis envolvem: empresas de grande porte que podem executar até 10 obras de mesma natureza e escopo deste Lote simultaneamente, ou outras obras de grandes projetos voltados à infraestrutura, com atuação nacional e internacional.

Além da hierarquia de competências verificada, o Consórcio pode contar com a colaboração, por meio de subcontratação de outras empresas. As subcontratações ocorrem de acordo com a necessidade da obra. Obedece-se, entretanto, o limite de $25 \%$ (vinte e cinco por cento) do valor total do Contrato para a subcontratação de empresas para a prestação de serviços acessórios relativos ao objeto da contratação. Esta subcontratação é submetida para aprovação do órgão Contratante do Consórcio, mediante cadastro da subcontratada (observam-se exigências de habilitação jurídica e exigências da qualificação técnica, tal qual ocorre para o próprio consórcio). O Consórcio permanece responsável pela prestação de serviço perante o contratante. É prevista a participação de mais 50 empresas subcontratadas de todos os portes, além de consultores.

As atividades no escopo dessas subcontratações são: instalações de canteiros de obras, frentes de serviço para execução de rede elétrica/subestação, remanejamento de redes públicas, demolição de imóveis, serviços de arqueologia, serviços de impermeabilização, remediação, rebaixamento de lençol freático, acabamento e urbanização, fundação de uma das fases da obra, projeto de uma fase específica da obra e fornecimento e montagem dos elementos desse projeto, tratamento de maciço e serviços de instalações nas fases de obra concluídas. Tais atividades foram representadas como papéis das empresas subcontratadas na Figura 5.2 - Modelo de Atores e Recursos do Consórcio.

O projeto é fornecido pelo cliente do Consórcio (o contratante) e também a expedição das ordens de serviço para construção. Por meio destes apenas, e considerando o tempo necessário para fechamento de contratos, são acordadas as subcontratações, conforme premissas apontadas. Da parte do Consórcio, apenas empresas cadastradas pela Empresa $B$ (conhecidas previamente ou qualificadas) estão aptas à contratação. A Empresa $B$ exerce liderança em termos de governança e gestão do Consórcio e da obra. A decisão comercial e técnica sobre o serviço a contratar, de acordo com competência/recurso necessário, ocorre em função da demanda da obra, características do projeto, e ordens de serviço recebidas. 
As principais fases da obra e seus subprocessos mais significativos contemplam:

1) a instalação de canteiros de obra e estruturas de apoio, possuindo como subprocessos a construção de refeitórios, ambulatórios, salas, escritórios, fábrica de componentes, laboratórios, manutenção, entre outros;

2) abertura de valas para entrada e saída de equipamento que realiza escavação do túnel e seus subprocessos;

3) fabricação de componentes pré-moldados utilizados na fase de escavação do túnel (fabricação, armazenamento e transporte), a qual ocorre durante toda a operação da fase 4;

4) operação do equipamento de escavação do túnel em Shield (descida, montagem, escavação, preenchimento, desmontagem);

5) escavação de poços 1 a 4 e construção de estação, todas contemplando os subprocessos: serviços preliminares (demolição de imóveis, arqueologia, rebaixamento de lençol freático, remanejamento de resíduos) e obras civis (escavação, estruturação interna, acabamento e urbanização);

6) instalação de Via e sistemas, contemplando fornecimento e montagem, inspeções e testes de fábrica, fixação dos aparelhos de mudança de via (AMVs), fixação de trilhos e inspeção e testes finais;

7) finalização, pela execução de acabamento e posterior desmobilização de máquinas, equipes e instalações para entrega da obra.

A escavação dos poços e da construção da estação possui basicamente os mesmos subprocessos. O primeiro subprocesso do Poço 1 precisa ser concluído para o início da escavação do Poço 2 e assim por diante, incluindo a construção da estação, presumindo o deslocamento de equipes entre eles. Assim, as fases ocorrem em paralelo, porém com uma pequena defasem em função dessa dependência.

A representação da descrição das fases da obra está contida na parte superior da Figura 5.1 - Modelo de Processos para fases de Operacionalização e Reconfiguração do Consórcio, na seção 5.2 do Capítulo.

Os serviços (cada uma das fases e seus subprocessos) são executados, de acordo com documentação técnica integrante do Contrato e mediante expedição de "Ordem de Serviço" escrita e emitida pelo contratante que também integrará o Contrato. A especificação da 
sequência de execução dos serviços é parametrizada pela contratante de forma sugestiva, por meio dos modelos fornecidos para a apresentação da proposta comercial da licitação. Os prazos para cada uma das fases e subfases é estabelecido em número máximo de dias para a conclusão da atividade após emissão da Ordem de Serviço.

Assim, esta obra foi planejada para ser finalizada em 48 meses, com aditivo para atingir até 55 meses, como forma de assegurar ao contratante e ao contratado garantias nas situações em que haja interrupção não prevista, porém necessária. Do total estipulado, 44 meses são destinados para a geração de valor em si: a construção. Para o cumprimento destes prazos, a disponibilidade dos projetos, fornecidos pelo contratante, por meio eletrônico ou impresso é considerada uma necessidade primordial para o atendimento ao planejamento realizado.

Os processos de tomada de decisão envolvendo corpo técnico e comercial ocorrem de acordo com a demanda. Outras decisões são tomadas em reuniões semanais de caráter gerencial e controle de produção, com participação de gerentes e coordenadores de planejamento do Consórcio. Sempre que necessário, o Contratante participa das decisões.

\subsection{Modelo de Processos}

Considerando o recorte específico das fases de operacionalização e reconfiguração, o Modelo de Processos é iniciado pelo detalhamento das fases que constituem o negócio "construir" do Consórcio. Cada fase é considerada um processo específico e, portanto, o modelo de processos apresentado aplica-se a cada uma das fases individualmente.

Cada processo subdivide-se em vários subprocessos, ainda com atividades específicas em cada um deles. Deste modo, o Modelo de Processos possui ainda maior complexidade, pois, o fluxo decisório para cada fase de obra considera todas as subfases e atividades contidas na fase. O Modelo de Processos é considerado um modelo iterativo, já que é replicado diversas vezes ao longo da operacionalização e reconfiguração da Obra. Ressaltase que o início de uma fase da obra ocorre apenas após o término da uma fase anterior. Entretanto, suas subfases podem ser executadas em paralelo, desde que todas as exigências sejam atendidas. Logo, o Modelo de Processos também pode possuir iterações em paralelo ao longo da obra.

A Figura 5.1 apresenta o Modelo de Processos para as fases de operacionalização e reconfiguração do Consórcio. A parte superior da Figura representa as fases da obra fundamentais para entrega do produto final e consequente alcance do objetivo da rede, conforme descrito na caracterização do Objeto de Estudo. 


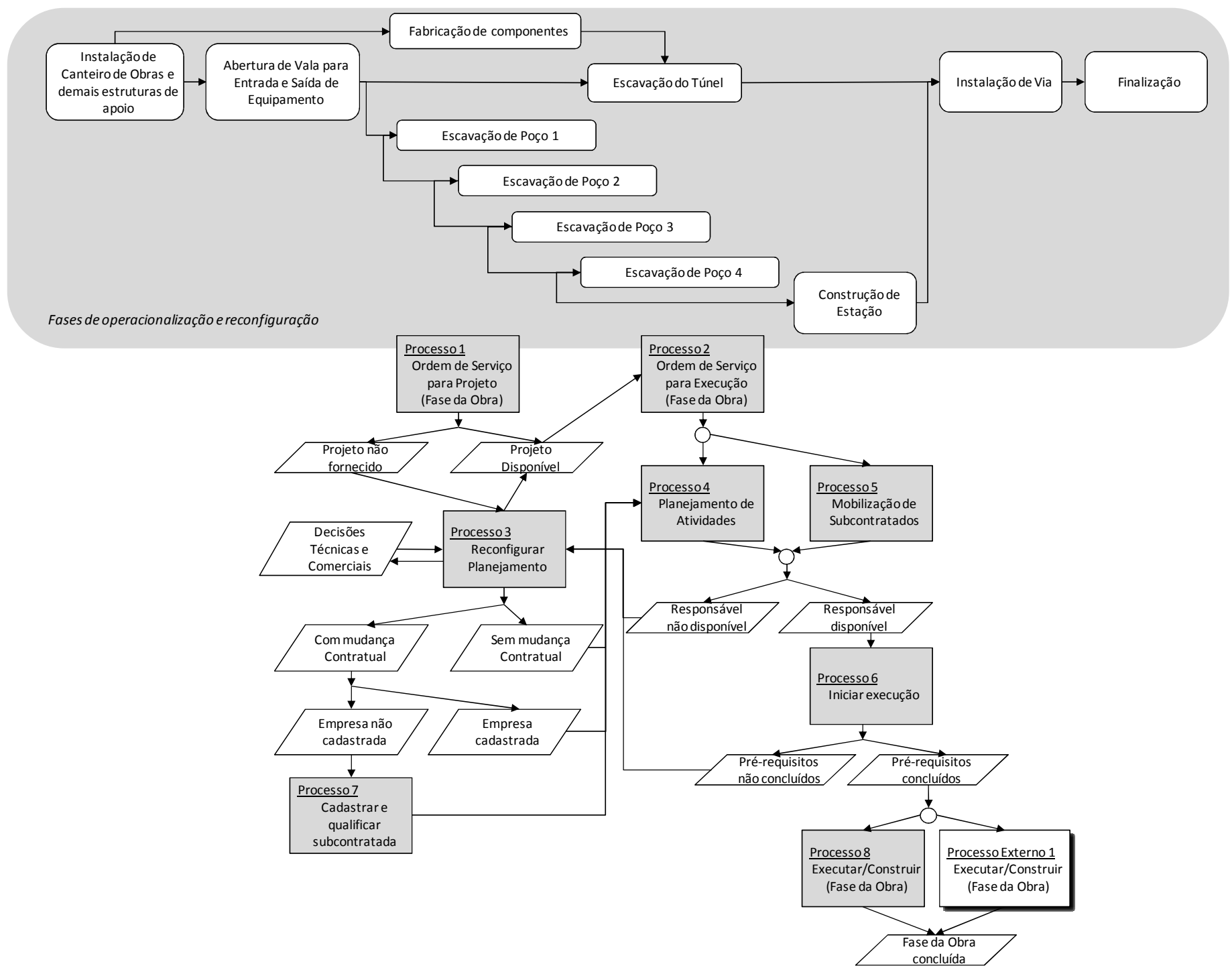

Figura 5.1 - Modelo de Processos para fases de Operacionalização e Reconfiguração do Consórcio 
Todas as fases da obra requerem seu projeto específico, portanto, o Processo 1 é de emissão de ordem de serviço para o projeto de determinada fase. Ressalta-se que, idealmente, os projetos já devam estar concluídos antes do início da execução da obra, mas é possível a ocorrência de projetos concluídos no decorrer da operação de construção. Para que o Processo 2 de emissão de ordem de serviço para execução de fase da obra ocorra, é necessário que o projeto esteja disponível. Quando o projeto não está disponível, é necessário readequar o planejamento para uma data prometida, envolvendo decisões técnicas e comerciais do próprio Consórcio (Processo 3), retomando a ocorrência do Processo 2 quando o projeto estiver disponível. Os Processos 1 e 2 são de responsabilidade do cliente do Consórcio e o Processo 3 do próprio Consórcio.

Diante do recebimento de uma ordem de serviço para execução de fase da obra, o Consórcio realiza os Processos de Planejamento de Atividades (execução da fase e suas subfases - Processo 4) e de Mobilização de subcontratadas (quando aplicável - Processo 5). Os responsáveis pela execução da fase são avaliados em termos de disponibilidade. Em casos de não disponibilidade, é necessário reconfigurar o planejamento. A reconfiguração pode ser dar nas dimensões de prazo, responsável pela subfase ou na própria forma de execução da subfase, sempre requerendo decisões técnicas e comerciais. Se a decisão não demanda mudança de contrato, principalmente nos casos de mudança de prazo ou forma de execução da atividade, realiza-se novo planejamento e contando-se com a disponibilidade do responsável ou novo responsável, presume-se o início da execução da fase (Processo 6). Quando é necessário que uma nova empresa preste serviço, principalmente nos casos em que é necessário fazer novos contratos (mudança de responsável), verifica-se o cadastramento da nova empresa junto ao Consórcio (representado pela empresa responsável pela gestão), indicando, quando necessário, o cadastramento e qualificação da subcontratada (Processo 7). Para empresa já cadastrada ou após o cadastramento e qualificação, retoma-se os Processos 4 e 5, seguindo o fluxo até o início da execução da fase.

As restrições aplicáveis aos Processos 4 e 5 e as decisões de reconfiguração do Processo 3 devem ser, sempre que possível, adiantadas em relação ao início da execução, pois possuem um lead time que deve ser considerado. Nos casos em que esse lead time é maior do que a necessidade de início da fase tem-se, muitas vezes, a impossibilidade de execução no tempo devido, ou ocorrência de atrasos. E nos casos em que esse lead time é menor ou igual à necessidade de início da fase, é importante verificar uma nova restrição a conclusão de pré-requisitos aplicáveis à fase. Quando estes pré-requisitos não estão concluídos, mais uma necessidade de reconfiguração (Processo 3) é disparada, lançando 
um desafio técnico e comercial de reconfigurar principalmente o período e a forma de execução das atividades, procurando minimizar o impacto possível no cumprimento de prazos. Refazendo o fluxo do processo, quando os pré-requisitos foram cumpridos, inicia-se o Processo 8 e/ou Processo Externo 1 de execução da obra - a construção - o processo real de geração de valor. O processo pode ser desempenhado pelo Consórcio ou sua(s) subcontratada(s).

Importante ressaltar o papel dos responsáveis pelas decisões técnicas e comerciais nestas fases de operacionalização e reconfiguração, pela sua constante necessidade de atuação quando da ocorrência de restrições.

O Modelo de Processos possui forte relacionamento com os atores (responsáveis) e recursos que desempenham esses processos, representados em termos de relacionamentos e papéis no Modelo de Atores e Recursos da seção seguinte.

\subsection{Modelo de Atores e Recursos}

O Modelo de Atores e Recursos apresentado na Figura 5.2 explora, principalmente, a representação dos atores envolvidos para a execução da obra, sua forma de relacionamento e os papéis desempenhados pelas suas unidades organizacionais, relacionados ao Objeto de Estudo.

Considera-se como Unidade Organizacional 1 o Governo do Estado, via órgão público relacionado à infraestrutura urbana, que é licitante e contratante do Consórcio (Unidade Organizacional 2). O Consórcio é uma entidade temporária resultante da associação das Empresa A e Empresa B (Unidades Organizacionais 3 e 4, respectivamente).

Este órgão público também licitou e contratou uma Empresa Projetista (Unidade Organizacional 5) responsável pelo fornecimento dos projetos necessários à execução da obra pelo Consórcio. A disponibilidade dos projetos dita o ritmo da obra e sua sequencia de execução, conforme explicitado na caracterização do Objeto de Estudo.

As Empresas Terceirizadas contratadas pelo Consórcio representam, portanto, as relações de subcontratação e são representadas no Modelo como Unidades Organizacionais de 6 a n, por ser este número de empresas não determinado (porém aproximadamente conhecido), dada a possibilidade de reconfigurações ao longo do ciclo de vida da rede. 


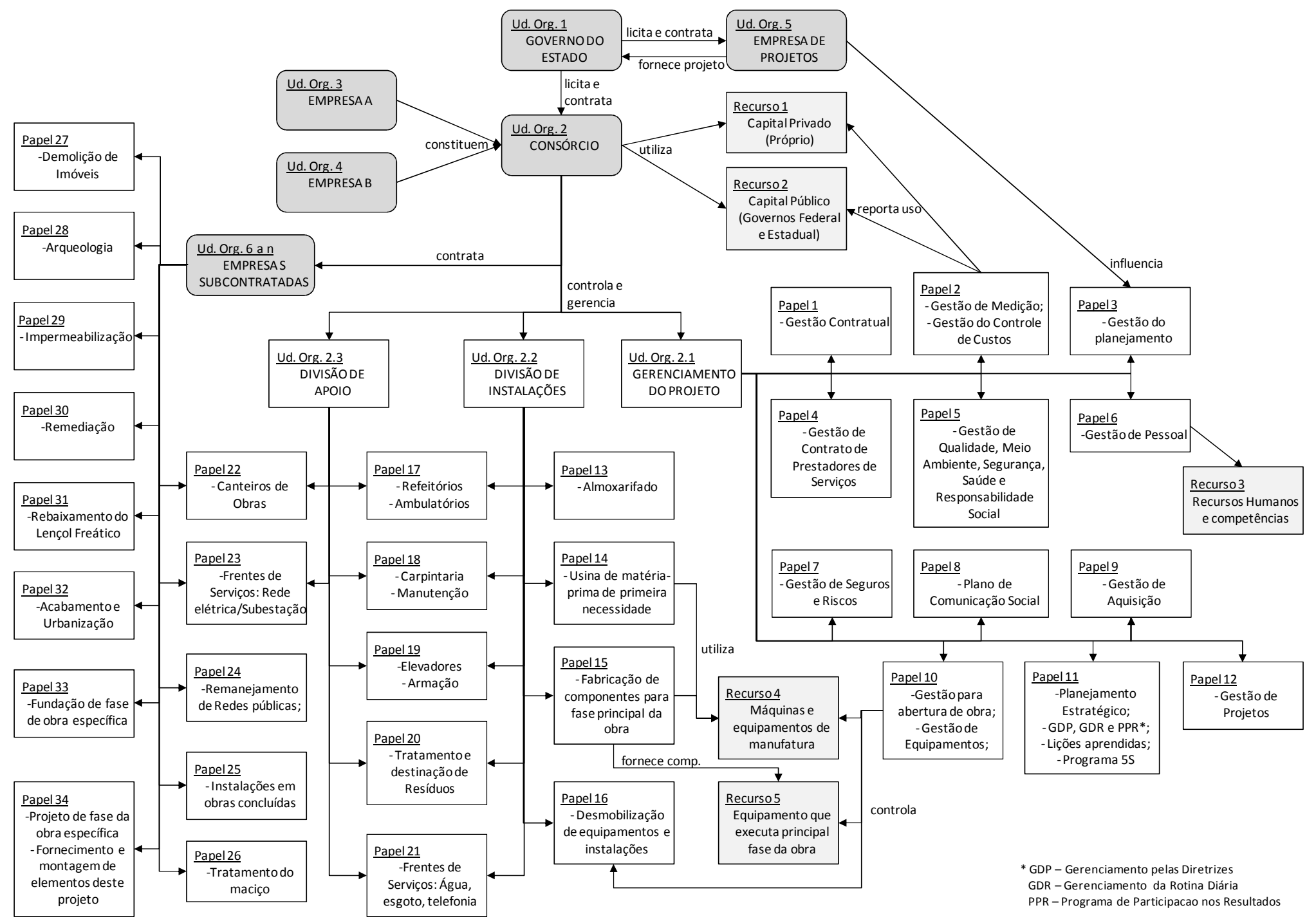

Figura 5.2 - Modelo de Atores e Recursos do Consórcio 
Por constituir-se em Parceria Público-privada, o Consórcio dispõe dos Recursos 1 e 2, representando o aporte de Capital próprio e Capital Público dos Governos Federal e Estadual para execução da obra. O uso de Capital próprio viabilizará, em contrapartida, a exploração por tempo determinado da infraestrutura construída.

O Consórcio divide-se em três Unidades Organizacionais maiores que desempenham papéis distintos, mas possuem interações entre si:

- A Unidade Organizacional 2.1, responsável pelo Gerenciamento do Projeto, compreende basicamente atividades administrativas voltadas ao Planejamento e Controle da Obra. Esta unidade desempenha papéis diversos (Papéis de 1 a 12) ligados às funções tradicionais de Escopo, Tempo, Custo, Qualidade e Confiabilidade, nos níveis operacional, tático e estratégico. Os Recursos Humanos e competências (Recurso 3) são de importância fundamental nesta Unidade Organizacional, que concentra os colaboradores com maior grau de qualificação. Pode-se observar também o relacionamento de entidades desta Unidade com entidades de outras Unidades. O uso de Recursos financeiros são reportados pela Gestão de Medição e Controle de Custos bem como a Gestão para abertura de obra e Gestão de Equipamentos exercem controle sobre máquinas e equipamentos de manufatura e instalações;

- A Unidade Organizacional 2.2, Divisão de Instalações, é responsável pela implantação de toda a infraestrutura necessária para as atividades de construção e de apoio (Papéis 13 a 21). Suas atividades são intensivas no início da fase de operacionalização do Consórcio. Após este período, uma boa parte de seu contingente é mobilizado para fornecer apoio à construção. Dois recursos são de especial importância nesta Unidade: a) as máquinas e equipamentos de manufatura utilizados para o fornecimento de matéria-prima de primeira necessidade e de componentes usados em larga escala na construção (Recurso 4) e o Equipamento que utiliza estes componentes (Recurso 5). Este equipamento é fundamental para a execução da principal fase da obra;

- A Unidade Organizacional 3, Divisão de Apoio, utiliza, após instalação, entidades fornecidas pela Unidade Organizacional 2 (Papéis 17 a 21). Por exemplo, refeitórios, ambulatórios, centrais de carpintaria e manutenção, que depois de concluídos serão utilizados durante todo o ciclo de vida da obra. Instalações de Apoio como Canteiros de Obra e Frentes de Trabalho que viabilizam Instalações Elétricas são de responsabilidade de Empresas Terceirizadas, mas são considerados também como entidades de apoio.

Fora do escopo das atividades do Consórcio estão as Empresas Terceirizadas com entidades diversas (Papéis 22 a 34), executando serviços em geral bastante específicos. 
Este Modelo de Atores e Recursos, apesar de possuir e pretender fornecer certo grau de detalhamento possui limitações quanto ao número de entidades representadas, por necessidades de agrupamentos de papéis e omissão de informações consideradas menos relevantes. Entretanto, considera-se que as dimensões de escopo e escala estão abordadas coerentemente.

\subsection{Verificação do Modelo de Conceitos para Operacionalização e Reconfiguração em Construção Civil}

Além dos dados coletados para desenho dos Modelos de Processos e de Atores e Recursos, as práticas e iniciativas próprias do Consórcio, considerando as áreas de conhecimento do Modelo de Conceitos para operacionalização e reconfiguração em Construção Civil, foram verificadas.

A maior parte dos conceitos identificados está relacionada à Estrutura da Unidade Organizacional de Gerenciamento do Projeto, contando com iniciativas aplicáveis ao escopo das atividades realizadas pelo próprio Consórcio.

Iniciando pela Medição de Desempenho, foram verificadas as iniciativas de Gerenciamento pelas Diretrizes, Gerenciamento de Rotina Diária e Programa de Participação nos Resultados como Sistemas de Medição de Desempenho e Indicadores próprios, que sofrem influência de iniciativas difundidas na indústria tradicional. Os indicadores estão relacionados principalmente à produtividade dos Recursos Humanos.

A gestão de qualidade, meio-ambiente, segurança, saúde e responsabilidade social, indica a preocupação com dimensões usualmente controladas por meio de normas específicas aplicáveis ao setor da construção civil.

$\mathrm{Na}$ dimensão financeira, a gestão de medição, constitui processo interno dos setores de custo e faturamento.

O Planejamento e Controle da Produção utiliza a abordagem tradicional de Gestão de Projetos, com a gestão de planejamento atuando em períodos de curto a longo prazo (planejamento estratégico), em revisões constantes para adequação de cronograma e alcance dos objetivos internos e do cliente (contratante).

A dimensão de Integração do Consórcio, de onde se origina o planejamento estratégico, aborda também o Plano de Comunicação Social e Lições Aprendidas, como evidências de iniciativas de Gestão do Conhecimento para a obra de grande porte. 
Em interface entre as áreas de conhecimento de Gestão do Conhecimento e Gestão de Recursos está a Gestão de Pessoal, ligada ao departamento de Recursos Humanos. Programas 5S também visam promover melhoria contínua, e por sua essência também representam uma forma de empowerment de pessoal.

A gestão de medição e controle de custos e gestão de seguros e riscos atendem à dimensão financeira da Gestão de Recursos. Na dimensão de Equipamentos, a gestão de equipamentos executa coordenação e controle destes recursos para a construção e para a operação de atividades de manufatura de componentes.

A Gestão da Cadeia de Suprimentos é destinada às questões mais estáticas de relações de mercado, incluindo Gestão Contratual, Gestão de Contrato de Fornecedores de Serviços e Gestão de Aquisição.

Em termos de Tecnologia de Informação e Comunicação, é utilizado software tradicional para gestão de projetos, um sistema de gerenciamento compartilhado da obra, possuindo as funcionalidades: controle diário de obra, projetos e lista mestre, atas de reuniões e correspondências. O sistema de gerenciamento é compartilhado com o cliente e fornecedores chave.

Sistemas $\mathrm{nD}$ CAD e BIM são utilizados na fase de projeto, idealmente antes do início da operação, mas que pode ser realizada também durante a operacionalização e reconfiguração, conforme ressaltado pela descrição do Modelo de Processos.

\subsection{Considerações Finais}

A Coleta de Dados a partir do Objeto de Estudo apresentado permite o conhecimento de uma realidade atual e suas particularidades. Os Modelos apresentados elucidam a complexidade em termos de processos e atores e recursos na estrutura de operacionalização e reconfiguração da rede de construção civil para execução de obra de infraestrutura de grande porte.

Diante dos dados levantados, percebe-se a forte relação dos conceitos apresentados no Modelo de Conceitos com os papéis apresentados no Modelo de Atores e Recursos.

Considera-se que algumas questões importantes para obtenção de melhor eficiência na operação da rede ainda não são consideradas. Deste modo, análises e oportunidades de mudança são exploradas para a elaboração do Modelo de Referência desenvolvido no capítulo seguinte. 


\section{ANÁLISE DE DADOS E RESULTADOS}

Este Capítulo tem base no conhecimento coletado a partir de revisão bibliográfica e consulta a especialistas, e considera oportunidades de mudança relativas à realidade atual da rede de construção civil representada por modelos no Capítulo anterior. São realizadas análises dos modelos elaborados e dados coletados, definindo as oportunidades de mudança. Como resultado, foi possível desenvolver o Modelo de Referência para Operacionalização e Reconfiguração de Redes de Construção Civil. Este Modelo tem base em dois submodelos: processos e atores e recursos - que utilizam diretrizes fundamentais do Modelo de Conceitos.

\subsection{Análise de dados, Modelos Elaborados e definições de mudanças}

Nesta seção os modelos elaborados nos Capítulos 3, 4 e 5 são analisados em termos de oportunidades de mudança como suporte ao desenho do Modelo de Referência. Estas análises são descritivas, e os modelos que contém as mudanças identificadas, são representados na seção 6.2 do Capítulo.

\subsubsection{Modelos de Conceitos}

Retomando as áreas de conhecimento representadas nos Modelos de Conceitos apresentados nos Capítulos 3 e 4, traça-se um paralelo entre as entidades verificadas na Coleta de Dados realizada com pesquisadores de Centros de Pesquisa de Referência e os aspectos verificados no Estudo de Caso em um Consórcio, possuindo como principal direcionador a colaboração em redes de construção civil.

Ressalta-se que os conceitos nem sempre são representados nos modelos de forma explícita, mas estão contemplados em seus fundamentos. 
A Medição de Desempenho, utilizando sistemas que se apliquem a todos os participantes da rede, dado que possuem um objetivo comum, é fundamental para que se alcance a colaboração. Logo, ela deve estar refletida no Modelo de Atores e Recursos como papel a ser desempenhado na coordenação e controle da rede. Essa atividade também deve ser realizada ao longo do ciclo de vida da rede e em nível individual, como função de apoio ao modelo de processos. Essa abrangência de escopo e escala da Medição de Desempenho foi destacada por Camarinha-Matos e Abreu (2007).

Não há evidências no Estudo de Caso de que as principais iniciativas de Medição de Desempenho sejam replicadas para toda a rede, estando restrita, principalmente, ao nível da produtividade dos recursos humanos do consórcio e utilização dos recursos financeiros.

Já os requisitos qualidade, meio-ambiente, saúde, segurança e responsabilidade social, que são normativos, aplicam-se a todos os atores do negócio, durante todo o ciclo de vida do projeto. Assim, muitos dos indicadores para obras públicas de grande porte apontados por Toor e Ongulana (2010) são contemplados.

Considerando estes indicadores mencionados e a estrutura do Modelo de Conceitos para Colaboração em Redes de Construção Civil da Figura 4.1, propõe-se que os requisitos do(s) cliente(s) e a estratégia do negócio, com metas baseadas em projeto, norteiem de forma mais evidente a Medição de Desempenho e que esta possua, em contrapartida, influência sobre o processo de Tomada de Decisão.

O Planejamento e Controle da Produção é realizado por Gestão de Projeto, coerente com obras de grande porte de construção (KELLER et al., 2006; VERHEIJ; AUGENBROE, 2006), e premissas são evidenciadas e atualizadas com utilização de software específico pelo Consórcio. Este utiliza, entretanto, um sistema de gerenciamento compartilhado da obra, cujas funcionalidades e permissões aplicam-se apenas a parte dos atores da rede. As diretrizes da política do Sistema de Gestão Integrada, certificado nas principais normas internacionais, são definidas para todas as fases da obra.

Considera-se necessário ampliar a utilização do sistema de gerenciamento tanto em termos de funcionalidades disponíveis, quanto no uso compartilhado entre os participantes. Ressalta-se que ferramentas e soluções específicas utilizadas pelas empresas também podem possuir interface com o sistema, de modo a facilitar o compartilhamento de informação. A utilização de plataforma de colaboração, conforme referências dos Projetos CoSpaces (2011) e Mefisto (2011), permite integração da perspectiva estratégica e dos detalhes operacionais melhorando o desempenho dos processos, principalmente no que envolve a tomada de decisão (PEÑA-MORA et al., 2008). 
No processo de tomada de decisão, a Gestão do Conhecimento é considerada premissa essencial, com perfeito alinhamento à estratégia do negócio. No Estudo de Caso, ela é capturada em termos das atividades do Consórcio pelas áreas de Lições aprendidas e pelo Plano de Comunicação Social, remetendo à melhoria da comunição e coesão, possuindo uma base de conhecimento dedicada, conforme sugerido por Rezgui (2007).

Entretanto, essas iniciativas não garantem o compartilhamento de conhecimento entre funções similares e geograficamente dispersas (DAVE; KOSKELA, 2009), pelas restrições de funcionalidades e permissões de uso do sistema de gerenciamento compartilhado. Novamente, a concepção desse sistema possui oportunidades de readequação.

Uma questão importante pertencente ao domínio da Gestão do Conhecimento é a geração de Inovação (RUTTEN; DOREÉ; HALMAN, 2009) e Melhoria Contínua, conforme coleta de dados em centros de pesquisa de referência e projetos analisados. Estes aspectos não foram verificados na configuração do Consórcio. Recomenda-se atenção ao apoio das relações de parceria e atendimento aos princípios da colaboração (comunicação e coesão entre membros), de modo que a questão levantada possa pautar a execução e operação da rede de construção, para obter maior eficácia e eficiência.

A Gestão de Recursos, conforme sugerido no Modelo de Conceitos para Colaboração em redes de construção, possui interface com a Gestão do Conhecimento no que diz respeito aos Recursos Humanos. A tentativa é de constituir uma cultura de criação de valor de conhecimento (VORAKULPIPAT; REZGUI; HOPFE, 2010), pela alocação correta das competências.

Os recursos físicos (equipamentos, máquinas e ferramentas) e financeiros possuem controle bastante evidente na estrutura do Consórcio. No primeiro caso a ênfase está na mobilização e desmobilização desses recursos e no segundo caso no controle dos custos. Tais considerações permanecem relevantes para a elaboração do modelo de referência, porém ressaltando-se o compartilhamento da informação para controles mais eficazes.

A Gestão da Cadeia de Suprimentos pode, por sua vez, focar na estrutura de colaboração baseada em confiança, nas dimensões intra e interorganizacionais, conforme indicações de Rezgui (2007) e Zou, Zhang e Wang (2007), em detrimento de relações estáticas de mercado verificadas na realidade atual do Consórcio.

Essa abordagem mais dinâmica, voltada à colaboração, favorece o controle dos aspectos fundamentais a serem considerados na cadeia de suprimentos - o fluxo de materiais e informações - de modo que princípios enxutos e novas tecnologias norteiem essa gestão. 
Indica-se o uso intensivo de Tecnologia de Informação e Comunicação como apoio para a colaboração, desde que princípios fundamentais das áreas de conhecimento descritas estejam atendidos. Todas as áreas de conhecimento do Modelo de Conceitos abordadas possuirão funcionalidades na plataforma de colaboração.

A tecnologia adotada deve objetivar principalmente o controle e compartilhamento da informação, de modo que a plataforma de colaboração auxilie no processo de tomada de decisão.

Neves e Guerrini (2010) apresentam um Modelo de requisitos e componentes técnicos para a formação e gerência de redes de cooperação entre empresas da construção civil. $O$ objetivo principal representado no modelo é manter uma base de dados com todas as informações relevantes de uma obra. Este objetivo principal é apoiado por outros objetivos: manter dados dos fornecedores, dos construtores e dos contratos realizados; manter registros atualizados do andamento do ciclo de vida da rede, do cronograma financeiro e de execução das atividades da obra, e; manter um relatório de ações inesperadas de cada obra. Os dados obtidos auxiliam também a avaliação de desempenho. Assim, a plataforma de colaboração indicada pode utilizar como base os objetivos descritos.

As considerações feitas para cada área de conhecimento e seus conceitos são consideradas nos modelos propostos. Além delas, problemas verificados nos modelos da realidade atual do consórcio são identificados e discutidos a seguir.

\subsubsection{Modelo de Processos}

Observando-se o Modelo de Processos do Consórcio descrito no Capítulo 5 e representado na Figura 5.1, verifica-se o grande número de restrições que contribuem para interrupções frequentes no processo de negócios. O modelo adotado, cuja referência maior é voltada para relações de mercado, possui uma estrutura com disfunção burocrática, com forte dependência e utilização de decisões técnicas e comerciais durante a operação da rede. Esta estrutura contribui para atrasar a tomada de decisão, principalmente em termos de reconfiguração, causando interrupções indevidas na execução da obra.

Devido à complexidade do projeto, não é possível que um processo único consiga atender a toda a obra. A própria divisão em fases de obra, que podem ser executadas em paralelo, demanda um modelo de processos que possa ser replicado para estas fases.

Considera-se necessário que o modelo de processos minimize o número de restrições aplicáveis à reconfiguração do negócio, reduzindo as possibilidades de interrupção na 
execução das fases, principalmente na execução adequada da fase de planejamento de atividades e mobilização dos responsáveis por determinada fase da obra. Oportuno também destinar, sempre que possível, as decisões ao nível operacional, de modo que o corpo técnico e comercial atue mais em planejamento da execução da obra, do que no seu controle.

Ainda, a obediência a uma ordem de serviço que parte do cliente aparentemente de forma arbitrária, aponta dois problemas na forma de conduzir os processos: a) a ausência de um planejamento sólido visando melhor eficiência do projeto e, b) a falta de alinhamento dos objetivos das empresas da rede, com vistas à colaboração.

Sugere-se a utilização da plataforma de colaboração como ferramenta também de planejamento em que as decisões sobre os processos sejam facilmente indicadas a todos os participantes da rede. Pode-se ter a geração automática de uma ordem de serviço, enviada diretamente ao executor da fase da obra, ou a solicitação do início da fase pela entidade coordenadora do projeto. Também, o desempenho pode ser continuamente verificado, como importante fonte de informação ao processo de tomada de decisão.

Assim, o modelo de processos pode minimizar as disfunções burocráticas, permitindo um fluxo mais dinâmico de operação e reconfiguração. Espera-se a redução do número de entidades representadas no modelo, atendendo aos objetivos da rede.

É imprescindível destacar a influência do planejamento anterior ao início da operação. Problemas com projeto, e interrupções por problemas contratuais (quando imprescindível a utilização de relações de contrato), devem ser sanadas na fase de planejamento. Portanto, na elaboração do Modelo de Referência essas questões não são consideradas.

\subsubsection{Modelo de Atores e Recursos}

O Modelo de Atores e Recursos do Consórcio, representado na Figura 5.2, apresenta uma estrutura hierárquica tradicional que evidencia, principalmente, a operação do consórcio com os princípios de rede de relação de mercado, cujos conceitos de colaboração não estão contemplados.

A presença dos verbos "contratar", "controlar", "reportar" e a existência de papéis de Gestão Contratual e Gestão de Contrato de Prestadores de Serviços dentro da estrutura de Gerenciamento do Projeto, evidenciam o rígido modelo de gestão da rede, para o qual as relações de confiança e parcerias estão longe de ser consideradas. 
O aspecto abordado constitui talvez o maior desafio na busca de implementação de redes colaborativas em construção, principalmente em obras de grande porte e de parceria Público-Privada. Sugere-se que o Modelo de Atores e Recursos para Operacionalização e Reconfiguração de Redes de Construção Civil, considere os princípios da colaboração adotando as seguintes premissas:

- Consolidação da rede nos moldes de Empresa Virtual, na qual os relacionamentos sejam baseados em confiança;

- Como forma de representação, a substituição dos verbos "contratar", "controlar", "reportar" pelos termos "solicitar participação", "coordenar", "compartilhar informação";

- Como forma de coordenação dos atores, a existência de uma entidade que exerça governança da rede, facilitando o alcance dos objetivos comuns;

- Papéis exercidos pelas empresas em termos de suas capacidades e competências essenciais.

Os papéis específicos para as empresas em termos de suas capacidades e competências, para obra de infraestrutura de metrô, estão relacionados aos papéis verificados no Modelo de Atores e Recursos do Consórcio.

As oportunidades de mudança ora sugeridas, são refletidas no Modelo de Referência para Operacionalização e Reconfiguração de Redes de Construção Civil para obras de metrô

\subsection{Resultados: Modelo de Referência para Operacionalização e Reconfiguração de Redes de Construção Civil para obras de metrô}

O Modelo de Referência é representado nas dimensões de Processos e Atores e Recursos, pressupondo a utilização dos conceitos e necessidades de mudanças dos modelos descritas na seção 6.1. Cada modelo é descrito, representado e seguido das discussões cabíveis.

\subsubsection{Modelo de Processos}

O Modelo de Processos, conforme representado no Modelo "como é" (As-Is), aplica-se às diferentes fases da obra. Este Modelo está representado na Figura 6.1 - Modelo de Processos para Operacionalização e Reconfiguração de Redes de Construção Civil.

As fases de obra são determinadas, conforme os processos verificados para o Consórcio e representadas na parte superior da Figura.

O Processo 1 - checar necessidades de execução de fase de obra - executado continuamente, é de responsabilidade da coordenação da Rede. Pode-se indicar uma das 
empresas da rede para exercer governança, possuindo além do papel relacionado às suas capacidades e competências essenciais, o papel de coordenar a rede. As informações necessárias para o processo são encontradas na plataforma de colaboração em termos de requisitos do projeto e também são confrontadas com as informações de desempenho compartilhadas continuamente na operação da rede.

A fase de obra a ser iniciada é então informada, gerando a necessidade de execução dos Processos 2 e 3 . O Processo 2 presume o planejamento das atividades em termos de suas subfases e dos aspectos operacionais, principalmente. O Processo 3 indica a mobilização do(s) executor(es) da fase.

Concluídos estes processos é feita a verificação de disponibilidade do responsável a ser alocado para a construção. Se o responsável não estiver disponível, será necessário proceder ao Processo 4 - Reconfigurar o Planejamento. A reconfiguração pode se dar em termos de prazos, características da execução ou o próprio responsável pela execução. As premissas de reconfiguração podem ou não requerer Decisões Técnicas e Comerciais. Para decisões simples, retorna-se aos processos 2 e 3. Quando for requerido acionamento do corpo técnico e comercial, será necessário aguardar as decisões tomadas para retornar aos processos 2 e 3. Quando o responsável está disponível após os processos 2 e 3, inicia-se o Processo 5 - Executar/Construir para determinada fase da obra.

O Processo 5 possui determinado tempo de execução. Ao longo do processo, informações sobre o andamento do trabalho em termos de desempenho (considerando-se as premissas de desempenho determinadas no Sistema de Medição de Desempenho) devem ser continuamente fornecidas para a plataforma de colaboração. O compartilhamento da informação permitirá conhecimento do andamento da operação de forma atualizada, favorecendo os processos decisórios e o próprio planejamento do trabalho.

A conclusão do Processo 5 resulta na finalização da fase da obra. O Processo 5 pode ser composto de várias subfases de obra e outras fases podem acontecer em paralelo. Assim, conforme observado no Modelo de Processos obtido pelo Estudo de Caso em um Consórcio de Construção Civil, o modelo é iterativo e replicado diversas vezes ao longo da operacionalização e reconfiguração da Obra. 


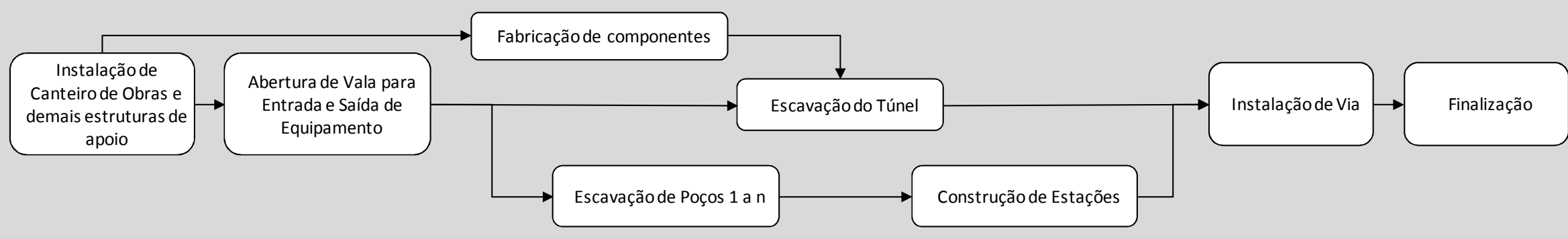

Fases de operacionalização e reconfiguração

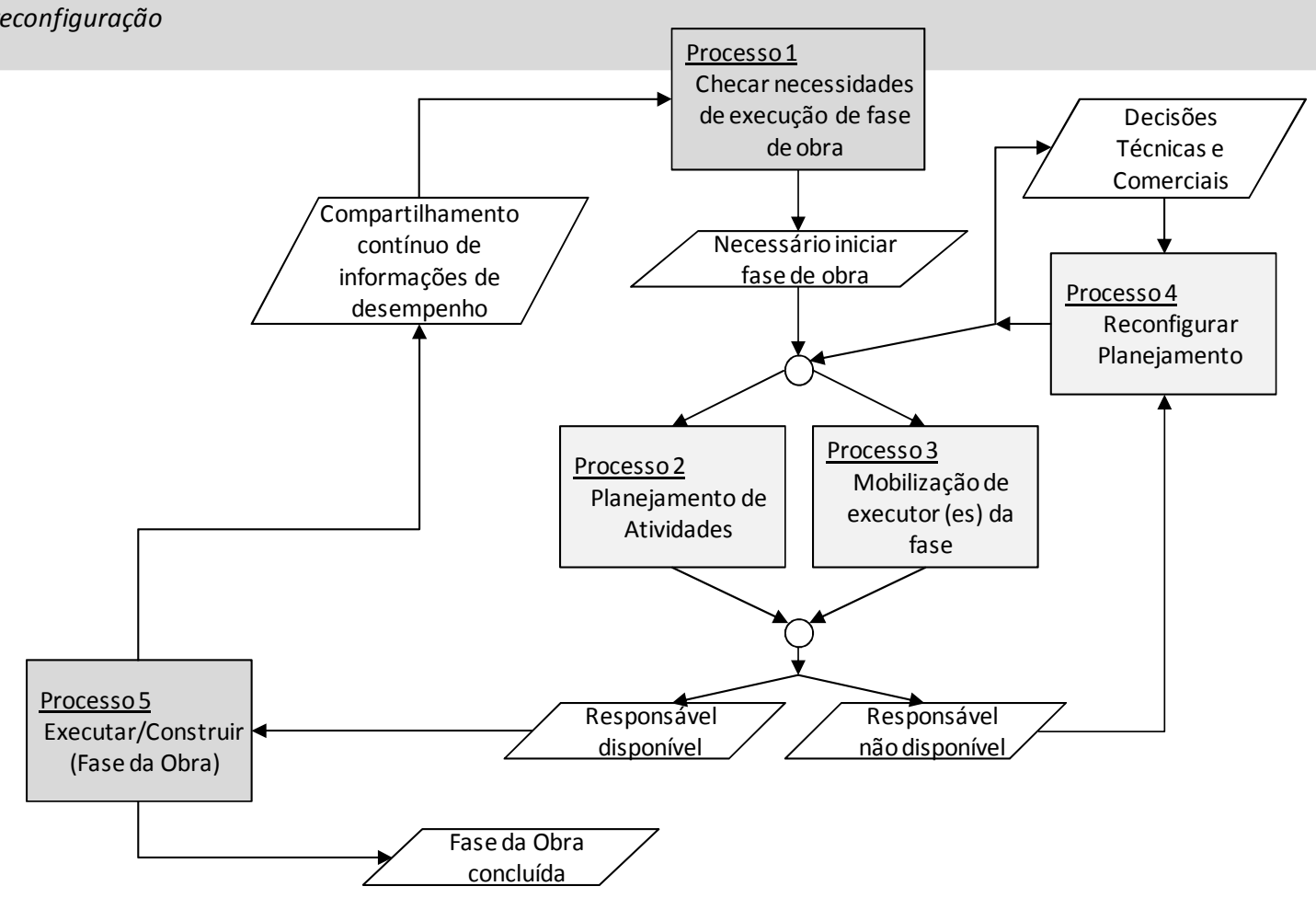

Figura 6.1 - Modelo de Processos para Operacionalização e Reconfiguração de Redes de Construção Civil 
Os processos de 1 a 4 são de responsabilidade da entidade que exerce governança na rede e o processo 5 de responsabilidade do executor da fase da obra, obtendo-se um planejamento mais centralizado e potencialmente menos sujeito à reconfigurações. Ressalta-se a importância dada ao compartilhamento contínuo de informações de desempenho pelo executor, favorecendo o fluxo dos processos de 1 a 4 , o conhecimento das decisões tomadas e dos processos decisórios envolvidos, até que o executor possa iniciar a operação.

Observa-se a inexistência de processos externos, pois todos os responsáveis pela execução da obra pertencem a um mesmo domínio da rede, de modo que são observadas relações de parceria e não de subcontratação. Deste modo, a necessidade de revisão e emissão de contratos não é considerada uma atividade do modelo de processos. Indica-se que mesmo quando a operação/reconfiguração da rede necessitar de relações contratuais, essas decisões sejam tomadas na fase de planejamento do negócio e não durante sua operação.

O modelo representado é considerado uma estrutura simplificada de processo de raciocínio, com poucas oportunidades de interrupção no processo, considerando-se a tomada de decisão. Sua complexidade está na replicação do Modelo nas diversas fases da obra para construção de metrô e sua aplicação a diferentes responsáveis pela execução da fase.

As unidades envolvidas no processo representado, seus papéis e relações, bem como os recursos de suporte são descritos no Modelo de Atores e Recursos.

\subsubsection{Modelo de Atores e Recursos}

O Modelo de Atores e Recursos contém as evidências relacionadas aos requisitos conceituais da seção 6.1.1 e das considerações da seção 6.1.3. Este Modelo é representado na Figura 6.2 - Modelo de Atores e Recursos para Operacionalização e Reconfiguração de Rede de Construção Civil.

A configuração da rede é iniciada pelos Clientes, representados no modelo pela Organização Individual de 1 a n, que possuem e determinam requisitos específicos (Papel 1) e permitem a identificação de uma Oportunidade de Negócio. A Oportunidade de Negócio motiva a constituição da rede colaborativa de empresas nos moldes da Empresa Virtual (Unidade Organizacional 1), presumindo os princípios da colaboração e a existência de um ciclo de vida determinado. A constituição da Empresa Virtual também visa promover Inovação e Melhoria Contínua, não se refletindo somente no atendimento aos requisitos dos clientes como também na maximização de suas capacidades e competências internas. 
A Empresa Virtual é composta de $n$ Empresas (Unidades Organizacionais de 1.1 a $1 . n$ ) que colaboram para o alcance de um objetivo comum. Este objetivo está contido na Estratégia do Negócio, atendendo aos requisitos dos clientes. Essas empresas compartilham informações e recursos que estão contidos em uma Plataforma de Colaboração (Recurso 1). Esta plataforma trata dos processos construtivos, dos produtos e recursos utilizados na construção, da coordenação das atividades e gestão da informação, e também das análises, simulações e avaliação da rede de empresas e/ou da obra/projeto a executar. Assim, a Plataforma de Colaboração reflete a estratégia do Negócio em suas funcionalidades e abrangência. Também possui como requisitos conceituais e funcionais as áreas de conhecimento contidos nos conceitos revisados (Requisitos 1 a 6). Os requisitos não são propriamente entidades do Modelo, mas por sua relevância são representados em formato próprio. Do mesmo modo, observa-se a necessidade de que o requisito de Medição de Desempenho seja norteado pelos requisitos dos Clientes e pela Estratégia do Negócio. Apesar de esta consideração estar implícita nas relações do modelo, ela é explicitada na sua representação.

Cada empresa que compõe a Empresa Virtual possui um papel de capacidade e competência associado, que justifica a sua participação na rede. Uma determinada empresa pode ter como papel a governança do negócio ou atuar como broker da rede (representada no modelo pela Unidade Organizacional 1.3), participando somente com essa função ou possuindo também um papel associado à sua capacidade e competência específica. A estrutura que exerce governança possui o papel de coordenação da rede e é o principal planejador e solicitador da operação por parte de cada uma das empresas envolvidas, conforme destacado no Modelo de Processos da Figura 6.1. Esta pode ser considerada uma atividade centralizada, mas a existência da plataforma de colaboração contribui para o compartilhamento da informação, de modo que os participantes da rede estejam cientes do status das atividades e das necessidades de operação da Empresa Virtual.

A capacidade e competência da empresa pode estar associada à disponibilidade de determinado recurso (máquina, equipamento, software), fundamental para o cumprimento do objetivo da rede, conforme representado nas Unidades Organizacionais 1.3 e 1.5. Decisões sobre uso de recurso específico podem pautar-se na alocação somente do recurso ou também das capacidades e competências necessárias para operá-lo.

Observa-se novamente a inexistência de relações de subcontratação, pois a Empresa Virtual é constituída seguindo os princípios da colaboração. 


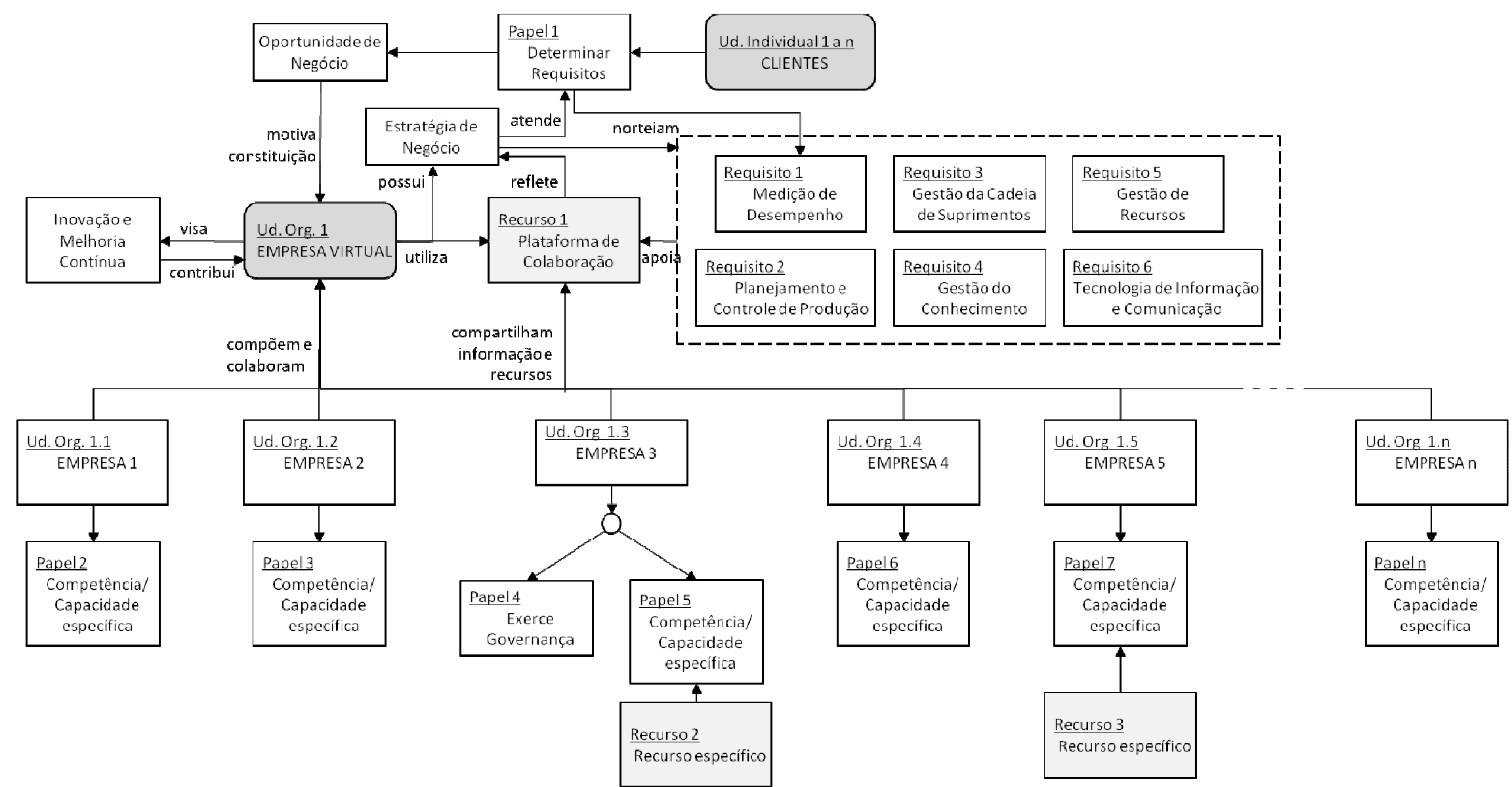

Figura 6.2 - Modelo de Atores e Recursos para Operacionalização e Reconfiguração de Rede de Construção Civil 
O Modelo apresentado não possui a representação tradicional de um "contratante" no centro de sua estrutura. Considera-se assim, que o principal motivador da formação da rede não é a existência de um contrato, mas de uma oportunidade de negócio percebida. Portanto, no centro de sua estrutura hierárquica está o cliente, como o principal disparador dos processos por meio de seus requisitos. O cliente será o usuário do resultado do negócio (bem ou serviço) e suas premissas norteiam a Estratégia do Negócio.

Este modelo de Atores e Recursos é uma representação generalista, em termos de papéis. Subentende-se que os papéis de cada Unidade Organizacional estarão contidos nas fases ou subprocessos de execução da obra de metrô a partir da instanciação do Modelo de Atores e Recursos da Figura 5.2 aos papéis a serem desenvolvidos pelas empresas. Assim, o modelo permite outras configurações, desde que respeitada a essência da colaboração.

A representação das áreas de conhecimento consideradas em Operacionalização e Reconfiguração de redes de construção civil determinam o escopo de sua aplicação para estas fases. Essas áreas trazem consigo os princípios da colaboração oriundos do Modelo de Conceitos apresentado no Capítulo 4.

Os Modelos de Processos e de Atores e Recursos para Operacionalização e Reconfiguração de Rede de Construção Civil para obras de metrô possuem influência um sobre o outro, conforme discute-se a seguir.

\subsection{Representação Integrada do Modelo de Referência}

Intuitivamente a representação dos Modelos considera uma dimensão hierárquica (de níveis de tomada de decisão), tanto no relacionamento entre entidades do modelo de atores e recursos, quanto no fluxo de processos.

Considera-se assim, que o Modelo de Atores e Recursos pode relacionar dois eixos: um vertical de níveis de tomada de decisão pelos papéis exercidos por diferentes atores (unidades individuais, organizacionais, recursos) e um longitudinal representando estes atores. Do mesmo modo, o Modelo de Processos possui uma dimensão de hierarquia do fluxo de informação e material, um eixo vertical, e uma sequência de processos executados ao longo das fases do ciclo de vida da rede, o eixo horizontal.

A integração entre esses modelos, e os eixos de referência estão representados na Figura 6.3 - Integração entre os modelos que compõem o Modelo de Referência. Conforme mencionado, os Modelos de Conceitos estão incluídos intrinsecamente, na própria elaboração dos modelos anteriores. 


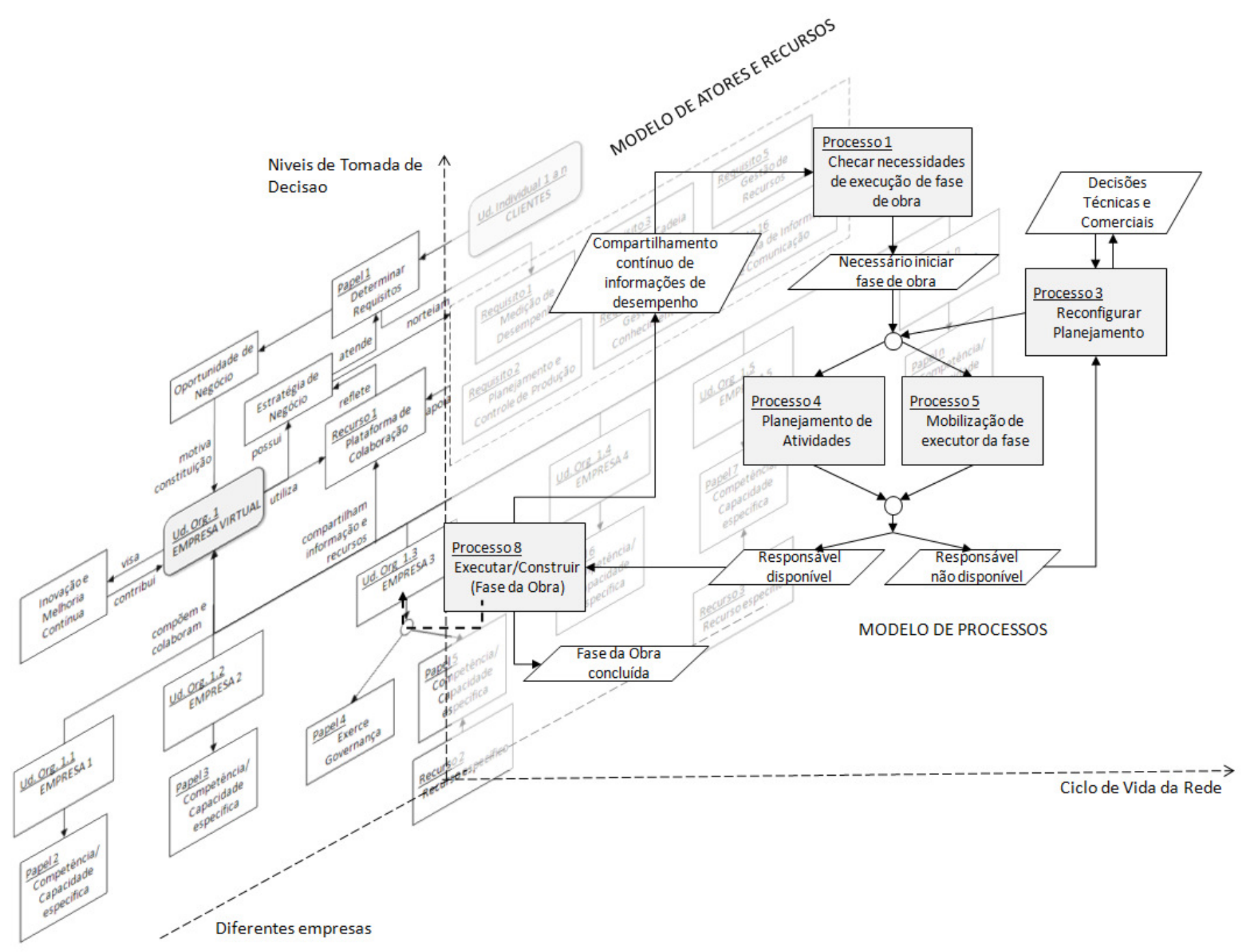

Figura 6.3 - Integração entre os modelos que compõem o Modelo de Referência 
A existência do eixo comum em termos de níveis de decisão, permite uma abstração tridimensional do relacionamento dos modelos, oferecendo noção da complexidade e dinamicidade da operação em redes de colaboração, facilitando a compreensão da aplicabilidade do Modelo de Referência. Estas dimensões utilizam como referência a o trabalho de Scherer, Schapke e Katranuschkov (2010), resultado também do projeto Mefisto (2011), que sugere a interoperabilidade da colaboração em três eixos relacionados a diferentes atores, ao longo das fases do ciclo de vida e diferentes níveis de tomada de decisão.

Apenas como forma de representação pode-se auferir o dinamismo destas relações imaginando-se as unidades organizacionais do Modelo de Atores e Recursos defasadas no eixo horizontal, ao longo do ciclo de vida, de acordo com sua participação nas fases do projeto. O modelo de processos aplicável é então replicado conjuntamente. Este modelo pode também ser representado em camadas ao longo do eixo longitudinal para a execução em paralelo de diferentes fases da obra, executadas por diferentes atores.

\subsection{Considerações Finais}

Este capítulo expõe o principal resultado do trabalho. Inicia por discutir oportunidades de mudança para uma realidade atual verificada, baseando-se no arcabouço teórico desenvolvido no trabalho. As oportunidades evidenciadas foram consideradas no desenho do Modelo de Referência representado nas dimensões de processos e atores e recursos.

Constitui o polo técnico do trabalho, onde são feitas as análises de dados, por análise de conteúdo, que permitem apontar um resultado com base nessas análises.

A descrição dos Modelos, como forma de documentação de um Modelo de Referência a partir dos modelos "para ser" (To-Be) desenvolvidos foi feita, fechando o processo de elaboração do Modelo. 


\section{CONCLUSÃO}

A expansão das atividades do setor de construção civil no Brasil, observada mais intensamente nos últimos 2 anos, e as perspectivas positivas em termos de investimentos e continuidade de fomento as atividades do setor para os próximos anos, o colocam na pauta estratégica da economia brasileira.

Entretanto, carências em termos de capacidade, qualificação de mão de obra e gestão são observadas, de modo que o setor possui uma hierarquia de competências ainda muito frágil. Considerando-se especificamente o subsetor de obras de infraestrutura, para o qual se destina a maior parcela dos investimentos nacionais do setor atualmente, verifica-se a necessidade de operação com maior eficiência e eficácia.

A condução de obras de infraestrutura por meio de redes de empresas, constituídas na forma de consórcio, provê os projetos em termos de capacidades necessárias, baseando-se fortemente em relações de mercado para as quais os contratos possuem papel fundamental. O objetivo do Consórcio é satisfazer as exigências e os requisitos do contrato, muitas vezes em detrimento de um bom desempenho em termos de gestão.

Sabe-se que o histórico das obras de infraestrutura pautadas no modelo de relação de mercado tem se apresentado ineficiente em termos de cumprimento de prazos e atendimento ao orçamento previsto. Ademais, as obras possuem um ciclo de vida delimitado e atuam no modus operandi de Empresa Virtual, para o qual o sistema com disfunções burocráticas por meio de contratos mostra-se cada vez menos adequado.

Considerando-se a importância das obras de grande porte do Brasil para a promoção de seu crescimento, a inadequação do modelo de gestão utilizado, e a existência de uma série de projetos, iniciativas e ferramentas voltadas ao setor para aumento de sua eficiência na real fase de geração de valor - a construção -, nesse contexto insere-se o desenvolvimento do Modelo de Referência. 
Assim, o delineamento epistemológico da pesquisa propôs duas questões fundamentais em apoio ao objetivo proposto:

- Quais as abordagens consideradas pelos centros de pesquisa de Referência para a operacionalização e reconfiguração em construção - considerando a perspectiva de colaboração?

- Como estão estruturadas as fases de operacionalização e reconfiguração da Obra de Consórcio verificada?

Utilizando a metodologia de Estudo de Caso Múltiplo, a primeira questão remeteu principalmente à experiência de projetos já desenvolvidos por, ou em parceria com, os centros de pesquisa de referência visitados. As abordagens de colaboração para os processos de operacionalização e reconfiguração observadas possuem em comum alguns pontos principais: os requisitos dos clientes como direcionadores do processo de negócios, competências essenciais como principais agentes de inovação e melhoria contínua, a necessidade de constituir parcerias baseadas em confiança para efetiva colaboração e o uso de plataformas ou sistemas integrados apoiando fortemente a geração, armazenamento e principalmente o compartilhamento de informação, para a colaboração.

A oportunidade de coletar dados de outros centros de pesquisa renomados permite ressaltar dois aspectos: a) as visitas e o acesso ao local onde se desenvolve a pesquisa enriqueceram a coleta de informações e facilitaram a busca por dados coerentes, em comparação à pesquisa "remota" feita através de sites e bancos de dados, e; b) a possibilidade de realizar visitas é, entretanto, limitada, justificando extensa revisão bibliográfica realizada anteriormente, que guiou a coleta de dados.

Observou-se também que em todos os centros visitados, as parcerias entre Academia, Instituições de Pesquisa e Empresas norteia a geração de conhecimento e inovação. A maior parte das pesquisas é motivada para aplicações práticas, observando-se a relação "ganha-ganha" desejada em relação de colaboração. No Brasil esse modelo de colaboração ainda é pouco verificado.

Para identificar as fases de operacionalização e reconfiguração de rede de construção civil, foi realizado estudo de caso em Consórcio de obra de infraestrutura urbana - obra de construção de linha de metrô. Os dados coletados permitiram caracterizar o objeto de estudo em termos de escopo, escala, competências essenciais, fases da obra e outras questões relacionadas. Com esta base, desenvolveram-se os Modelos de Processos e de Atores e Recursos do Consórcio, e revisaram-se os conceitos neles contidos. 
Foi obtido um modelo de processo com disfunções burocráticas em função, principalmente, das interrupções necessárias por requisitos de contrato, caracterizando nitidamente relações de mercado. Ademais, o modelo de Atores e Recursos, identifica a necessidade de uso de controles tradicionais do consórcio em relação aos seus agentes internos e externos e do Contratante em relação ao Consórcio. Neste modelo, o desempenho é medido e fundamentado basicamente em premissas normativas em detrimento de um Sistema de Medição de desempenho baseado em metas comuns, desejável em redes de colaboração.

A utilização de apenas um Estudo de Caso como forma de verificação de uma realidade atual, apesar de possuir limitações, mostrou-se importante e pertinente no âmbito do objetivo deste trabalho. O processo de construção do Modelo de Referência requer a representação de uma realidade atual. Se esta for atendida, desde que cumpridas as etapas anteriores, já é possível elaborar as demais etapas do processo. Ratifica-se que o objetivo do Modelo de Referência é prover à rede uma solução inicial para seus processos de negócios.

Entretanto, a dificuldade em realizar o Estudo de Caso, após tentativas em outros três diferentes consórcios em operação, identifica a cultura pouco colaborativa do meio empresarial em relação à Academia. Tal situação é bem diferente do observado em países desenvolvidos, conforme verificado nas visitas aos centros de pesquisa de referência.

As respostas às questões de pesquisa foram parte do processo de alcance do objetivo proposto. Utilizando também diretrizes para um processo de elaboração de Modelos de Referência e o apoio teórico de revisão bibliográfica, foi possível atender o objetivo de desenvolver um modelo de referência para as fases de operacionalização e reconfiguração de redes de construção civil constituídas para a execução de obras de grande porte de infraestrutura urbana.

O Modelo de Referência desenvolvido tem como resultado dois submodelos: Modelo de Processos e Modelo de Atores e Recursos. Os Modelos de Conceitos apresentados ao longo do trabalho estão contidos implicitamente ou explicitamente na elaboração e representação do Modelo de Referência.

O Modelo de Referência contribui para processos de operacionalização e reconfiguração de redes de empresas de construção civil, voltadas à condução de Sistemas de Grandes Projeto de metrô. Permite melhor alocação dos atores e recursos de uma obra e contribui para melhor adequação de coordenação e controle organizacionais utilizados, que são os principais desafios na gestão de obras com constituições institucionais. 
A operacionalização e reconfiguração para redes de Construção, considerando a colaboração, ainda necessita de esforços acadêmicos e práticos para que se torne um assunto consistente na pauta de pesquisadores e gestores. Deve-se focar na melhoria da qualidade dos processos de tomada de decisão aumentando-se a eficiência e eficácia dos projetos e da rede. A própria carência de profissionais com formação específica em gestão de grandes projetos, verificada na hierarquia de competências do estudo de caso, indica oportunidades de intervenções acadêmicas e empresariais neste processo de qualificação. O modelo de alocação de competências apenas baseado em experiência diminui as possibilidades de aumento de valor em termos de inovação e melhoria contínua dos Sistemas de Grande Projeto.

Assim, o desenvolvimento do Modelo de Referência auxilia no processo de sistematização do conhecimento, notadamente incipiente no caso verificado. O intuito é de identificar aspectos, práticas, configurações que possam ser replicados para outras obras de metrô, servindo de referência ao poder público e privado de interesse. O Modelo apresentado pode ser utilizado também como uma nova abordagem em termos de Gestão Pública, podendo os órgãos contratantes exercer o papel da governança da rede. Esta premissa demanda uma quebra de paradigma em termos de configuração da rede e dos relacionamentos baseados em contrato, exigindo a inserção dos requisitos de confiança na pauta dos projetos públicos.

O Modelo permite utilização em obras de outros segmentos do subsetor de infraestrutura (pontes, estradas, estádios, barragens etc.), desde que consideradas as particularidades da configuração e características da rede e dos sistemas e processos construtivos envolvidos. Fases intermediárias do modelo proposto, respeitando as restrições, disponibilidade de recursos e a própria estratégia do negócio podem ser também implementadas em diferentes contextos.

O uso de Tecnologia de Informação e Comunicação parametrizada para os projetos específicos na forma de plataformas de colaboração, podendo utilizar, entre outras, diretrizes apontadas pelo modelo desenvolvido, configura-se como oportunidade de pesquisa, tal qual verificado nos projetos desenvolvidos nas abordagens apresentadas. Essa oportunidade pode ser desdobrada em objetivos menores, ou desenvolvida na sua totalidade por meio de projetos de colaboração.

Indica-se também como oportunidade de pesquisa a construção de Modelos "como é" (AsIs) em outras obras com as mesmas características (obras de infraestrutura de metrô) e utilizando o mesmo processo de construção voltado à Gestão de Mudança, para que novas oportunidades de melhoria possam ser coletadas e possam promover o aprimoramento do 
Modelo de Referência desenvolvido. Notadamente, generalizações poderão ser feitas de forma mais consistente para desenvolvimento de um modelo que consiga atender um número maior de requisitos próprios para operacionalização e reconfiguração das redes. $\mathrm{O}$ desenvolvimento de Modelos de Referência também é indicado para outras obras de infraestrutura considerando Sistemas de Grande Projeto.

Também, a instanciação do Modelo de Referência em obras de metrô pode auxiliar sua melhoria, na tentativa de permitir a resolução de problemas práticos de uma organização, para a qual novos requisitos e adequações possam ser identificados. A replicação e adequação o modelo para outras fases do ciclo de vida da rede também podem configurarse como evoluções deste trabalho.

De modo geral, outras oportunidades que avancem em escopo e escala, visando maior eficiência e eficácia das redes de construção civil, são consideradas pertinentes.

Ressalta-se que a estrutura deste trabalho oferece resultados em cada uma das seções apresentadas, de modo que uma seção apoia a seção seguinte para alcance do objetivo proposto. Cada seção possui então oportunidade de avançar para o delineamento de novas pesquisas com objetivos diversos. 



\section{REFERÊNCIAS}

ABDALLAH, H.; EMARA, H.M.; DORRAH, H.T.; BAHGAT, A. Using Ant Colony Optimization algorithm for solving project management problems. Expert Systems with Applications, v.36, n.6, p. 1000410015, 2009.

AHLEMANN, F., GASTL, H. Process model for an Empirically Grounded Reference Model Construction. In: Fettke, P., Loos, P. (Eds.), Reference Modeling for Business Systems Analysis, Idea Group Publishing, Hershey et al., p. 77-97, 2007.

AHUJA, V.; YANG, J.; SHANKAR, R. Benchmarking Framework to Measure Extent of ICT Adoption for Building Project Management. Journal of Construction Engineering and Management - ASCE, v.136, n. 5, p. 538-545, 2010.

AHUJA, V.; YANG, J.; SHANKAR, R. Benefits of collaborative ICT adoption for building project management. Construction Innovation: Information, Process, Management, v.9, n.3, p. 323-340, 2009a.

AHUJA, V.; YANG, J.; SHANKAR, R. Study of ICT adoption for building project management in the Indian construction industry. Automation in Construction, v. 18, n. 4,p. 415-423, $2009 \mathrm{~b}$.

ALAGHBARI, W.; KADIR, M.R.A.; SALIM, A.; ERNAWATI The significant factors causing delay of building construction projects in Malaysia. Engineering, Construction and Architectural Management, v. 14, n. 2, p. 192-206, 2007.

ALA-RISKU, T.; KÄRKKÄINEN, M. Material delivery problems in construction projects: A possible solution . International Journal of Production Economics, v. 104, n. 1, p. 19-29, 2006.

ALNUAIMI, A.S.; TAHA, R.A.; AL MOHSIN, M.; AL-HARTHI, A.S. Causes, Effects, Benefits, and Remedies of Change Orders on Public Construction Projects in Oman. Journal of Construction Engineering and Management - ASCE, v.136, n. 5, p. 615-622, 2010.

AMATO NETO, J. Redes de cooperação produtiva e clusters regionais: oportunidades para as pequenas e médias empresas. São Paulo: Atlas, 2000.

ANDERSON, G. R.; MUKHERJEE, A.; ONDER, N. Traversing and querying constraint driven temporal networks to estimate construction contingencies. Automation in Construction, v. 18, n. 6, p. 798-813, 2009.

ANUMBA, C.J.; PAN, J.; ISSA, R.R.A.; MUTIS, I. Collaborative project information management in a semantic web environment. Engineering, Construction and Architectural Management, v.15, n.1, p. 78-94, 2008.

ANVUUR, A.M., KUMARASWAMY, M.M. Conceptual model of partnering and alliancing. Journal of Construction Engineering and Management, v. 133, n.3, p. 225-234, 2007.

ARAIN, F.M. IT-based approach for effective management of project changes: A change management system (CMS). Advanced Engineering Informatics, v. 22, n. 4, p. 457-472, 2008. 
ARAIN, F.M.; PHENG, L.S. Modeling for management of variations in building projects. Engineering, Construction and Architectural Management, v.14, n.5, p. 420-433, 2007.

ARDITI, D.; POLAT, G. Graduate Education in Construction Management. Journal of Professional Issues in Engineering Education and Practice, v.136, n. 3, p. 175-179, 2010.

BANKVALL, L.; BYGBALLE, L.E.; DUBOIS, A.; JAHRE, M. Interdependence in supply chains and projects in construction. Supply Chain Management: An International Journal, v.15, n.5, p. 385-393, 2010.

BARRIE, D. S., PAULSON, B. C. Professional construction management. 3 Ed. New York: McGraw Hill, 1992.

BAUPROZESS- UND BAUUNTERNEHMENSMANAGEMENT. Disponível em: <http://www.ibi.ethz.ch/ bb/index>. Acesso em: 23 Jun. 2011.

BELL, J.; DEN OUDEN, B.; ZIGGERS, G. Dynamics of cooperation: at the brink of irrelevance. Journal of Management Studies, v. 43, n. 7, p. 1606-1618, 2006.

BINDER, M.; EDWARDS, J.S. Using grounded theory method for theory building in operations management research - A study on inter-firm relationship governance. International Journal of Operations \& Production Management, v.30, n.3, p. 232-259, 2010.

BLACK, C.; AKINTOYE, A.; FITZGERALD, E. An analysis of success factors and benefits of partnering in construction. International Journal of Projects Management, v. 18, p. 423-434, 2000.

BOHN, J.S.; TEIZER, J. Benefits and Barriers of Construction Project Monitoring Using HighResolution Automated Cameras. Journal of Construction Engineering and Management - ASCE, v.136, n. 6, p. 632-640, 2010.

BOWEN, P.; EDWARDS, P.; CATTELL, K.; JAY, I. The awareness and practice of value management by South African consulting engineers: Preliminary research survey findings. International Journal of Project Management, v. 28, n. 3, p. 285-295, 2010.

BPMN. Disponível em: <http://www.bpmn.org/>. Acesso em: 23 Jun 2011.

BRASIL. Lei $n^{\circ}$ 6.404, de 15 de dezembro de 1976. Dispõe sobre as Sociedades por Ações. Disponível em: <http://www.planalto.gov.br/ccivil_03/LEIS/L6404consol.htm>. Acesso em: 21 set. 2009.

BRASIL. Lei $n^{\circ}$ 8.666, de 21 de junho de 1993. Regulamenta o art. 37, inciso XXI, da Constituição Federal, institui normas para licitações e contratos da Administração Pública e dá outras providências. Disponível em: <http://www.planaltogov.br/ccivil_03/LEIS/ L8666cons.htm>. Acesso em: 21 set. 2009.

BREMER, C. F.; LENZA, R. de P.. Um modelo de referência para gestão da produção em sistemas de produção assembly to order - ATO e suas múltiplas aplicações. Revista Gestão \& Produção. v. 7, n.3, p.269-282, 2000.

BUBENKO JR., J.A.; BRASH, D.; STIRNA, J. EKD User guide. Department of Computer and Systems Sciences. Stockholm: Royal Institute of Technology, 2001.

CAMARINHA-MATOS, L., ABREU, A. Performance indicators for collaborative networks based on collaboration benefits, Production Planning \& Control, v.18, p.592-609, 2007.

CAMARINHA-MATOS, L.; AFSARMANESH, H. The virtual enterprise concept. Working Conference on Infrastructure for Virtual Enterprise (PRO-VE'99). Porto, Portugal, p. 15-30, 1999. Proceedings...

CAMARINHA-MATOS, L., AFSARMANESH, H. Elements of a base VE infrastructure. Journal of Computers in Industry, v.51, p.139-163, 2003.

CAMARINHA-MATOS, L.; AFSARMANESH, H. Collaborative networks: a new scientific discipline. Intelligent Manufacturing, v. 16, p. 439-452, 2005.

CAMARINHA-MATOS, L.; AFSARMANESH, H. On reference models for collaborative network organizations, Journal of Production Research, v. 46, n. 7, p. 2453- 2569, 2008.

CARRILLO, P.; CHINOWSKY, P. Exploiting knowledge management: The engineering and construction perspective. Journal of Management in Engineering, v.22, n.1, p. 2-10, 2006. 
CBIC. Construção Civil: Desempenho e Expectativas. Informativo Econômico. Câmara Brasileira da Indústria da Construção, 2011.

CENTRE FOR INFORMATION TECHNOLOGY IN CONSTRUCTION. Disponível em: $<$ http://www.construct-it.org.uk>. Accesso em: 25 Jul. 2011.

CHALMETA, R., CAMPOS, C., GRANGEL, R., References architectures for enterprise integration. Journal of Systems and Software, v.57, n.3, 175-191, 2001.

CHAN, A.P.C.; CHAN, D. W. M.; CHIANG, Y. R.; TANG, B. S.; CHAN, E. H.: HO, K. S. K. Exploring critical success factors for partnering in construction projects. Journal of Construction Engineering and Management. Mar/Apr, p.188-197, 2004.

CHAN, E.W.L.; WALKER, D.H.T.; MILLS, A. Using a KM framework to evaluate an ERP system implementation. Journal of Knowledge Management, v.13, n.2, p. 93-109, 2009.

CHASSIAKOS, A.P.; SAKELLAROPOULOS, S.P. A web-based system for managing construction information. Advances in Engineering Software, v. 39, n. 11, p. 865-876, 2008.

CHEN, J.H. KNN based knowledge-sharing model for severe change order disputes in construction . Automation in Construction, v. 17, n. 6, p. 773-779, 2008.

CHENG, E. W. L.; LI, H. Construction partnering process and associated critical success factors: quantitative investigation. Journal of Management in Engineering. Oct., p.194-201, 2002.

CHENG, M.Y.; TSAI, H.C.; LAI, Y.Y. Construction management process reengineering performance measurements. Automation in Construction, v. 18, n. 2, p. 183-193, 2009.

CHENG, M.Y.; TSAI, M.H.; SUTAN, W. Benchmarking-based process reengineering for construction management. Automation in Construction, v.18, n.5, p. 605-623, 2009.

CHENG, M.Y.; TSAI, M.H.; XIAO, Z.W. Construction management process reengineering: Organizational HR planning for multiple projects. Automation in Construction, v.15, p.785-799, 2006.

CHENG, M.Y.; ROY, A. F. V. Evolutionary fuzzy decision model for construction management using support vector machine. Expert Systems with Applications, v. 37, n. 8, p. 6061-6069, 2010.

CHINOWSKY, P.; CARRILLO, P. Knowledge management to learning organization connection. Journal of Management in Engineering, v.23, n.3, p. 122-130, 2007.

CHOUDHARI, S.C.; ADIL, G.K.; ANANTHAKUMAR, U. Congruence of manufacturing decision areas in a production system: a research framework. International Journal of Production Research, v.48, n.20, p. 5963-5989, 2010.

COSPACES. Disponível em: <http://www.cospaces.org/>. Acesso em: 25 Jul. 2011.

COSPACES. D1 - Initial analysis of current collaborative engineering practices in user companies, 2006.

COSPACES. D95 - Plan for Using and Disseminating knowledge, 2009.

COSPACES. D76 - Final publication of CoSpaces Reference Architecture, 2010.

CRAIG, N.; SOMMERVILLE, J. Information management systems on construction projects: case reviews. Records Management Journal, v. 16, n. 3, p. 131-148, 2006.

DAINTY, A., BRISCOE, G., MILLET, S. New perspectives on construction supply chain integration. Supply Chain Management: An International Journal, vol. 6, n.4, p. 163-173, 2001.

DAVE, B.; KOSKELA, L. Collaborative knowledge management-A construction case study. Automation in Construction, v. 18, n. 7, p. 894-902, 2009.

DAVIS, P.R. A relationship approach to construction supply chains. Industrial Management \& Data Systems, v.108, n.3, p. 310-327, 2008.

DAWOOD, N.; SIKKA, S. Development of 4D based performance indicators in construction industry. Engineering, Construction and Architectural Management, v. 16, n. 5, p. 438-458, 2009.

DEMAID, A.; QUINTAS, P. Knowledge across cultures in the construction industry: sustainability, innovation and design. Technovation, v. 26, n. 5-6, p. 603-610, 2006. 
DIEESE. Estudo Setorial da Construção 2011. Departamento Intersindical de Estatística e Estudos Sócio Econômicos, 2011.

DONG, A.; MAHER, M. L.; KIM, M. J.; GU, N.; WANG, X. Construction defect management using a telematic digital workbench. Automation in Construction, v. 15, n. 6, p. 785-799, 2009.

DUAN, Q.; LIAO, T. W. Improved ant colony optimization algorithms for determining project critical paths . Automation in Construction, v. 19, n. 6, p. 676-693, 2010.

EL-MASHALEH, M.; O'BRIEN, W.J.; MINCHIN, R.E. Firm performance and information technology utilization in the construction industry. Journal of Construction Engineering and Management - ASCE, v.132, n.5, p. 499-507, 2006.

ERIKSSON, P.E. Improving construction supply chain collaboration and performance: a lean construction pilot project. Supply Chain Management: An International Journal, v.15, n.5, p. 394-403, 2010.

ERIKSSON, P.E.; NILSSON, T.; ATKIN, B. Client perceptions of barriers to partnering. Engineering, Construction and Architectural Management, v.15, n.6, p. 527-539, 2008.

ERMILOVA, E., AFSARMANESH, H. Competency modelling targeted on boosting configuration of Virtual Organizations. International Journal of Production Planning \& Control, v.21, n.2, 2010.

FERNIE, S.; THORPE, A. Exploring change in construction: supply chain management. Engineering, Construction and Architectural Management, v.14, n.4, p. 319-333, 2007.

FETTKE, P., LOOS, P. Perspectives on Reference Modeling. In: Fettke, P., Loos, P. (Eds.), Reference Modeling for Business Systems Analysis, Idea Group Publishing, Hershey et al., p. 1-21, 2007.

FRANCE, K.; JONES, I.; KHOSROWSHAHI, F.; ROWLAND, M.; UNDERWOOD, J. Building on IT 2010 - a survey of information technology expenditure and trends in the UK construction industry. London: Construct IT for Business, 2010.

FROESE, T. M. The impact of emerging information technology on project management for construction. Automation in Construction, v. 19, n. 5, p. 531-538, 2010.

GEHRE A., KATRANUSCHKOV P. SCHERER R.J.: Managing Virtual Organization Processes by Semantic Web Ontologies, In: Rebolj D. (ed.): "Bringing ITC knowledge to work", W78 Conference, 24, 26-29 June 2007, Maribor, Slovenia, 2007, Proceedings...

GIL, A. C. Como elaborar projetos de pesquisa. São Paulo: Atlas, 1991.

GIRMSCHEID, G.; RINAS, T. Business Design Modeling for Industrialization in Construction: Cooperative Approach. Journal of Architectural Engineering, v.18, p. 164-175, 2012.

GOLDENBERG, M.; SHAPIRA, A. Systematic evaluation of construction equipment alternatives: Case study. Journal of Construction Engineering and Management - ASCE, v.133, n.1, p. 72-85, 2007.

GOODRUM, P. M.; MCLAREN, M. A.; DURFEE, A. The application of active radio frequency identification technology for tool tracking on construction job sites. Automation in Construction, v. 15, n. 3, p. 292-302, 2006.

GORANSON, H.T. The Agile Virtual Enterprise: Cases, Metrics, Tools. Quorum Books, Westport, CT (1999)

GUERRIERO, A.; KUBICKI, S.; HALIN, G. Toward a Trust-Based Construction Management. Computer-aided Civil and Infrastructure Engineering, v.25, n. 4, p. 253-268, 2010.

HAPONAVA, T.; AL-JIBOURI, S. Identifying key performance indicators for use in control of preproject stage process in construction. International Journal of Productivity and Performance Management, v. 58, n. 2, p. 160-173, 2009.

HARTMANN, A.; GIRMSCHEID, G. The innovation potential of integrated services and its utilization through co-operation. Engineering, Construction and Architectural Management. v.11, n. 5, p. 335341, 2004.

HARTMANN, T.; FISCHER, M.; HAYMAKER, J. Implementing information systems with project teams using ethnographic-action research. Advanced Engineering Informatics, v. 23, n. 1, p. 57-67, 2009. 
HENDERSON, J.R.; RUIKAR, K. Technology implementation strategies for construction organisations. Engineering, Construction and Architectural Management, v.17, n.3, p. 309-327, 2010.

HO, S.P., LIN, Y., CHU, W., WU, H. Model for organizational governance structure choices in construction joint ventures. Journal of Construction Engineering and Management, v. 135, n. 6, p.518530, 2009.

HOLMEN, E.; PEDERSEN, A.; JANSEN, N. Supply network initiatives - a means to reorganise the supply base?. Journal of Business \& Industrial Marketing, v.22, n.3, p. 178-186, 2007.

HYARI, K.; EL-RAYES, K. Optimal planning and scheduling for repetitive construction projects. Journal of Management in Engineering, v.22, n.1, p. 11-19, 2006.

IBBS, W.; LIU, M. An improved methodology for selecting similar working days for measured mile analysis. International Journal of Project Management, In Press, Corrected Proof, Available online 22 September 2010.

IBBS, W.; NGUYEN, L.D. Schedule analysis under the effect of resource allocation. Journal of Construction Engineering and Management - ASCE, v.133, n.2, p. 131-138, 2007.

IBGE. Pesquisa anual da indústria da construção. Ministério do Planejamento, Orçamento e Gestão. Instituto Brasileiro de Geografia e Estatística - IBGE. Rio de Janeiro, v. 16, p.1-86, 2006.

IBGE. Pesquisa anual da indústria da construção. Ministério do Planejamento, Orçamento e Gestão. Instituto Brasileiro de Geografia e Estatística - IBGE. Rio de Janeiro, v. 20, p.1-96, 2010.

IBGE. Classificação Nacional de Atividades Econômicas - CNAE Versão 2.0. Disponível em: <http://www.ibge.gov.br/home/estatistica/economia/classificacoes/cnae2.0/default.shtm> Acesso em: 15 jun. 2012.

IDEF3. Disponível em <http://www.idef.com/IDEF3.htm>. Acesso em: 23 Jun. 2011.

INSTITUT FÜR BAUINFORMATIK. Disponível em: <http://cib.bau.tu-dresden.de>. Acesso: 10. Jun. 2011.

JAVIDAN, M. Core competence: what does it mean in practice? Long Range Planning, v.31. n. 1, p. 60-71, 1998.

KAGIOGLOU, M.; COOPER, R.; AOUAD, G.; HINKS, J.; SEXTON, M.; SHEATH, D. A Generic Guide to the Design and Construction Process Protocol. The University of Salford, Salford, 1998.

KANAPECKIENE, L.; KAKLAUSKAS, A.; ZAVADSKAS, E. K.; SENIUT, M. Integrated knowledge management model and system for construction projects. Engineering Applications of Artificial Intelligence, v. 23, n. 7, p. 1200-1215, 2010.

KANDIL, A.; EL-RAYES, K. Parallel genetic algorithms for optimizing resource utilization in large-scale construction projects. Journal of Construction Engineering and Management - ASCE, v.132, n.5, p. 491-498, 2006.

KARIM, K.; MAROSSZEKY, M.; DAVIS, S. Managing subcontractor supply chain for quality in construction. Engineering, Construction and Architectural Management, v.13, n.1, p. 27-42, 2006.

KARLSEN, J.T.; GRÆEE, K.; MASSAOUD, M.J. Building trust in project-stakeholder relationships. Baltic Journal of Management, v.3, n.1, p. 7-22, 2008.

KATZY,B.R.; CROWSTON, K. Competency rallying for technical innovation - The case of the Virtuelle Fabrik. Technovation, n. 28, p. 679-692, 2008.

KE, Y.; WANG, S.; CHAN, A.P.C.; CHEUNG, E. Research Trend of Public-Private Partnership in Construction Journals. Journal of Construction Engineering and Management - ASCE, v.135, n.10, p. 1076-1086, 2009.

KELLER, M. Informationstechnisch Unterstütze Kooperation bei Bauprojekten. Kurzfassung und Thesen. Dissertation (Doktorat). Technische Universität Dresden. Dresden, 2007.

KELLER, M., SCHERER, R. J., MENZEL, K., THELING, T., VANDERHAEGHEN, D., LOOS, P. Support of collaborative business process networks in AEC, ITcon Vol. 11, Special Issue Process Modelling, Process Management and Collaboration, pg. 449-465, 2006. 
KHALFAN, M.M.A.; MCDERMOTT, P.; SWAN, W. Building trust in construction projects. Supply Chain Management: An International Journal, v.12, n.6, p. 385-391, 2007.

KHOSROWSHAHI, F.; HOWES, R. A framework for strategic decision-making based on a hybrid decision support tools. Journal of Information Technology in Construction (ITCon), n. 10, p. 111-124. 2005.

KIM, K. Delay analysis in resource-constrained schedules. Canadian Journal of Civil Engineering, v.36, n.2, p. 295-303, 2009.

KIM, B.C.; REINSCHMIDT, K.F. Probabilistic Forecasting of Project Duration Using Kalman Filter and the Earned Value Method. Journal of Construction Engineering and Management - ASCE, v.136, n. 9, p. 834-843, 2010.

KOO, B.; FISCHER, M.; KUNZ, J. A formal identification and re-sequencing process for developing sequencing alternatives in CPM schedules . Automation in Construction, v. 17, n. 1, p. 75-89, 2007.

KUMARASWAMY, M. M.; PALANEESWARAN, E.; RAHMAN, M. M.; UGWU, O.; NG, S.T. Synergising R\&D initiatives for e-enhancing management support systems. Automation in Construction, v. 15, n. 6, p. 681-692, 2006.

LAM, P.T.I.; WONG, F.W.H.; TSE, K.T.C. Effectiveness of ICT for Construction Information Exchange among Multidisciplinary Project Teams. Journal of Computing in Civil Engineering, v.24, n. 4, p. 365376, 2010.

LANDESMANN, M.; SCAZZIERI, R. Coordination of production processes, subsystem dynamics and structural change. In: LANDESMANN, M.; SCAZZIERI, R. Production and economic dynamics. Cambridge Press, 1996.

LAU, E.; ROWLINSON, S. Trust relations in the construction industry. International Journal of Managing Projects in Business, v.3, n.4, p. 693-704, 2010.

LAUFER, A.; SHAPIRA, A.; TELEM, D. Communicating in dynamic conditions: How do on-site construction project managers do it?. Journal of Management in Engineering, v.24, n.2, p. 75-86, 2008.

LEE, S.H., PEÑA-MORA, F., PARK, M.: Dynamic planning and control methodology for strategic and operational construction project management. Automation in Construction v.15, p. 84-97, 2006.

LI, Y.W.; NIE, X.T.; CHEN, S.Y. Fuzzy Approach to Prequalifying Construction Contractors. Journal of Construction Engineering and Management - ASCE, v.133, n.1, p. 40-49, 2007.

LIN, Y.C. Developing construction assistant experience management system using people-based maps. Automation in Construction, v. 18, n. 6, p. 814-824, 2008.

LIN, Y.H.; LEE, P.C.; CHANG, T.P.; TING, H. Multi-attribute group decision making model under the condition of uncertain information. Automation in Construction, v.17, n.6, p. 792-797, 2008.

LING, F.Y.Y.; HARTMANN, A.; KUMARASWAMY, M.; DULAIMI, M. Influences on innovation benefits during implementation: Client's perspective. Journal of Construction Engineering and Management ASCE, v.133, n.4, p. 306-315, 2007.

LÖNNGREN, H.M.; ROSENKRANZ, C.; KOLBE, H. Aggregated construction supply chains: success factors in implementation of strategic partnerships. Supply Chain Management: An International Journal, v.15, n.5, p. 404-411, 2010.

LU, M.; LAM, H.C.; DAI, F. Resource-constrained critical path analysis based on discrete event simulation and particle swarm optimization. Automation in Construction, v.17, n.6, p. 670-681, 2008.

LUU, V.T.; KIM, S.Y.; TUAN, N.V.; OGUNLANA, S.O. Quantifying schedule risk in construction projects using Bayesian belief networks. International Journal of Project Management, v. 27, n. 1, p. 39-50, 2009.

MALE, S.; KELLY, J.; GRONQVIST, M.; GRAHAM, D. Managing value as a management style for projects. International Journal of Project Management, v. 25, n. 2, p. 107-114, 2007.

MATURANA, S., ALARCÓN, L.F., GAZMURI P., VRSALOVIC, M. On-site subcontractor evaluation method based on lean principles and partnering practices. Journal of Management in Engineering, ASCE, v. 23, n.2, p. 67-74, 2007. 
MESFISTO. Disponível em: <http://www.mefisto-bau.de/>. Acesso: 10. Jun. 2011.

MINCHIN JR., R.E.; HENRIQUEZ, N.R.; KING, A.M.; LEWIS, D.W. Owners Respond: Preferences for Task Performance, Delivery Systems, and Quality Management. Journal of Construction Engineering and Management - ASCE, v.136, n. 3, p. 283-293, 2010.

NA, L.J.; OFORI, G.; PARK, M. Stimulating construction innovation in Singapore through the National System of Innovation. Journal of Construction Engineering and Management - ASCE, v.132, n.10, p. 1069-1082, 2006.

NELSON, M.M., LEE, A., COOPER, R., KAGIOGLOU, M., FLEMING, A. Process re-engineering in the construction industry - Buzzword or reality? University of Salford, 1999.

NEVES, F. F., GUERRINI, F. M. . Modelo de requisitos e componentes técnicos para a formação e gerência de redes de cooperação entre empresas da construção civil. Gestão \& Produção, v. 17, p. 195-206, 2010.

NITITHAMYONG, P.; TAN, Z. Determinants for effective performance of external project management consultants in Malaysia. Engineering, Construction and Architectural Management, v.14, n.5, p. 463478, 2007.

NUDURUPATI, S.; ARSHAD, T.; TURNER, T. Performance measurement in the construction industry: An action case investigating manufacturing methodologies. Computers in Industry, v. 58, n. 7, p. 667676, 2007.

NURCAN, S., ROLLAND, C. A multi-method for defining the organizational change. Information and Software Technology, v.45, n.2, p.61-82, 2003.

O'BRIEN, W.J.; HAMMER, J.; SIDDIQUI, M.; TOPSAKAL, O. Challenges, approaches and architecture for distributed process integration in heterogeneous environments. Advanced Engineering Informatics, v. 22, n. 1, p. 28-44, 2008.

OLAVE, M. E. L.; AMATO NETO, J. . Redes de Cooperação Produtiva: Uma Estratégia de Competitividade e Sobrevivência para Pequenas e Médias Empresas. Gestão e Produção, v. 8, n. 3 , p. 289-303, 2001.

OMG. Disponível em: <www.omg.org>. Acesso em: 26 Jun. 2011.

ORABI, W.; SENOUCI, A.B.; EL-RAYES, K.; AL-DERHAM, H. Optimizing Resource Utilization during the Recovery of Civil Infrastructure Systems. Journal of Management in Engineering, v.26, n.4, p. 237-246, 2010.

OZORHON, B.; ARDITI, D.; DIKMEN, I.; BIRGONUL, M. T. Effect of host country and project conditions in international construction joint ventures. International Journal of Project Management, v. 25, n. 8, p. 799-806, 2007.

OZORHON, B.; ARDITI, D.; DIKMEN, I.; BIRGONUL, M.T. Performance of International Joint Ventures in Construction. Journal of Management in Engineering, v.26, n.4, p. 209-222, 2010.

PAIVA, E.L. Manufacturing and marketing integration from a cumulative capabilities perspective. International Journal of Production Economics, v.126, p. 379-386, 2010.

PARRY, G.; MILLS, J.; TURNER, C. Lean competence: integration of theories in operations management practice. Supply Chain Management: An International Journal, v.15, n.3, p. 216-226, 2010.

PENA-MORA, F.; HAN, S.; LEE, S.; PARK, M. Strategic-operational construction management: Hybrid system dynamics and discrete event approach. Journal of Construction Engineering and Management - ASCE, v.134, n.9, p. 701-710, 2008.

PILKINGTON, A.; MEREDITH, J. The evolution of the intellectual structure of operations management - 1980-2006: A citation/co-citation analysis. Journal of Operations Management, v.27, p. 185-202, 2009.

PIRES, S. R. I. Gestão da cadeia de suprimentos: conceitos estratégias, práticas e casos - Supply chain management. São Paulo: Atlas, 2004. 
PLISSON, J.; LJUBIC, P.; MOZETIC, I.; LAVRAC, N. An Ontology for Virtual Organization Breeding Environments, IEEE transactions on systems, man, and cybernetics - part c: applications and reviews, v. 37, n. 6, p.1327-1341, 2007.

POKU, S.E.; ARDITI, D. Construction scheduling and progress control using geographical information systems. Journal of Computing in Civil Engineering, v.20, n.5, p. 351-360, 2006.

PROVAN, K.G.; FISH, A.; SYDOW, J. Interorganizational networks at network level: a review of empirical literature on whole networks. Journal of Management, v. 33, p. 479-516, 2007.

RAHMAN, M.M., KUMARASWAMY, M.M., LING, F.Y.Y. Building a relational contracting culture and integrated teams. Canadian Journal of Civil Engineering, v. 34, n.1, p. 75-88, 2007.

RASDORF, W.; GRASSO, B.; BRIDGERS, M. Public versus Private Perceptions on Hiring an External Program Manager. Journal of Construction Engineering and Management - ASCE, v.136, n. 2, p. 219226, 2010.

REBEIZ, K.S.; SALAMEH, Z. Relationship between governance structure and financial performance in construction. Journal of Management in Engineering, v.22, n.1, p. 20-26, 2006.

REZGUI, Y. Exploring virtual team-working effectiveness in the construction sector. Interacting with Computers, v. 19, n. 1, p. 96-112, 2007.

REZGUI, Y.; HOPFE, C.J.; VORAKULPIPAT, C. Generations of knowledge management in the architecture, engineering and construction industry: An evolutionary perspective. Advanced Engineering Informatics, v.24, n. 2, p. 219-228, 2010.

RIBEIRO, F. L. Enhancing knowledge management in construction firms. Construction Innovation, v. 9, n. 3, p. 268-284, 2009.

RINAS, T.; GIRMSCHEID, G. Business model: a two-dimensional cooperation network for successful market penetration with prefabricated concrete elements and systems. In: Challenges, opportunities and solutions in structural engineering and construction, ISEC 05, Las Vegas, 2009, p. 677-682. Proceedings...

RINAS, T.; GIRMSCHEID, G. Business model: the cooperative production network that enables masscustomized production methods in the swiss precast concrete industry; In: CIB World Congress 2010 - University of Salford - UK, 2010. Proceedings...

RINAS, T.; GIRMSCHEID, G. Industrialization of the swiss construction market - a cooperative approach. In: International Structural Engineering and Construction Conference. 6. ETH Zurich, 2011. Proceedings...

ROCHA , D.; DEUSDARÁ, B. Análise de Conteúdo e Análise do Discurso: aproximações e afastamentos na (re)construção de uma trajetória. Alea, Rio de Janeiro, v.7, n.2, p. 305-322, 2005.

ROWLISON, S.; CROKER, N. IT sophistication, performance and progress towards formal electronic communication in the Hong Kong construction industry. Engineering, Construction and Architectural Management, v. 13, n. 2, p. 154-170, 2006.

RUSSELL, A.D.; CHIU, C.Y.; KORDE, T. Visual representation of construction management data. Automation in Construction, v.18, n. 8, p. 1045-1062, 2009.

RUTTEN, M.E.J.; DORÉE, A.G.; HALMAN, J.I.M. Innovation and interorganizational cooperation: a synthesis of literature. Construction Innovation: Information, Process, Management, v.9, n.3, p. 285297, 2009.

RUUSKA, I.; TEIGLAND, R. Ensuring project success through collective competence and creative conflict in public-private partnerships - A case study of Bygga Villa, a Swedish triple helix egovernment initiative. International Journal of Project Management, v. 27, n. 4, p. 323-334, 2009.

SACKS, R.; ESQUENAZI, A.; GOLDIN, M. LEAPCON: Simulation of lean construction of high-rise apartment buildings. Journal of Construction Engineering and Management - ASCE, v.133, n.7, p. 529-539, 2007.

SACKS, R.; KOSKELA, L.; DAVE, B.A.; OWEN, R. Interaction of Lean and Building Information Modeling in Construction. Journal of Construction Engineering and Management - ASCE, v.136, n. 9, p. 968-980, 2010. 
SACKS, R.; RADOSAVLJEVIC, M.; BARAK, R. Requirements for building information modeling based lean production management systems for construction. Automation in Construction, v.19, n. 5, Special Issue, p. 641-655, 2010.

SALEM, O.; MOHANTY, S. Project management practices and information technology research. Journal of Construction Engineering and Management - ASCE, v.134, n.7, p. 501-508, 2008.

SALMAN, A.F.M.; SKIBNIEWSKI, M.J.; BASHA, I. BOT Viability Model for Large-Scale Infrastructure Projects. Journal of Construction Engineering and Management - ASCE, v.133, n.1, p. 50-63, 2007.

SCHEER, A.W. ARIS toolset: A software product is born. Information Systems, v.19, n.8, p.607-624, 1994.

SCHERER, R.J.; SCHAPKE, S.-E.; KATRANUSCHKOV, P. Ontology-based ICT platform for management, simulations and decision making in large scale projects. In: International Conference on Computing in Civil and Building Engineering. Nothingham, UK. 2010. Proceedings...

SEGERSTEDT, A.; OLOFSSON, T. Supply chains in the construction industry. Supply Chain Management: An International Journal, v.15, n.5, p. 347-353, 2010.

SENARATNE, S.; SEXTON, M.G. Role of knowledge in managing construction project change. Engineering, Construction and Architectural Management, v.16, n.2, p. 186-200, 2009.

STAUB-FRENCH, S.; RUSSEL, A.; TRAN, N. Linear scheduling and 4D visualization. Journal of Computing in Civil Engineering, v.22, n.3, p. 192-205, 2008.

STYHRE, A. The bureaucratization of the project manager function: The case of the construction industry. International Journal of Project Management, v. 24, n. 3, p. 271-276, 2006.

TAM, V.W.Y.; SHEN, L.Y.; KONG, J. S.Y. Impacts of multi-layer chain subcontracting on project management performance. International Journal of Project Management, In Press, Corrected Proof, Available online 24 February 2010.

TANG, L.Y.; SHEN, Q.; CHENG, E.W.L. A review of studies on Public-Private Partnership projects in the construction industry. International Journal of Project Management, v. 28, n. 7, p. 683-694, 2010.

TANSKANEN, K.; HOLMSTRÖM, J.; ELFVING, J.; TALVITE, U. Vendor-managed-inventory (VMI) in construction. International Journal of Productivity and Performance Management, v.58, n.1, p. 29-40, 2009.

TARANTILIS, C.D.; KIRANOUDIS, C.T. A flexible adaptive memory-based algorithm for real-life transportation operations: Two case studies from dairy and construction sector. European Journal of Operational Research, v. 179, n. 3, p. 806-822, 2007.

TARANTILIS, C.D.; KIRANOUDIS, C.T.; THEODORAKOPOULOS, N.D. A Web-based ERP system for business services and supply chain management: Application to real-world process scheduling. European Journal of Operational Research, v. 187, n. 3, p. 1310-1326, 2008.

TATARI, O.; CASTRO-LACOUTURE, D.; SKIBNIEWSKI, M.J. Current state of construction enterprise information systems: survey research. Construction Innovation, v. 7, n. 4, p. 310-319, 2007.

TAYLOR, A.; TAYLOR, M. Operations management research: contemporary themes, trends and potential future directions. International Journal of Operations \& Production Management, v.29, n.12, p. 1316-1340, 2009.

TEERAJETGUL, W.; CHAREONNGAM, C.; WETHYAVIVORN, P. Key knowledge factors in Thai construction practice. International Journal of Project Management, v. 27, n. 8, p. 833-839, 2009.

TELEM, D.; LAUFER, A.; SHAPIRA, A. Only dynamics can absorb dynamics. Journal of Construction Engineering and Management - ASCE, v.132, n.11, p. 1167-1177, 2006.

THINKLAB. Disponível em: <http://www.thinklab.salford.ac.uk>. Accesso em: 25 Jul. 2011.

THOMAS, H.R.; HORMAN, M.J. Fundamental principles of workforce management. Journal of Construction Engineering and Management - ASCE, v.132, n.1, p. 97-104, 2006.

TOOR, S.; OFORI, G. Leadership for future construction industry: Agenda for authentic leadership. International Journal of Project Management, v. 26, n. 6, p. 620-630, 2008. 
TOOR, S.R.; OGUNLANA, S. Beyond the 'iron triangle': Stakeholder perception of key performance indicators (KPIs) for large-scale public sector development projects. International Journal of Project Management, v. 28, n. 3, p. 228-236, 2010.

TSAI, M.K.; YANG, J.B.; LIN, C.Y. Synchronization-based model for improving on-site data collection performance. Automation in Construction, v. 16, n. 3, p. 323-335, 2007.

TZORTZOPOULOS, P., SEXTON, M., COOPER, R. Process models implementation in the construction industry: a literature synthesis, Engineering Construction \& Architectural Management, v.12, n.5, 2005.

VENNSTRÖM, A.; ERIKSSON, P.E. Client perceived barriers to change of the construction process. Construction Innovation: Information, Process, Management, v.10, n.2, p. 126-137, 2010.

VERHEIJ, H.; AUGENBROE, G. Collaborative planning of AEC projects and partnerships. Automation in Construction, v. 15, n. 4, p. 428-437, 2006.

VERNADAT, F.B. Enterprise Modeling and Integration: Principles and Applications. Chapman \& Hall: London, 1996.

VIRTUELLBAU. Disponível em: <www.virtuellbau.ch>. Acesso em: 20 Abr. 2009.

VIRTUELLE FABRIK. Disponível em: <www.virtuelle-fabrik.com>. Acesso em: 14 Abr. 2009.

VOLLMANN, Thomas E.; BERRY, William L.; WHYBARK, D. Clay; JACOBS, F. Robert. Sistemas de Planejamento \& Controle da Produção para o Gerenciamento da Cadeia de Suprimentos. Porto Alegre: Bookman, 2006.

VOORDIJK, H.; MEIJBOOM, B.; HAAN, J. Modularity in supply chains: a multiple case study in the construction industry. International Journal of Operations \& Production Management, v. 26, n. 6, p. 600-618, 2006.

VORAKULPIPAT, C.; REZGUI, Y.; HOPFE, C. J. Value creating construction virtual teams: A case study in the construction sector. Automation in Construction, v. 19, n. 2, p. 142-147, 2010.

VRIES, B.; HARINK, J.M.J. Generation of a construction planning from a 3D CAD model. Automation in Construction, v. 16, n. 1, p. 13-18, 2007.

VRIJHOEF, R.; KOSKELA, L. The four roles of supply chain management in construction. European Journal of Purchasing \& Supply Management, v.6, p. 169-178, 2000.

WAN, S.K.M, KUMARASWAMY, M.M. Industrial management approaches for improving material control in building service works. Engineering, Construction and Architectural Management, v. 16, n. 3, p. 208-223, 2009.

WANG, L.C.; LIN, Y.C.; LIN; P.H. Dynamic mobile RFID-based supply chain control and management system in construction. Advanced Engineering Informatics, v. 21, n. 4, p. 377-390, 2007.

WESTPHAL, I.; THOBEN, K.; SEIFERT, M. Managing collaboration performance to govern virtual organizations, Journal of Intelligent Manufacturing, v.21, 311-320, 2008.

XIE, C.; WU, D.; LUO, J.; HU, X. A case study of multi-team communications in construction design under supply chain partnering. Supply Chain Management: An International Journal, v.15, n.5, p. 363-370, 2010.

YANG, J.; SHEN, G. Q.; HO, M.; DREW, D. S.; XUE, X. Stakeholder management in construction: An empirical study to address research gaps in previous studies. International Journal of Project Management, In Press, Corrected Proof, Available online 30 August 2010.

YANG, J.B.; PENG, S.C. Development of a customer satisfaction evaluation model for construction project management. Building and Environment, v. 43, n. 4, p. 458-468, 2008.

YANG, J-B. Developing a knowledge map for construction scheduling using a novel approach. Automation in Construction, v. 16, n. 6, p. 806-815, 2007.

YATES, J.K.; EPSTEIN, A. Avoiding and minimizing construction delay claim disputes in relational contracting. Journal of Professional Issues in Engineering Education and Practice, v.132, n.2, p. 168179, 2006.

YIN, S.Y.L.; TSERNG, H.; TSAI, M.D. A model of integrating the cycle of construction knowledge flows: Lessons learned in Taiwan. Automation in Construction, v. 17, n. 5, p. 536-549, 2008. 
YIN, R. K. Case study research: Design and methods, 3rd Ed., California: Sage Publications, 2003.

YU, A.T.W.; SHEN, Q.P.; KELLY, J.; HUNTER, K. Investigation of critical success factors in construction project briefing by way of content analysis. Journal of Construction Engineering and Management - ASCE, v.132, n.11, p. 1178-1186, 2006.

YU, H.; TWEED, T.; AL-HUSSEIN, M.; NASSERI, R. Development of lean model for house construction using value stream mapping . Journal of Construction Engineering and Management ASCE, v. 135, n. 8, p. 782-790, 2009.

YU, I.; KIM, K.; JUNG, Y.; CHIN, S. Comparable performance measurement system for construction companies. Journal of Management in Engineering, v.23, n.3, p. 131-139, 2007.

YU, J.H.; LEE, H.S.; KIM, W. Evaluation model for information systems benefits in construction management processes. Journal of Construction Engineering and Management - ASCE, v.132, n.10, p. 1114-1121, 2006.

ZOU, P. X.W.; ZHANG, G.; WANG, J. Understanding the key risks in construction projects in China. International Journal of Project Management, v. 25, n. 6, p. 601-614, 2007.

ZWIKAEL, O. Critical planning processes in construction projects. Construction Innovation: Information, Process, Management, v.9, n.4, p. 372-387, 2009. 



\section{APÊNDICE 1}

Semi-structured Interview

REFERENCE MODEL FOR OPERATION AND RECONFIGURATION OF CONSTRUCTION NETWORKS

São Paulo Research Foundation (FAPESP) Process 2009/16392-0

Conducted by: Larissa Elaine Dantas de Araújo

$\mathrm{PhD}$ Student - EESC/USP

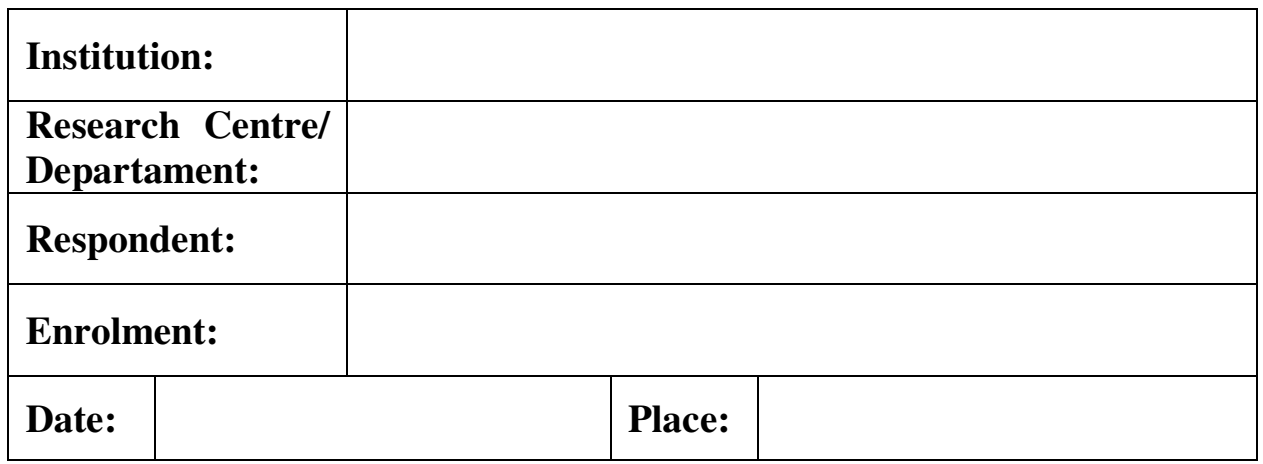

I declare for any purpose that the PhD Student Larissa Elaine Dantas de Araújo conducted a semi-structured interview in this Institution in the date and place stated above.

* A digital copy of this interview is required for the data confirmation. Otherwise, the data will not be used. 


\section{BRIEF DESCRIPTION}

Construction Management is a well-known difficult task. Due to the dynamic environment and inherent characteristics of most construction projects, the activities related to management are increasable challenging. Considering that the construction industry operates as a Virtual Enterprise, with its projects having a delimited life cycle (creation, operation, reconfiguration and conclusion), it is stated that this new collaborative approach offers opportunities to managers to enhance their capacity of decision making in this dynamic environment, especially in the operation and reconfiguration phases (value creation).

Some issues, based in a systematic literature review, using mostly traditional approaches found in the recent literature, led to the elaboration of a Concepts Model of Construction Operations Management (Figure 1 below). The Concepts Model used the EKD (Enterprise Knowledge Development) methodology.

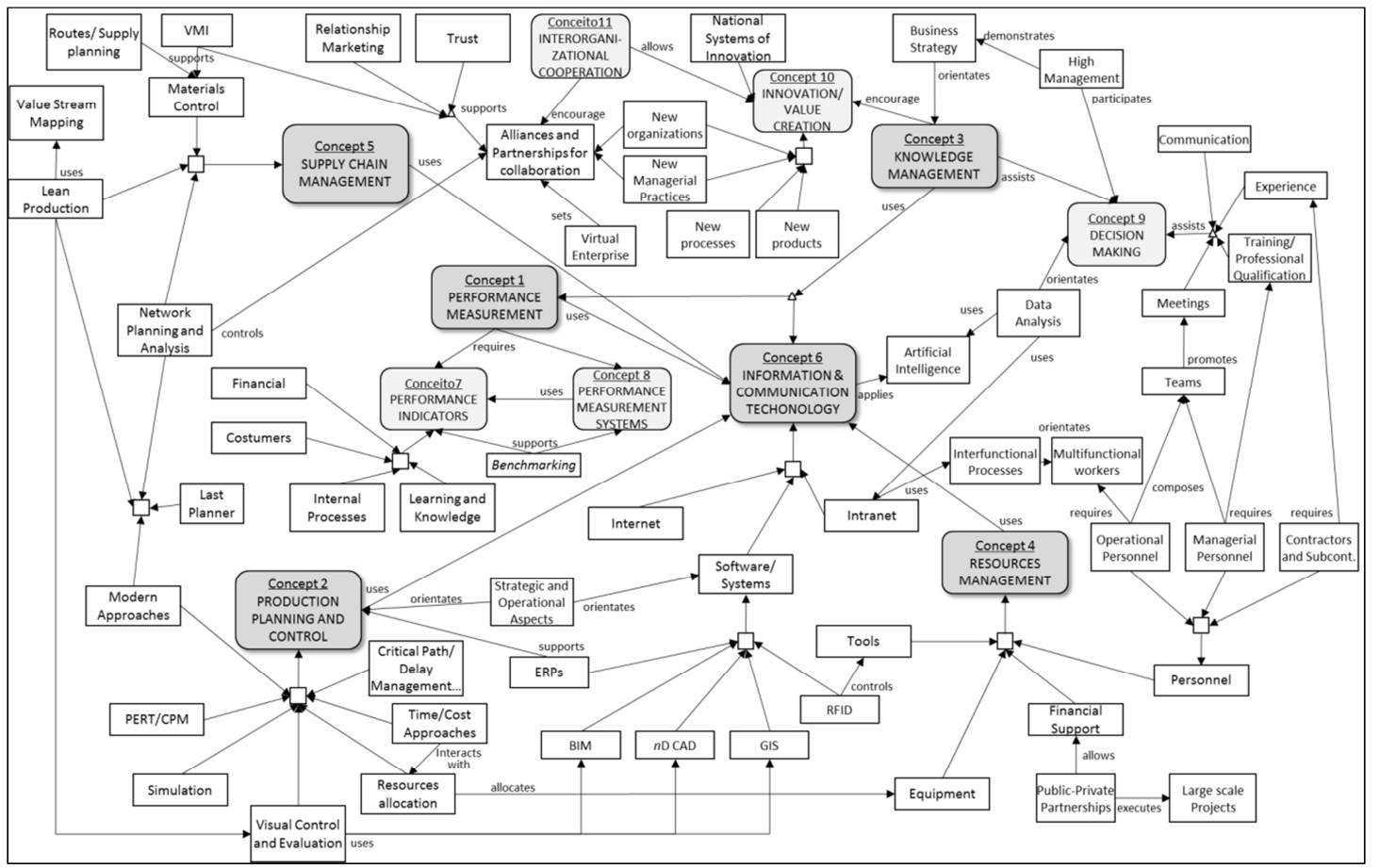

Figure 1 - Concepts Model of Construction Operations Management

But it is also known that there are many challenges and benefits of managing the operations of a construction project considering a collaborative and dynamic environment as a Virtual Enterprise. This way, this investigation aims to collect the most important issues regarding the management of construction project as a Collaborative Network from renowned Research Centers. The main goal is to indicate the link between key factors regarding the traditional thinking and the new approaches, so that new managerial reference models can emerge from that to enhance the capacity of decision making in dynamic environments. 


\section{TOPICS}

1. MAIN APPROACH FOR THE COLLABORATION PROJECTS IN CONSTRUCTION:

2. CONSIDERATIONS ABOUT LIFE CYCLE OF THESE PROJECTS:

3. MAIN CONCEPT FOR OPERATIONS MANAGEMENT IN CONSTRUCTION:

4. ISSUES:

\subsection{PERFORMANCE MEASUREMENT}

- Dimensions for Performance Measurement

- Nature of Indicators - for measurement

- Depends on/ strongly related to

\subsection{RESOURCES MANAGEMENT}

- Gorvenance and leadership

- Human Resources

- Physical Resources (Equipment, Machines, Tools, Hardware, Software)

- Investiment/Risk

\subsection{SUPPLY CHAIN MANAGEMENT}

- Partnering

- Trust

- Lean Supply Chain

- Depends on/ strongly related to

4.4 PRODUCTION PLANNING AND CONTROL

- Techniques used

- Dimensions considered

- Performed by

- Depends on/ strongly related to

\subsection{KNOWLEDGE MANAGEMENT}

- Decision Making and Learning

- Innovation and R\&D

- Team working

- Depends on/ strongly related to

\subsection{INFORMATION AND COMMUNICATION TECHNOLOGY}

- Software used

- Networks resources used

- Collaboration issues considered

- Depends on/ strongly related to

5. OTHER IMPORTANT QUESTIONS 



\section{APÊNDICE 2}

Roteiro de Coleta de Dados

Estudo de Caso para Tese de Doutorado

\section{MODELO DE REFERÊNCIA PARA OPERACIONALIZAÇÃO E RECONFIGURAÇÃO DE REDES DE CONSTRUÇÃO CIVIL}

Processo Fapesp 2009/16392-0

\section{ROTEIRO 1 - Caracterização do Objeto de Estudo}

- Número de empresas do Consórcio.

- Porte das empresas do Consórcio.

- Número de empresas participantes da obra.

- Porte das demais empresas participantes da obra.

- Principais fases da obra (macro).

- Programação inicial (meses).

- Padrão de emissão de ordens (produção e serviços).

- Sistema(s) de Tecnologia de Informação e Comunicação (TIC), se existente, utilizado(s).

- Padrão de Reconfiguração de prazos e atores (empresas participantes da obra). 


\section{ROTEIRO 2 - Atores e Recursos}

- Principais atores do negócio.

- Relação entre os atores.

- Necessidade de cada ator, competências essenciais percebidas.

- Objetivos dos atores.

- Processos pelos quais o ator é responsável.

- Processos que o ator desempenha.

- Recursos providos pelo ator.

- Recursos de responsabilidade do ator.

\section{ROTEIRO 3 - Processos}

- Principais processos realizados pelas empresas.

- Relações entre os processos.

- Necessidades dos processos.

- Fluxos de materiais e informações necessários.

- Fluxos de materiais e informações produzidos.

- Atores e recursos responsáveis pela execução e suporte dos processos listados.

\section{ROTEIRO 4 - Uso de Conceitos para Gestão de Operações}

- Fluxo do modelo de processos representados no modelo de Conceitos.

- Atores e Recursos apresentados no Modelo de Conceitos.

- Conceitos de Medição de Desempenho utilizados na obra.

- Ferramentas de Planejamento e Controle da Produção utilizadas na obra.

- Práticas de Gestão do Conhecimento utilizadas na obra.

- Conceitos de Gestão de Recursos utilizados na obra.

- Práticas de Gestão da Cadeia de Suprimentos utilizados na obra.

- Ferramentas de TIC utilizadas na obra. 